University of Rhode Island

DigitalCommons@URI

Open Access Dissertations

1992

\title{
The Cognitive Control of Leveling-Sharpening and Acceptance of Interpersonal Violence in Adults
}

Bertram S. Gibbes

University of Rhode Island

Follow this and additional works at: https://digitalcommons.uri.edu/oa_diss

\section{Recommended Citation}

Gibbes, Bertram S., "The Cognitive Control of Leveling-Sharpening and Acceptance of Interpersonal Violence in Adults" (1992). Open Access Dissertations. Paper 943.

https://digitalcommons.uri.edu/oa_diss/943

This Dissertation is brought to you for free and open access by DigitalCommons@URI. It has been accepted for inclusion in Open Access Dissertations by an authorized administrator of DigitalCommons@URI. For more information, please contact digitalcommons-group@uri.edu. 
THE COGNITIVE CONTROL OF LEVELING-SHARPENING AND ACCEPTANCE OF INTERPERSONAL VIOLENCE IN ADULTS

BY

BERTRAM S. GIBBES

A DISSERTATION SUBMITTED IN PARTIAL FULFILTMENT OF THE REQUIREMENTS FOR THE DEGREE OF DOCTOR OF PHILOSOPHY

IN

PSYCHOLOGY

THE UNIVERSITY OF RHODE ISLAND

1992

28329931 


\section{ABSTRACT}

The cognitive performance of three groups of college students ( $N=251,135$ males, 116 females) who differed in their attitudes toward accepting interpersonal violence were compared as they processed two leveling-sharpening measures used to assess their leveling-sharpening cognitive control. Two leveling-sharpening test stimuli were used, one aggressive and one nonaggressive. The first levelingsharpening test was neutral in content while the second portrayed an interpersonal (inter-sex) aggressive scene. Subjects were administered the Burt (1980) scale of Acceptance of Interpersonal Violence and classified into three groups of either High Acceptors, Moderate Acceptors, or Rejectors of interpersonal violence. Using Santostefano's $(1985,1986,1990)$ experimental paradigm, it was predicted that differences in leveling-sharpening cognitive control performance would result depending on 'subjects' predisposition toward the acceptance of interpersonal violence and changes in the content of the leveling-sharpening tasks.

Differences were assessed statistically by utilizing a repeated measures ANOVA design. The analyses revealed a significant effect for task showing a decrease in the rate of detecting changes for all groups as they moved from the neutral to the aggressive task. Two simple interaction 
effects also resulted showing, in turn, significantly different patterns of detecting changes between Levelers and Sharpeners depending on their attitudes toward interpersonal violence, and sex differences regarding the performance of male and female Sharpeners on the interpersonal aggressive task. Compared to their performance with the neutral test stimuli, subjects who were Sharpeners and accepting of interpersonal violence were less efficient at detecting changes when they processed the interpersonal aggressive task than were levelers. In sharp contrast, subjects, both Levelers and Sharpeners, who were not accepting of interpersonal violence (Rejectors) performed similarly on both the neutral and interpersonal aggressive tasks. Further, findings show that female Sharpeners were significantly less efficient at detecting changes on the aggressive task than their male counterparts. Findings are discussed in terms of the influence of anxiety on cognitive performance and the nature of the aggressive measure, acceptance of interpersonal violence, for males versus females. 


\section{ACKNOWLEDGEMENT}

This research represents an endpoint in a graduate school experience that was enriched by many. I would first like to acknowledge my tremendous debt to $\mathrm{Dr}$. Sebastiano Santostefano on whose decades of work this research is based. My hands-on exposure to Seb's work throughout the many exciting years I spent at the Child Psychology and Psychoeducation Department at McLean Hospital in Belmont MA., under his directorship, stands out as an experience which greatly influenced my thinking in psychology and my choice of subject matter in my modest effort to broaden the knowledge base of the discipline I love. I appreciate the fact that he has so liberally allowed me the use of some of his material for this endeavor.

My gratitude also extends to the members of my committee for their efforts in assisting me through this process. Dr. Albert Lott for his encouragement and support and Dr. Richard Nelson who stood with me as I attempted the many graduate school hurdles. While not a committee member, Dr. Lawrence Grebstein has been an important mentor and teacher. I am very thankful to Dr. Dominic Valentino, Dr. Joseph Rossi and Dr. Charles Collyer for their time and help on this project. I am also very thankful to Dr. Bernice Lott whose conversations were a rich source of knowledge and 
ideas.

My "uncle-ish" major professor Dr. Allan Berman deserves special mention since he has been a tremendous singular source of support for me over the years in helping me keep frustrations in perspective and my essential goals in focus. An especially wise, patient and invaluable teacher who has deeply influenced my way of being a psychologist.

During the course of my life and my learning, I have become increasingly aware of the debt I owe to those whose love and guidance enriched my childhood, it would take me several volumes to list them and point out their contributions. I also want to thank my brother Peter, and my sisters, Susan, Jacqueline, Wendy, Carol, Alison, and Rathy-Ann just because. I am truely twice blessed to have two fathers, Joe Ross and E. Bertram Gibbes who have both been invaluable sources of love and support for me through my many struggles in living. I am indeed a lucky person. 


\section{DEDICATION}

To Nami, Malin and Maya for all the joy they have brought me.

Also to my mother, Erva Thompson Ross for her many years of love and encouragement that has so enriched my life. 


\section{Table of Contents}

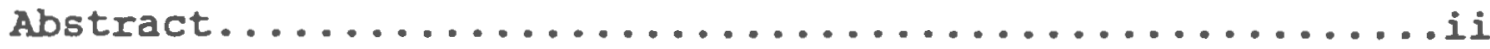

Acknowledgements............................

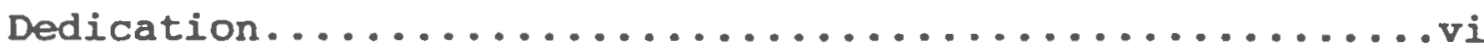

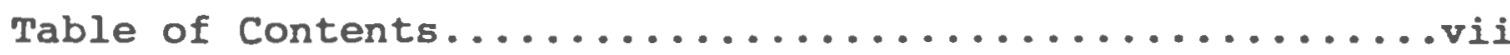

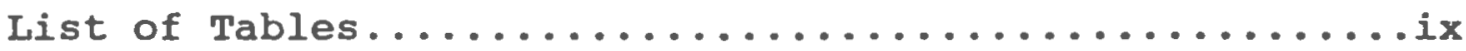

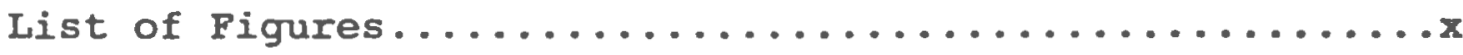

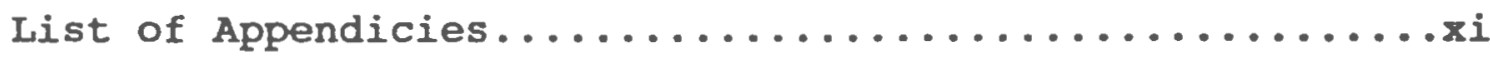

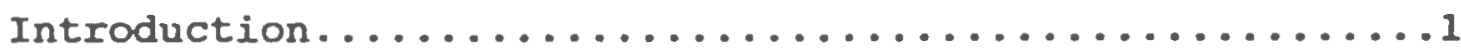

Cognitive Controls: A Historical Review.............

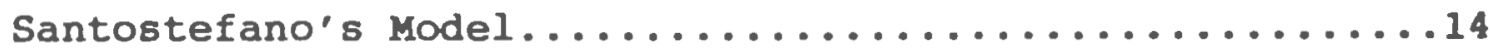

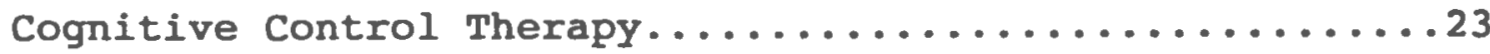

Studies with The Leveling-Sharpening Cognitive Control...24

Acceptance of Interpersonal violence.............28

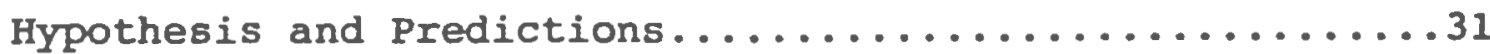

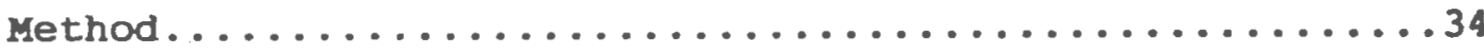

Results ............................. 


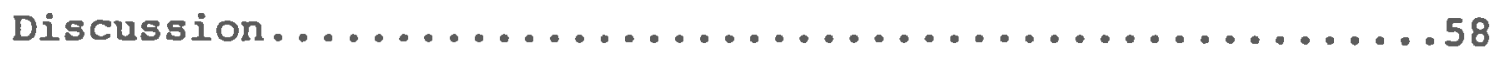

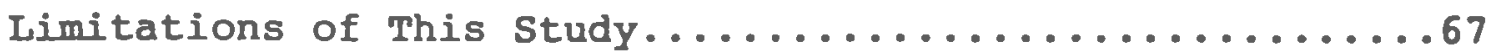

Implications Por Further Research..................69

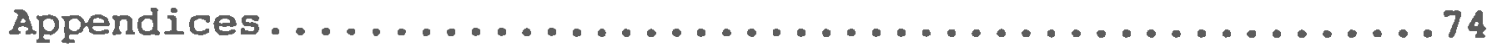

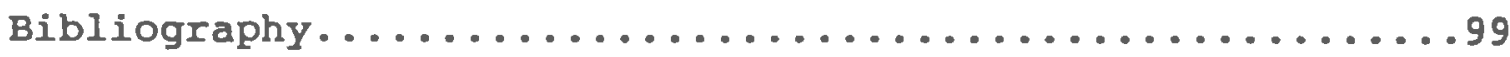




\section{List of Tables}

Table I _ - - Means, Standard Deviations, and Range on all variables for Sharpeners $(\mathrm{N}=124)$ and Levelers $(\mathrm{N}=127)$. (p. 48).

Table II _ - ANOVA Summary Source Table for 2 (SEX: male/female) X 3 (AIV: High / Moderate / Rejectors) \& 2 (Levelers / Sharpeners) $x$ 2 (Task: H'T-C vs IAT-C) repeated measures. (p.49).

Table III _ _ ANOVA Summary Source Table for 2 (SEX: male/ female) X 3 (AIV: High / Moderate / Rejectors) × 2 (Levelers / Sharpeners) I 2 (Task: HT-FS vs IAT-FS) repeated measures. (P.56). 


\section{List of Figures}

Figure 1 _ - Developmental Model of Cognitive Controls.

Figure 2 _. - Orientation of Cognitive Controls in Normal Development. (p. 19).

Figure 3 _. - Orientation of Cognitive Controls in Abnormal Development. (p. 21). Figure 4 - - Pormula for Calculating Leveling
Sharpening Ratio. (p.42).

Figure 5 _ $\ldots$ Graph of AIV X L/S X TASKS(HT-C vs IAT-C). (p. 52 ).

Figure 6 _ $\ldots$ - Graph of SEX \& L/S X TASKS(HT-C v8 IAT-C). (p. 53).

Figure 7 _ $\ldots$ Graph of L/S X TASKS (HT-FS vs IAT-FS). (p. 57) 


\section{LIST OF APPENDICES}

Appendix

Page

I..........................

II........... Demographic Questionaire........76

III....................77

IV...........Main Scene L-S Training Test......81

V..........Main Scene L-S House Test.......82

VA...... List of Items that Drop Out of LSHT....83

VI..Main Scene L-S Interpersonal Aggression Test..84

VIA....List of Items that Drop out of the LSIAT...85

VII........Main Scene L-S Aggression Test......86

VIII......... Instructions for L-S Tests.......87

IX............ Scoring Form for LSHT........91

x.....................92

XI...Raw Data for All Subjects on All Variables...93 
INTRODUCTION

\section{PURPOSE OF THE RESEARCH}

The purpose of this study was to investigate the cognitive control, leveling-sharpening (Klein, 1951, 1954, 1970., Holzman \& Klein, 1951, 1954) as it relates to the personality disposition of attitudes toward the acceptance of interpersonal violence (Burt,1980) in adults. The question pursued was, to what extent does a person's attitude toward interpersonal violence influence their leveling-sharpening cognitive control functioning when processing a neutral versus an affectively arousing stimulus .

In general terms, cognitive control schemata are seen as unique, relatively permanent, information-processing mechanisms employed by the individual in an adaptive function to organize, regulate and manage information from both the external environment and the internal environment of thoughts, fantasies and motives (Gardner et al, 1959). The cognitive control that is of interest in this study is the cognitive control of leveling-sharpening. The levelingsharpening cognitive control concerns "the manner in which the individual constructs images of information and compares these images with present perceptions." (Santostefano, 1986, p. 177)- Santostefano $(1978,1988)$ defines Levelers as individuals who process information by constructing 
relatively global and unstable images of that information, fusing the present with past information so that information loses its discreteness and differences are not noticed over time. Sharpeners, on the other hand, are individuals who maintain articulate and stable images of information over time. Thus, upon successive presentations of stimuli, they are able to differentiate present information from past information and differences and distinctions in information are maintained.

The theory of cognitive controls provides a single comprehensive conceptual model that gives cognition a central role in personality formation and development. This approach is primarily concerned with the cognitive functions that are nonverbal. Cognitive processes are thus seen as highly mobile structural functions (controls) operating in a reciprocal interaction in coordinating the information of both external stimuli and contexts, and inner fantasies and emotions (Santostefano, 1978, 1984, 1985, 1988).

Acceptance of interpersonal violence is the belief that force and coercion are acceptable ways to gain compliance in intimate and sexual relationships (Burt, 1980). How does the leveling-sharpening cognitive control function with adults who show acceptance of interpersonal violence versus those who reject interpersonal violence? Given a subject's disposition toward the acceptance of interpersonal violence, this relationship can be explored by examining how subjects, depending on whether they are Levelers or Sharpeners, 
process information that is neutral versus information which portrays interpersonal aggression. Do people who reject interpersonal violence typically level (avoid) information that is highly affectively charged interpersonally or do they sharpen on this information? If it is the case that subjects shift more toward leveling, then it seems reasonable to conclude that, by processing more global diffuse images of information in their environment, they may inadvertently be supporting the perpetuation of rape and other acts of violence and aggression, or furthermore, be inefficient around detecting clues in their environment that make for successful adaptations. Do these people, in large part, appear immune to the conditions (i.e., violence against women and rape myths perpetuated in the media and the environment) due to their tendency to level (avoid or ignore) information, and in turn appear to be condoning it? The present research also inquired into possible sex differences by exploring whether the adult females in this study responded like the females in other studies such as with Santostefano \& Rieder's (1984) High-aggression young females, who leveled more on information while processing affectively charged images of aggression as opposed to their male counterparts whose tendency was to sharpen on aggressive information.

A search of the literature has not revealed any studies examining what role the psychological disposition of acceptance of interpersonal violence plays in cognitive 
control functioning. The present research represents an attempt to integrate what sometimes appears to be disparate areas of psychology, feminist social psychology and psychodynamic cognitive psychology. This study also offers substantive improvements in instruments and procedures over past studies which attempted to look at other types of generalized aggression through the cognitive control lense. This research further explored how these systems interact and possibly influence adaptation attempts in the short term. Given the increasing level of interpersonal violence in our society evidenced by recent reports of alleged campus rape and date-rape (Koss et al, 1987., Sweet, 1985., Seligman et al, 1984), exploring how people who show differences in their acceptance of interpersonal violence process information on interpersonal aggression versus neutral information seems an area worthy of further study. This systematic investigation is an attempt to add a significant piece of knowledge regarding cognition and interpersonal violence to the field of psychology. 
COGNITIVE CONTROLS: A HISTORICAL REVIEW

Cognitive controls have a long and rich history in the clinical literature that span some 40 years. The concept was formulated by George Klein (Klein \& Schlesinger, 1949., Klien, 1951, 1954, 1970), following his experimental work on perception which resulted in empirical observations that adults consistently used particular cognitive strategies to approach, avoid, select, compare and cluster information. Central to the development of the concept of cognitive controls was the idea that motivational and environmental forces operated within structural constraints of the perceiver's information-processing, cognitive capacities expressed in the observation of these consistent individual perceptual cognitive differences (Klein, 1951, 1954, 1970). Klein initially used several other names for these cognitive processes such as ego regulators, perceptual attitudes, and cognitive attitudes finally settling on the term "cognitive controls" to emphasize the regulatory aspects of these mechanisms (Gardner et al, 1959., Klein, 1954, 1970).

The general thrust of klein's work was an attempt to explore the relationship between personality variables and perceptual processes. His main focus was to look at the cognitive strategies people employed in their mental processes like thinking, perceiving and reasoning and relate them within personality functioning. Klein sees perception as an adaptive cognitive act that is always rooted in the 
intentional life of the person in their motives and aims in relation to the environment (Klein, 1970).

Klein's ideas grew out of his studies on perception which were part of a movement in experimental psychology that came to be known as the "New Look" in perception (Bruner \& Klein, 1960). In the 1940s many clinicians and researchers studying perception called for a shift from "formal" to "functional" approaches. Formal approaches, which dominated research in perception up to that point, emphasized perception as being determined by physical properties of stimuli (e.g., inherent structural aspects such as closure, contrast, and pairing) or biological need states (e.g., hunger). In contrast, "functional" approaches of this "New Look" saw perception, for the most part, as being determined by the perceiver's cognitive constructs, that is, the way cognitive behaviors of individuals operated in helping them adjust to changing environments (Bruner \& Postman, 1948., Bruner, 1951). Bruner \& Klein (1960) suggested that this movement should have been more aptly referred to as "New Looks" since it consisted of a collection of hypotheses and research pursuits, all with the ubiquitous theme that adaptive regulatory functions including perception were very important to psychological processes. Klein, along with other theoreticians and researchers wearing the hat of the "New Look" approach held the broad "functional" view that: 
"... man learns not only to modify his overt behavior, his muscular movements and verbal comments; he learns also to modify his looking and hearing so as to be able to notice what he needs to notice in order to survive, or sometimes to avoid noticing what it hurts to notice, even at the price of survival value." (Wolitzky and Wachtel, 1973; p. 826).

Further, these "New Look" researchers supported a dymamic, functional perspective which saw humans from the point of view of an "organismic model" of behavior "inherently and spontaneously active-approaching, avoiding, selecting, modifying, and giving meaning to stimuli in the service of adaptation and learning" (Santostefano, 1988, p.6). However, an important difference between Klein and many who embraced this zeitgeist was Rlein's formulation of cognitive control as an information-processing function rather than being concerned with perceptual defence and vigilance, or psychological and physical need states.

The other major orientation that guided klein's theoretical formulations and added to his conception of cognitive controls as concerned with information-processing, was psychoanalytic ego psychology and in particular the theories of Heinz Hartmann. In Hartmann's treatise the ego is much more than just a mediator between id and superego, or limited to a role of trying to avoid pain and service instinctual gratification. The ego is an important autonomous force whose primary functions such as perception, attention, memory, rational thought and action in normal behavior are "conflict free" and more concerned with adaptation to environmental demands. Hartmann saw 
adaptation as a reciprocal relationship between organism and environment. The organism changes the environment to make it more agreeable and then changes itself in order to adapt to the changes it has created (Hartmann, 1958, 1964). Thus Klein's cognitive control mechanisms are ego-cognitive functions concerned with adaptation to environmental demands and management of information rather than with inner psychic conflict. Klein's embrace of both Hartmann's ideas and the "New Look" posited a system involving a reciprocal interaction between active perceiver and stimuli, that revolved around conflict free, information-processing, with each (perceiver and stimuli) influencing and being influenced by the other (Klein, 1970).

Klein's emphasis on cognitive functions is consonant with current interest in the role of cognition in personality formation and development particularly those of Bandura (1986). Bandura posits the concept of triadic reciprocal determinism wherein "behavior, cognitive and other personal factors, and environmental influences all operate interactively as determinants of each other." (Bandura, 1986, p.23). Bandura goes on to assert that "Behavior is, therefore, a product of both selfgenerated and external sources of influence. Most external influences affect behavior through intermediary cognitive processes. Cognitive factors partly determine which environmental events will be observed, what meaning will be conferred on them, whether they leave any lasting effects, what valence and efficacy they will have, and how the information they convey will be organized for future use." (Bandura, 1986 p. 454). 
However, Bandura does not see the self as an autonomous psychic entity but a collection of "cognitive structures that provide reference mechanisms" or "a set of cognitive sub-functions for the perception, evaluation, and regulation of behavior" (Bandura, 1978, p. 348). Nonetheless, when Bandura does talk about the self (i.e., self-efficacy and self-reinforcement) his postulations fall very much in line with Klein's conceptions and some argue that "a case could be made that he is describing the same phenomenon from another point of view" (i.e., Loevinger, 1987, p.158).

The roots of Klein's ideas on cognitive controls extend well beyond his experimental work in psychophysiology and concepts borrowed from psychoanalytic ego psychology. It can be further traced to Brentano, Benussi and FrenkelBrunswik (Helson, 1964), studies of expressive movement (Allport, G., \& Vernon, P., 1933), Gestalt psychology and studies of perception by Thurstone (1944). The development of Klein's ideas and his extensive thinking over decades of his pioneering work in psychology are clearly and comprehensively laid out in his book Perception, Motives, and Personality (Klein, 1970).

The -first major set of research aimed at systematizing the field of cognitive controls was made in 1959 by George Klein and his colleagues, Riley Gardener, Philip Holzman, Harriet Linton and Donald Spence at the Menninger's Clinic in Topeka, Ransas. Their objective was "...to discover the most general regulatory principles that determine a person's 
responses and account for individual differences among people." (Gardner et al, 1959, p.6). From factor analyses of their data, these researchers isolated and focused on five separate cognitive control principles namely Focusing or Scanning, Constricted-Flexible control, LevelingSharpening, Equivalence range, and Tolerance for Unrealistic Experiences. They also added another, Field DependenceIndependence which resembled the Constricted-Flexible control but was constructed separately through the work of witkin (1954).

The Focusing or Scanning cognitive control principle referred to cognitive behavior observed when individuals attempted to register the information in a visual field. The constricted-flexible principle referred to the manner in which an individual was able to focus upon relevant information while ignoring the irrelevant details within a visual field. The Leveling-Sharpening control concerned the manner in which individuals were able to maintain stable memory images. Levelers fused new information with old. Sharpeners were able to keep memories stable and differentiated over time. The Equivalence-Range principle referred to the cognitive behavior observed when individuals were asked to categorize an array of information in meaningful relationships and concepts. Tolerance for Unrealistic Experience was a control principle which measured the extent to which an individual departed from a strict reality orientation and accepted perceptual 
experiences known to be unreal. To these researchers these mechanisms were unique in the type of cognitive behavior each employed (Gardner et al, 1959).

An extensive amount of research using cognitive controls followed the efforts of these early researchers. These subsequent studies attempted to explore the relationship of cognitive controls to factors such as attention and consciousness (Gardner, 1969., Silverman, 1964a), drives and defenses (Gardner \& Messick, 1960, Gardner, 1962., Zimbardo, 1969), physiological correlates (Israel, 1966., Witkin \& Ottman 1967), physical maturation (Broverman, Broverman, Vogel, Palmer \& Kaiber, 1964), development (Santostefano, 1963, 1964., Santostefano \& Paley, 1964., Gardner, 1964a., Witkin, Goodenough \& Karp, 1967., Gardner \& Moriarty, 1968), and psychopathology (Silverman, 1964a, 1964b, 1964c., Shapiro, 1965., Silverman \& Gaarder, 1967., Ottenson \& Holzman, 1976). For a comprehensive review see Wolitzsky and Wachtel (1973). Overall however, with the exception of a few (Santostefano, 1963, 1964., Santostefano \& Paley, 1964., Shapiro, 1965), most of the research that followed the seminal work of klein and his colleagues conceptualized cognitive control as defense. However, as may be recalled from prior discussion, Klein was careful to distinguish cognitive controls from defense mechanisms. Cognitive controls were conflict free and concerned with information processing, whereas defense mechanisms dealt with intrapsychic conflict. 
The proliferation of research that followed the seminal work of Klein and his colleagues (Gardner et al, 1959) fell into decline in academic psychology during the middle seventies, as behaviorism, which dismissed the importance of internal mental processes, took center stage (Erdelyi, 1974., Zimiles, 1981., Santostefano, 1978, 1988). However, Santostefano who began applying Klein's ideas with children in the 1960s (Santostefano, 1963, 1964., Santostefano \& Paley, 1964 ) persisted in his research in this area and in 1978 completed and published a longitudinal course of study aimed at systematizing the field and extending Klein's work on cognitive controls. Santostefano like klein also focuses on cognitive controls as information processing mechanisms. Santostefano's extensive work in elaborating and extending Klein's ideas now spans three decades with normal and pathological groups of children. In addition many others have followed with research using Santostefano's ideas.

Santostefano takes an organismic-developmental approach to the field of cognitive controls and puts forth an integrative theory which specifies a hierarchical organization in the development of these mechanisms. More inclusively, in addition to his extensive research programs, theoretically Santostefano sought a systematic, adaptivedevelopmental understanding of the role of cognitive controls in personality formation and development. This point of view holds that any meaningful account of human behavior must include environmental considerations or the 
context in which behavior occurs (Werner, 1958., Santostefano, 1978, 1985). Santostefano integrated many different ideas from contemporary developmental psychology and drew heavily from the developmental theory of Heinz Werner (1958) (organismic development), the work of L. W. Sander (1969) regarding mother-infant interaction, the work of Sigmund Freud, Jean Piaget, Heinz Hartmann and many others in formulating a comprehensive model of cognitive control development.

Like Gardner et al, Santostefano (1978) used factor analysis in his research. He employed some modifications of the instruments and methods originally used with adults by Gardner et al (1959) since those approaches ran into problems when applied to children. The children's general capacities and their emotional reactions to the tests obscured their cognitive control preferences. Santostefano therefore constructed new measures to assess these controls. He found only four of the five cognitive controls isolated by Klein and his colleagues (Gardner et al, 1959) relevant in assessing the cognitive control processes of both children and adults. Tolerance for unrealistic experience was not üsed. Santostefano also added another cognitive control that emerged from his research called Body-Ego Tempo regulation which concerns sensory motor capacity reflected in the way an individual uses images and symbols to represent and regulate body motility. Santostefano's definition of cognitive controls have remained essentially 
the same as the original concept. They are defined by him as a particular set of mobile cognitive functions having "the status of intervening variables that define principles by which motor behavior, perception, memory, and other aspects of cognition are organized as an individual coordinates himself or herself with environmental demands." (Santostefano, 1985, p.7).

Santostefano's Model

In Santostefano's conceptual model, there are five distinct cognitive controls that form a developmental hierarchy. These processes follow a developmental course throughout childhood consisting of increasing differentiated levels of organization from global immature states to mature differentiated states following the organismic developmental principle of "directedness of behavior" (Werner, 1958., Santostefano, 1978). That is: "whenever development occurs, it proceeds from a state of relative globality and lack of integration to a state of increasing differentiation, articulation and integration." (Santostefano, 1978, p.340). Cognitive controls are also defined by a range of behaviors along continuums which represent levels of maturity in functioning.

These cognitive controls (including Leveling-Sharpening which is the subject of the present study) are listed as follows with regard to their order of ontogenesis including 
their process of differentiation in the course of development:

(1) Body Ego-Tempo Regulation: this control concerns the manner in which an individual uses images and symbols to represent and regulate body motility. From global body percepts and little motoric delay to differentiated representations with differentiated and regulated tempos.

(2) Focal Attention: concerns the manner in which an individual attends to a field of information from slow and narrow to broad and active scanning.

(3) Field Articulation: the manner in which a person deals with a field of information that contains relevant and irrelevant information. From attending equally to both relevant and irrelevant information to attending selectively to only relevant information.

(4) Leveling/Sharpening: the way in which a person holds information in images over time. From retaining global images that are fused with present perceptions, so that differences are not noticed, to constructing stable and distortion-free memory images that are distinguished from present perceptions, so that similarities and differences are noticed.

(5) Equivalence Range: concerns the manner in which a person categorizes information in the environment. From using narrow and concrete categories to using increasingly broad, abstract and complex groupings (Santostefano, 1988).

Santostefano (1978) provides evidence that these cognitive controls are measurable by the age of three. In fact the first four cognitive controls do not require the use of verbal processes. The Equivalence Range cognitive control (\$5) is the only one involving a verbal mediation process .

Figure 1 graphically depicts the developmental model of cognitive controls that emerged from Santostefano's studies (Santostefano, 1988, p.9). The arrangement of these cognitive controls or the cognitive control profile within a 
particular person is referred to as his or her "cognitive style" (Santostefano, 1978, 1988).

Cognitive controls follow a specified sequence in their development that is necessarily ordered due to their function as information processing mechanisms. The individual must therefore be sufficiently efficient at those cognitive controls that develop earlier before proficiency is attained with those cognitive controls which develop later.

For example, the process of leveling sharpening, emerging later in the developmental sequence, therefore, necessarily incorporates the earlier processes and can be conceptualized during adequate adaptive functioning as an executor over three independent components: (1) sensorimotor efficiency at representing and regulating body motility through images and symbols, (2) ability to focus and attend to a field of information, and (3) ability to articulate and differentiate relevant from irrelevant information in that field. Leveling-sharpening, the ability to hold the discreteness of information in a memory image over time, integrates the processes of the other cognitive functions lower in the hierarchy. To put it another way, one cannot complete the function of holding images in memory over time (leveling-sharpening) without being able to regulate body movements so as to position one's self to focus on the information, attend to the information, and articulate the field of information (discern relevant from irrelevant). 
Eigure?

Revelopmental Model of Cognitive Controls

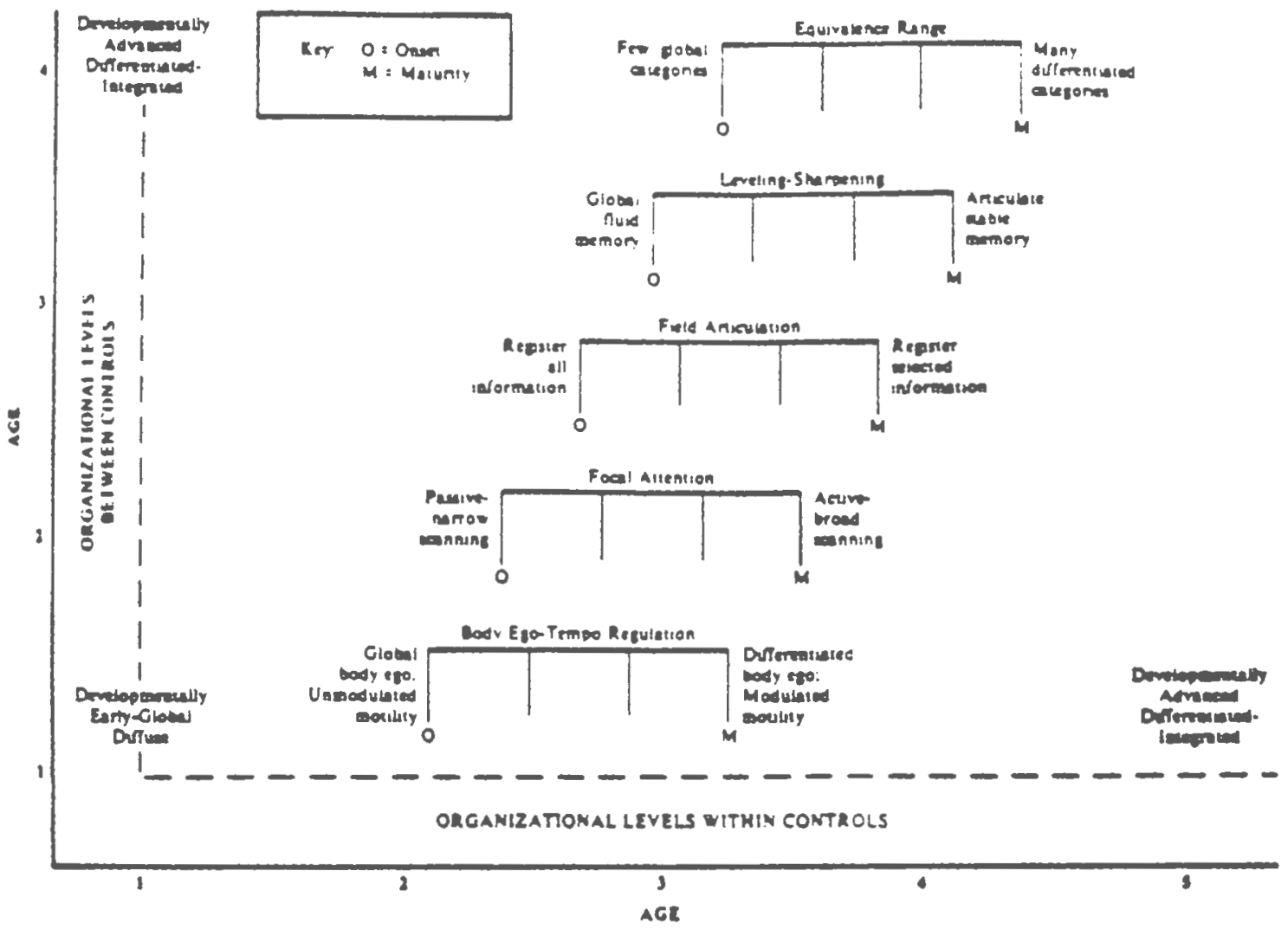

(Santostefano, 1988, P.9) 
Research on normal development by Santostefano (1978, 1988) has shown that as development proceeds, the orientation of these cognitive controls take on a particular sequence regarding whether they primarily focus on inner versus outer information at different points in development. Three phases in the orientation maintained by cognitive controls within long term normal development have been observed. A graphic illustration of cognitive control orientation in normal development (Santostefano, 1978, 1988) is provided in Figure 2. Before the age of four, cognitive controls are primarily inner oriented. Between the ages of five to nine cognitive controls become more outer-oriented toward information in reality. From age 9 on the orientation cognitive controls take become more mobile. Thus, the person responds flexible to the requirements of both sources of information, the external reality as well as the internal world of representative metaphors and symbols. Therefore, cognitive controls in normal functioning are not rigid but considered to be flexibly regarding their ability to switch from an inner to an outer orientation or vice versa depending on which orientation is necessary to mediate adaptive-functioning. Given this flexibility in orientation, the person is better adept at integrating the two sources of information (outer and inner) and thus broadening their knowledge about both their inner world and outer world, which in turn, contributes to their success as they develop and adapt to changing environments. 
Figure 2

Orientation of Cognitive Controls in Normal Development

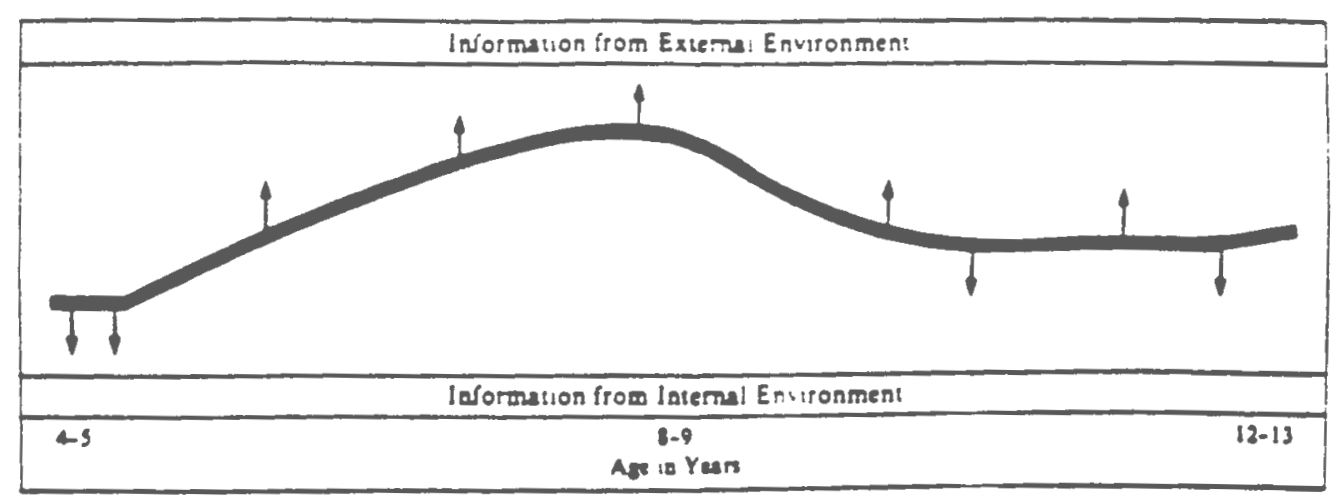

(Santostefano, 1988, P. 12) 
Santostefano's research with groups of children who had clinical diagnoses found that these children deviated markedly from the long term developmental phases observed with normal children. A graphic illustration of cognitive control orientation in abnormal development (Santostefano, 1985, 1988) is provided in Figure 3. In contrast with normal development, cognitive control orientation of clinical groups are shown to remain oriented toward inner information well through the age of nine. These children showed a rigidity and excessiveness in their orientation to their inner world that tended to compromise their attempts to deal with the demands of external reality. They were thus unable to shift their attention adaptively away from internal fantasies, memories, and affects. From nine on, the orientation of cognitive controls of these clinically diagnosed children took one of two courses. They either remained rigidly and excessively inner oriented or switched to a rigid outer orientation. Either extreme orientation exacts a high toll with regard to successful adaptation and acquisition of knowledge. Rigid inner orientations fail to efficiently assimilate external information and rigid outer orientation fails to assimilate the contributions of private, thoughts, memories and fantasies. These children are thus at a great disadvantage around being able to use the available information in their world.

In short term adaptation, cognitive control mechanisms also shift along a continum "in response to changing 


\section{Eigure 3}

orientation of Cognitive Controis in Abrorma? Sevelopmer:

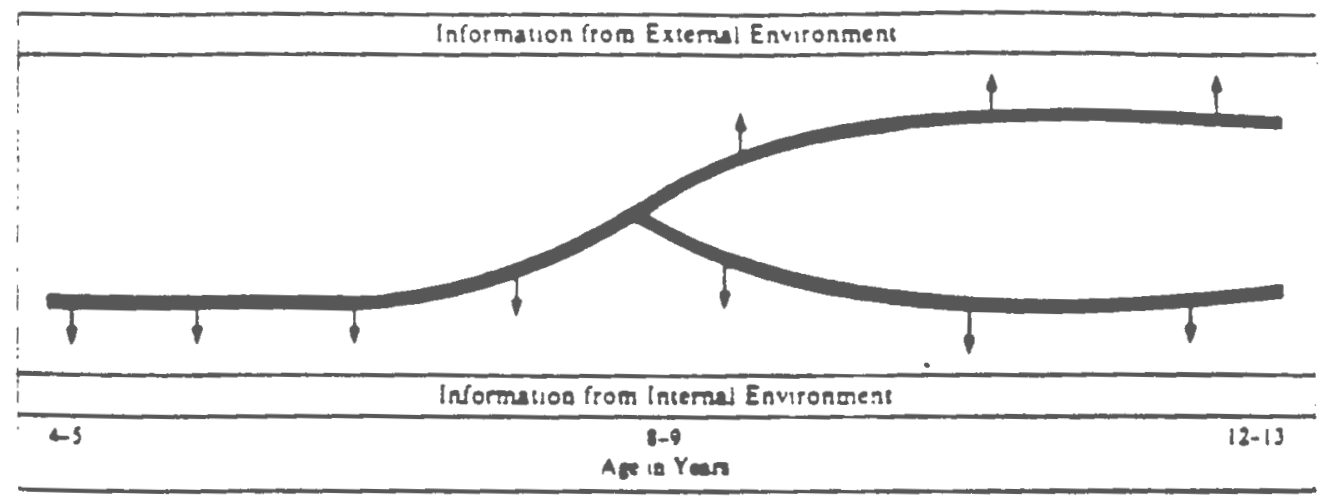

(Santostefano, 1988, P. :5) 
stimulation, responding simultaneously to task stimuli and associated fantasies and affect, i.e., the inner environment." (Santostefano 1985, p. 178). In affectively arousing conditions the leveling-sharpening cognitive control (the focus of the present study) is said to serve this coordination function by reorganizing either in the direction of increased leveling (regressively) or in the direction of increased sharpening (progressively). Regressions (i.e., leveling) are not meant to mean bad and progressions (i.e., sharpening) good. Whether adaptation is adequate depends on both the requirements of the individual and the situation. This occurs as cognitive controls balance the demands of the environmental situation with an individual's predisposition toward that affective situation or stimulus in its attempt at adaptation. Santostefano contends that

"While environments unusual for a person typically creates stress, stress as such is not an inherent characteristic of situations but is determined by the way a person evaluates the demands of the situation and his/her ability to handle them successfully."

(Santostefano 1985, p. 27).

Santostefano (1985) proposes a model to study cognition and affect as prescribed in cognitive control theory. It is suggested that a subject's cognitive control functioning be observed in the processing of at least two contexts or stimuli to understand better how the cognitive control coordination process works. In one instance, the requirements of the stimuli should be usual and/or neutral 
in terms of the person's history or disposition, and in the other, unusual and/or not neutral. The cognitive control functioning in each is then compared.

In addition to identifying the processes and developmental course of each cognitive control, different tests have been developed to assess each control. Santostefano $(1978,1988)$ also presents data from over a dozen separate factor analytic studies designed to illustrate the uniqueness of each cognitive control and the validity and reliability of those tests designed to measure them. Santostefano's work continues at a voluminous rate. However, it is mostly focused on diagnosis and therapeutic intervention with children (Santostefano, 1985, 1988, 1990). Most of this work has focused on exploring how cognitive controls work in normal and abnormal development, establishing norms and standards, in assessing cognitive control dysfunctions and learning disabilities.

Cognitive Control Therapy

One of Santostefano's distinctive contributions to the field is the development of a therapeutic method called Cognitive Control Therapy to aid in modifying dysfunctional cognitive controls. Cognitive Control Therapy is a combination of traditional psychotherapy along with the setting of tasks that are structured in ways that the participant is forced, through a series of steps, to restructure their cognitive approaches to tasks and in turn, 
render cognitive controls more efficient at processing information. Santostefano (1985) has found that children with dysfunctional cognitive controls have difficulty benefitting from traditional psychotherapies (talk therapies) since their dysfunctional cognitive subprocesses make the processing of verbal information, which is required for the success of these types of psychotherapies, very difficult.

STUDIES WITH THE LEVELING-SHARPENING COGNITIVE CONTROL UNDER NEUTRAL AND AFFECTIVE CONDITIONS

Several studies have been conducted to examine how the cognitive control of leveling-sharpening shifts under shortterm stressful or affectively arousing conditions. In two previous studies which explored situations that were affectively arousing using the leveling-sharpening cognitive control, subjects were evaluated in two environments, one usual (neutral) and one unusual. Guthrie (1967) assessed the leveling-sharpening cognitive control of novice male parachutists (adults) in their home and again at the airport before a-jump. When compared with a control group not scheduled to jump, the experimental group showed a significant shift toward increased sharpening when at the airport. Shapiro (1972) assessed the leveling-sharpening cognitive control of boys scheduled to undergo surgery for hernia repair. When compared with a control group (dental 
evaluation), the surgical group showed the greatest shift toward leveling information when in the hospital

environment. On the one hand, in the case of the parachutists, it was adaptive to sharpen to reduce fear and anxiety over the jump. For the parachutists, sharpening on the information at the airport (i.e., whether the main parachute was folded properly, or whether the backup parachute was intact) was quite necessary for them to be assured they will survive the jump. Conversely, for the boys undergoing surgery (over which they had no control) it was adaptive to level (avoid information) in the hospital environment to reduce fear or anxiety over impending surgery by turning to inner thoughts and fantasies. Surgery subjects who shifted most toward leveling were less anxious and were rated by their mothers as adjusting better after surgery than their counterparts who showed less of a shift. Two other studies (Santostefano 1978., Santostefano \& Reider, 1984) explored the leveling-sharpening cognitive control of high-aggressive versus low-aggressive psychiatrically hospitalized children in their processing of a neutral versus an affectively charged stimulus. Highaggressive children were significantly more efficient in maintaining images of aggressive stimuli in memory and comparing them with present perceptions (sharpening) than their low-aggressive counterparts. These findings were interpreted to reflect 
"that the requirements of aggressive fantasies of highaggression children (which included low anxiety about aggression) were concordant with those of aggressive stimuli, prescribing a coordination that called for the ready assimilation of aggressive test stimuli.

Conversely, the requirements of aggressive fantasies of low-aggression children (which included high anxiety and conflict with aggression) were discordant with those of aggressive test stimuli, prescribing a coordination that avoided (leveled) the attributes of aggressive test stimuli" (Santostefano, 1985, p. 190).

An interesting outcome of this research that seems difficult to reconcile is that high-aggressive females, unlike their male counterparts, leveled with aggressive stimuli.

Another study that is somewhat related to the present research was conducted by Libon (1985) who was primarily concerned with the role of the Orientation Response (a psychophysiological measure of heart rate) as a measure of attention in the cognitive control of leveling-sharpening. Secondary to his main focus, Libon (1985) employed a scale measuring generalized aggression (Edwards, Personal Preference Schedule (EPPS), 1959) to separate subjects into high and low aggressive groups (median split method) and examined whether the subject's Orientation Responses changed while processing a neutral stimulus versus an affectively arousing one. While Libon's findings resembled Santostefano and Reidèr's (1984) results with aggressive versus nonaggressive children, as the author himself acknowledges, the measures, Leveling-Sharpening House Test (LSHT) and Leveling-Sharpening Aggression Test (LSAT), were not administered in the standardized manner making results and 
conclusions somewhat tentative. In addition the sample size in Libon's study 48 (24 males, 24 females) was quite small and thus very restricted regarding the question of statistical power. Further, it could be successfully argued that the female participants, both the adults in Libon's case and young girls in Santostefano's study, were not significantly aroused by the aggressive stimulus (LSAT-two cowboys engaged in a fist fight) to warrant a shift in their leveling-sharpening cognitive control. To females the stimulus must have just represented two males fighting, which is something males always do, and does not concern them. In addition, in the case of Libon's study, the use of a generalized measure of aggression is confounding since it is difficult to know whether the study was referring to aggressive/hostile feelings, behavioral actions, or attitudes toward aggression and violence.

Moncata (1990) used the leveling-sharpening cognitive control to compare four groups of children and adolescents (N=359, 185 males, 174 females). The subjects were classified as aggressive by their "in vivo" aggressive behaviors which were judged by the type of institution in which they were housed. The groups were drawn from prisons (high aggressive), training schools (moderate aggressive), behavior disordered classrooms (low aggressive), and public school (control). In general, Moncata's (1990) findings show that the high aggressive and moderate aggressive groups were more efficient at detecting changes with the aggressive 
task than were their counterparts in the low aggressive and nonaggressive groups.

\section{ACCEPTANCE OF INTERPERSONAL VIOLENCE}

Aggression, like cognition, is an area that has long been the object of extensive study in psychology. More recently the concentration on generalized aggression has been giving way to a focus on more specific distinctions of what is meant by aggression (i.e., hostile feelings, aggressive actions, or attitudes toward aggression and violence). In the area of sexual violence, social psychological research and feminist theory (Weis \& Borges, 1973., Brownmiller, 1975., Clark \& Lewis, 1977., Burt, 1978, 1980) see the cause of rape and violence against women as primarily stemming from cultural attitudes and the persistence of false beliefs which condone rape through the perpetuation of "rape myths" in our society, which effectively supports and excuses sexual assault. Some examples of rape myths that were found are "any healthy woman can successfully resist a rapist if she really wants to"; "women ask for it"; "many women have an unconscious wish to be raped"; "in the majority of rapes, the victim was promiscuous and had a bad reputation".

Burt (1980) tested some of the tenants of feminist analysis of rape by examining whether acceptance of rape 
myths could be predicted from attitudinal variables associated with people's beliefs about rape and interpersonal violence. The attitudinal variables she examined through a structural model analysis were sex-role stereotyping, sexual conservatism, adversarial sexual beliefs and acceptance of interpersonal violence. These concepts were operationalized and quantified by the formation of scales so that their relationship toward rape myth acceptance could be examined empirically.

As stated earlier, acceptance of interpersonal violence refers to the belief that force and coercion are legitimate ways to gain compliance in intimate and sexual relationships. The Burt (1980) Acceptance of Interpersonal Violence scale (AIV) along with the scales that measure the other attitudinal variables (sex-role stereotyping, sexual conservatism and adversarial sexual beliefs) were all developed in the same way. Promising items for each scale were selected from item analysis of a larger pool of questions with the final interview form containing twice as many items to measure each attitude as were desired for the final scale. Responses were examined and item analyses carried out on those items measuring a single attitude. The best of these items were then selected for the final scale. Reliability, of the six items of the AIV scale as indicated by Cronbach's alpha is estimated at .586 using a large sample $(N=598)$ of adults from the general population. The final items retained show good item-to-total correlations 
with the total scale. Results found that acceptance of rape myths was not related to personality characteristics such as age and job status but among both genders was connected with the attitudinal variables. Acceptance of interpersonal violence was the strongest predictor among the attitudinal correlates Burt examined, accounting for 27.98 of the variance ( $p<.05$ level) of the measure of rape myth acceptance. Burt sees acceptance of interpersonal violence as "the attitudinal releaser of assaultive action." (Burt, 1980 , p. 229 ).

Several other studies have used the Burt Acceptance of Interpersonal Violence Scale with great success in attempts to expand on the work of Burt (1980). For example, the AIV Scale has also proved to be a successful predictor of men's laboratory aggression against women (Malamuth, 1983). Briere (1987) also found the AIV scale to be a good predictor of subjective expectancy ratings of battering.

The present study is an attempt to relate aspects of specific findings in the feminist literature around acceptance of interpersonal violence (Burt, 1980) with findings and premises of cognitive control theory and research. This study also represents some major procedural and measurement improvements over former studies in this area. For one, it offers a new affectively arousing stimulus that depicts a scene involving male-female interpersonal violence designed to engage both males and females. This task is the Leveling-Sharpening Interpersonal 
Aggression Test, LSIAT (a man and woman fighting, as described below). For another, rather than using a measure of generalized aggression (Libon, 1985) or aggression in action, fantasy and language (Santostefano, 1978., Santostefano \& Reider, 1984), or generalized "in vivo" aggressive types based on residency status at institutions (Moncata, 1990), the present study is directly concerned with a specific dimension of aggression, attitudes toward interpersonal violence. Further, unlike Santostefano's work with psychiatrically hospitalized children or Moncata's work with institutionalized juveniles, the present study attempts to explore whether the same phenomena can be observed within a normal adult population sample of college students.

\section{HYPOTHESES AND PREDICTIONS}

The first hypothesis of this research is that the leveling-sharpening cognitive control will shift due to the changes in the signal value of the two leveling-sharpening tasks, from neutral to aggressively ladened. This hypothesis has been supported before (Santostefano, 1978.. Santostefano and Reider, 1984., Libon, 1985., Moncata, 1990). It is expected that it will be replicated by the findings of this experiment.

(1.) It is therefore predicted that when the signal value of the leveling-sharpening task changes from neutral to aggressive, the leveling-sharpening behavior of all subjects 
will shift toward leveling. That is, their score on the aggressive task will be lower than their score on the neutral task. This prediction will be supported by a significant two-way interaction between Levelers and Sharpeners, and the two repeated measures tasks, collapsed across acceptance of intexpersonal violence attitude groups. The second hypothesis is the major hypothesis of this research and concerns the relationship between an individual's predisposition toward accepting interpersonal violence and their leveling-sharpening cognitive control behavior. This relationship should be clearer when subjects, given their differing attitudes toward accepting interpersonal violence, are looked at across levelingsharpening tasks of differing signal value (neutral versus aggressive) .

(2.) It is therefore predicted that subjects who score high on the acceptance of interpersonal violence scale (High Acceptors and Moderate Acceptors) will show a lesser shift toward leveling when attending to the aggressive stimulus than will their counterparts who are rejectors of interpersonal violence. Conversely, subjects who score low on the acceptance of interpersonal violence scale (Rejectors) will show a shift toward more leveling when attending to the aggressive task as compared with subjects who show acceptance of interpersonal violence. This prediction would be supported by a significant interaction among the three variables Acceptance of Interpersonal 
Violence, Leveling-Sharpening Ratio, and Tasks (repeated measures, neutral versus aggressive).

The third hypothesis based on the results of prior research (Santostefano, 1978, Santostefano \& Reider, 1984) is that male-female differences exist among Levelers and Sharpeners depending on their predisposition toward accepting interpersonal violence.

(3.) It is therefore predicted that some sex differences between males and females (depending on their attitudes toward the acceptance of interpersonal violence) are to be expected. This prediction will be supported by a significant interaction among the four variables sex, Acceptance of Interpersonal Violence, Leveling-Sharpening Ratio and Tasks (neutral versus aggressive) or three way interactions involving either Sex $\mathrm{x}$ Acceptance Interpersonal Violence $\mathrm{x}$ Leveling-Sharpening Ratio, or Sex $\mathrm{x}$ Acceptance of Interpersonal Violence X Tasks (neutral versus aggressive). The major aim of this research is to see how attitudes toward interpersonal violence influence the responses of Levelers and Sharpeners when the signal value of the leveling-sharpening task changes from a neutral to one with an aggressive content. 
METHOD

This was an exploratory study which took place in two phases.

\section{Part one:}

First, a leveling-sharpening task was developed involving male-female interpersonal aggression, the Leveling Sharpening Interpersonal Aggression Test (LSIAT) a man and woman engaged in a fight. This test, the LSIAT, as stated above, was modeled on Santostefano's Leveling-Sharpening Aggression Test (LSAT), two cowboys in a fist fight (Santostefano, 1978). The LSIAT was then used as a dependent measure in the second phase of the study. The main elements in the scene of the LSIAT (Appendix VI) and the LSAT (Appendix VII) are identical in structure except for the fact that the left figure is male in the case of the LSAT and female in the case of the LSIAT. In addition, the female figure's gun is in a handbag (LSIAT) rather than a holster as is the case with the parallel male figure (LSAT). To make the scene more realistic, the right hand figure (male) in the LSIAT has his extended hand in an open palm position rather than in a close fist as is the case with the LSAT. The same elements drop out of each test in the same order (a list is presented in Appendix VIA). The LSIAT (and likewise the LSAT), was constructed under the same principals and has similar psychometric properties as 
the Leveling-Sharpening House Test (LSHT) as described below.

\section{Part Two:}

Subjects :

The second part of the study consisted of testing 251 subjects ( 135 male and 116 female) solicited from the undergraduate student population from a state university in the northeastern United States. All of the participants were students taking psychology courses and all the testing took place in the spring of 1991. Most of the subjects (95\%) were required to participate in psychological research as part of their course work. The remaining 5 t were volunteers. While a large portion of the participants were enrolled in liberal arts programs, many were from varying colleges and departments within the university (i.e., pharmacy, nursing, engineering, business, physical education, military science, pre-med, dental hygiene etc...). The majority of subjects were Caucasian and middle class, and all were at least 18 years of age.

Measures :

Participants were assessed with the following five instruments: (1.) A demographic questionnaire (a copy of which can be found in Appendix II). (2.) A 35 item 
questionnaire in which the Burt (1980) scale of Acceptance of Interpersonal Violence is embedded (Appendix III); (3.) A training session with the Leveling-Sharpening Training Test (Santostefano, 1988), a picture of the main scene appears in Appendix IV. (4.) The Leveling-Sharpening House Test (LSHT), (main scene and list of details that drop out Appendix V\&VA); and (5.) The Leveling-Sharpening Interpersonal Aggression Test (LSIAT), (main scene and list of details that drop out Appendix VI \& VIA).

(1) The Burt (1980) Acceptance of Interpersonal Violence scale (AIV) consists of six (6) statements about interpersonal violence (Appendix III, *s $10-15$ ). The general questionnaire and the Burt scale asks a person to indicate, on a seven point scale, to what extent they agree or disagree with each statement. The scale ranges from 1 ("strongly agree") to 7 ("strongly disagree"). On the basis of their responses on the AIV scale, each person will be classified as either highly accepting of interpersonal violence (High Acceptors), moderately accepting of interpersonal violence (Moderate Acceptors), or rejecting of interpersonal violence (Rejectors). High score $(>+.5 S D)$ will indicate High Acceptors, low score (<-.5SD) will indicate Rejectors, and Moderate Acceptors will be those who scored within + or - .5SD from the mean. The Burt scale appears to have sound psychometric properties in that it does seem to tap attitudes toward interpersonal violence by 
setting the task directly of having the subject indicate their attitude to the six statements. Five of the six statements involve inter-sex violence and the other is nonsex specific.

(2) The Leveling-Sharpening House Test (LSHT) (Santostefano, 1964), measures the leveling-sharpening cognitive control under neutral conditions. It assesses the degree to which the person is able to hold an image (a house scene) in memory when changing information is presented sequentially over time. The test consists of 60 cards displaying lined, achromatic drawings of a house scene. Each card is presented one at a time for 5 seconds. From card to card, elements of the drawing are omitted cumulatively. The subject is asked to examine each card as carefully as possible and to tell the examiner to stop the display whenever "the picture changes or looks different." The examiner then goes on to turn the cards face up one at a time. The main elements of the scene are as follows: a house, a chimney emitting smoke, a weather vane, a sidewalk, a fence, a tree, a cloud and the sun. (A copy of the picture of the entire main scene is presented in Appendix v). The first three displays contain all elements. With the fourth display, the doorknob drops out and remains absent throughout the test. On the seventh display a part of the fence drops out, and so on, until all 60 frames (cards) are shown. In this manner 19 elements are omitted 
accumulatively, and each new configuration, representing some combination of omissions, is displayed three times. The least conspicuous element is eliminated first and the most conspicuous last. A list of the details that drop out is provided in Appendix VA). Instructions for the administration of the LSHT and likewise the LSIAT is presented in Appendix VIII. The examiner records the subjects responses on the LSHT scoring sheet a copy of which can be found in Appendix $\mathrm{X}$.

As stated above, the concept of leveling-sharpening concerns the manner in which an individual constructs images of information, holds these images in memory over time, and compares them with memories of present information, thus differences are noticed. The task and the process elicited by the LSHT (and likewise the LSIAT) appear to operationalize the concept of leveling-sharpening quite well. Information in the form of a picture of a house scene, (a picture of a fight between a man and a woman in the case of LSIAT) is presented repeatedly and sequentially over time and the guiding intention set by the instructions is to notice whether the information "changes or looks different". It is therefore reasonable to assume that the subject compares the present display with a memory image of the scene that has been constructed to that point (Santostefano, 1988, 1990).

Criterion-related validity also seems satisfied since the task correlates well with measures that tap similar 
processes. For example, one of the measures Santostefano (1978) found to be correlated with the LSHT is the Benton Visual Retention Test (BVRT). The BVRT is an individually administered test (like the LSHT and LSIAT) in which the subject is required to look over a design and then draw it from memory. Scores are obtained for accuracy, errors produced when completing the designs, omissions, and time taken. Santostefano (1978) has found LSHT scores (LevelingSharpening Ratio, \# of correct changes, first stop score) to show correlations significant at $p<.01$ level with scores of the BVRT.

Reliability of the LSHT has also been well documented with regard to stability and consistency over time. For example, Guthrie (1967), using the LSHT scores with adults and an alternate scene of a parachutist, found correlations that were significant $(r=.38$ at $p<.01$ level). Guthrie (1967) also found stability over a one week period with both his experimental group $(r=.70$ at $p<.01)$ and control group $(r=.67$ at $p<.01)$ showing that the LSHT produced very consistent scores over a short period of time in both stress and nonstress conditions. Shapiro (1972) has also shown the LSHT to be correlated well with a similar levelingsharpening measure of a scene of a doctor standing in a hospital room, obtaining significant correlations between the two measures in 13 of the 18 comparisons ( $r$ 's ranged from .08 to .75). Sharpiro's study has also shown these measures to be stable over a four week period. Santostefano 
(1988) has also demonstrated test-retest reliability of the LSHT over a 5 year period with latency aged children.

(3) The Leveling-Sharpening Interpersonal Aggression Test (LSIAT) developed by this author, measures the leveling-sharpening cognitive control with an inter-sex aggressive stimulus. It is administered in the same manner as is the LSHT (instructions for the administration can be found in Appendix VIII). The LSIAT consists of 63 lined, achromatic drawings of a scene depicting a man and a woman engaged in a fight. As is the case with the model on which it was based (LSAT), 20 elements are eliminated accumulatively from the first to the last card, and each configuration of details is displayed three successive times. The order of which the LSHT and LSIAT were presented was randomized (switched for each student) to avoid ordering effects.

The LSHT and LSIAT yield the following three primary scores which were employed in the data analysis: (1.) The Content score or total number of correct changes of details detected (for the LSHT = LSHT-C., for the LSIAT = LSIAT-C), (2.) the First Stop score, which is the number of the first card at which the first correct change in the information is perceived (for the LSHT = LSHT-FS., for the LSIAT = LSIATFS), and (3.) the Leveling-Sharpening Ratio score or LSratio (for the LSHT $=$ LSHT-R., for the LSIAT $=$ LSIAT-R). 
The LS-ratio, which determines whether a subject is a Leveler or Sharpener, is established by using the neutral leveling-sharpening test, the LSHT. This ratio takes into account correct changes not detected, correct changes perceived and how soon the correct changes were detected after they were introduced. That is, people who detect first changes early, who report many correct changes, and who detect changes soon after they are introduced are viewed as Sharpeners, maintaining stable images of information over time. On the other hand, people who detect first changes late, who report fewer changes, and who detect changes long after they are introduced are seen as Levelers, maintaining global, diffuse images of information over time. The sum of all the opportunities to detect unperceived changes is added to the sum of the opportunities to detect correct changes before they were eventually seen. This sum, the numerator, is divided by the number of changes in each test. The formula for the LS-ratio is depicted graphically in Figure 4. A median split process was employed to divide subjects into Sharpeners, low LS-ratio and Levelers, high LS-ratio (Santostefano, 1978, 1988, 1990). 
Figure 4.

\author{
\# of opportunities to detect + of opportunities \\ changes not perceived. \\ to detect changes \\ before they were \\ reported. \\ LS-ratio $=$ \\ 19 (total * of changes in the test) \\ (adapted from Santostefano, 1988, p. 74 ).
}

Procedure:

Each subject was tested individually by one examiner and the order in which each of the leveling-sharpening tasks were administered was randomized for all subjects to guard against practice (order) effects. All procedures were administered at the same testing session and each subject took about one hour to complete all the measures.

Each subject was first taken to a lounge area where the procedures of the experiment were outlined. Consent forms were then administered to all participants. A copy of the consent form is provided in Appendix 1. After the participant read the consent form and signed it, the experimenter again highlighted the procedures for maintaining confidentiality and the right for the subject to withdraw from the study at any time. Next, the subjects were made to draw one card of stickers, which had the same number written on it 5 times, from a large manila envelope (series numbered 1-300). Subjects were further instructed 
that these numbers were to be kept hidden from the examiner, and used to paste on their protocols after testing so as to identify all protocols belonging to a particular subject. The demographic questionnaire and the 35 item questionnaire which includes the Burt (1980) AIV scale were then filled out privately by each participant. Each subject was then directed to a small testing room to complete the rest of the measures. When they arrived at the testing room they were instructed to place their completed measures face down in a box. The investigator was blind to the subjects' responses through both the assignment of numbers and by the fact that the AIV scale and demographic questionnaire were seen and scored only after all testing was completed.

\section{Training Phase:}

Before beginning testing on the leveling-sharpening measures (LSHT and LSIAT), each subject had to successfully complete a training exercise, so that they may understand better the requirements of the leveling-sharpening tasks. Six practice cards (developed by Santostefano, 1988) were used during the training phase. The main scene of these practice cards consists of a chair with a hat hanging on it and a shoe and toy car on the floor next to it as presented in Appendix IV. The scene is a simple black and white two dimensional drawing. The first two cards contain the complete scene. With the third and fourth cards, the top board of the chair is omitted. With card five and six, the 
front legs of the chair are removed. The practice cards are stacked down with card 1 at the top and card 6 at the bottom (and similarly, the test cards (LSHT and LSIAT) with card 1 at the top and card 60 (63) at the bottom) when they are being administered.

The testing (Training Test, LSHT and LSIAT) was done at a small table with one side (length) leaning against the wall of the room. The examiner sat to the right of each subject.

After the subject completed the training phase and it was clear that the procedures were understood, the LSHT and LSIAT measures were administered. As stated before, these tasks were randomized for each subject. As stated above, the instructions for the administration of these tests can be found in Appendix VIII. At the end of the testing, protocols (with numbered stickers attached for identification) were placed, face down into a box by the subjects. A short debriefing session (5-10 minutes) followed. The researcher debriefed all participants by direct inquiry to assess for any adverse reactions, and made himself available for any necessary follow up. During the debriefing period of this experiment, aside from a few who indicated some minor test performance anxiety, no subject indicated any distress with the content area (questionnaire including AIV scale and scenes from the LSIAT) and no subject required any clinical intervention or referral. 
Since this study also involved the use of measures of aggression (AIV and LSIAT), to lessen the influence of social desirability, special care was taken to assure subjects that their protocols would remain anonymous (numbers assigned to each protocol) and it was underscored that the study was not one about them as individuals but a study of the instruments and groups. The fact that the Burt (1980) scale was embedded in a larger questionnaire should also have significantly reduced reactivity (social desirability) to the measure. 
RESULTS

Demographic Characteristics

Two hundred and fifty one subjects were tested, 135 were male and 116 were female. All the variables were obtained for every subject. Raw data for all subjects $(N=251)$ on all variables are presented in Appendix $X I$.

Descriptive analyses indicated that the sample was significantly skewed for all demographic variables. While subjects ranged in age from 18-54, 938 were between 18 and 24 years old, with the mean age being 20 . Ethnic/racial variability was also extremely skewed, $90 z$ of the subjects were of Anglo European ancestry, with African, Hispanic, Asian, Native American and Indian comprising the remaining 108 of the sample. Marital Status was also skewed with $94 \%$ of the sample being single. Socioeconomic status, assessed in terms of present personal, and familial income was skewed in the direction of the middle to upper middle class. 458 reported family incomes between $\$ 35,000$ and $\$ 65,000$, and another $45 \%$ reported family incomes that exceeded $\$ 65,000$. The remaining 108 reported family incomes that were under $\$ 35,000$.

The means, standard deviations, and range of scores for Levelers (127) and Sharpeners (124) on all variables used in the ANOVAs are listed in Table I. The scores are listed as follows: The Acceptance of Interpersonal Violence Scale 
Score (AIV); The Content Score ( of correct changes detected) for the neutral task, LSHT (LSHT-C); The Content Score for the aggressive task, LSIAT (LSIAT-C); The First Stop Score ( card subject first noticed a change) for the LSHT (LSHT-FS); The First Stop Score for the LSIAT (LSIATFS): The Ratio Score for the LSHT (LSHT-R) and the Ratio Score for the LSIAT (LSIAT-R).

All hypotheses were tested by performing $2 \times 3 \times 2 \times 2-$ way ANOVAs with repeated measures on the last factor. The first ANOVA was conducted with the dependent variable, tasks (repeated measures) being the Content scores (number of correct changes) from the LSHT (LSHT-C) and LSIAT (LSIAT-C). This ANOVA consisted of a 2 (male versus female) $\times 3$ (High Acceptors X Moderate Acceptors x Rejectors) X 2 (Levelers versus Sharpeners) $\times 2$ (repeated measures Tasks: LSHT-C versus LSIAT-C). The summary source table for this repeated measures ANOVA is presented in Table II.

Results revealed two significant three-way interactions. One for Acceptance of Interpersonal Violence $X$ Leveling-Sharpening $X$ Tasks $F(2,239)=5.09 *, p<.05 \ldots$ and the other for Sex $X$ Leveling-Sharpening $X$ Tasks $F(1,239)=$ 4.12*, $p<.05$. While some main effects and simple effects were significant, because of the interaction effects, interpretation of these main effects and simple effects are necessarily delayed until the interactions are examined. 
Table I.

The Means, Standard Deviations, and Range of scores for Sharpeners $(\mathrm{N}=124)$ and Levelers $(\mathrm{N}=127)$ on all variables.

\begin{tabular}{|c|c|c|c|c|}
\hline & & Means & $\begin{array}{l}\text { Standard } \\
\text { Deviations }\end{array}$ & Range \\
\hline & All & 13.295 & 4.702 & 21 \\
\hline \multirow[t]{3}{*}{ AIV } & Sharpeners & 13.669 & 4.657 & 21 \\
\hline & Levelers & 12.929 & 4.736 & 20 \\
\hline & All & 13.896 & 1.752 & 9 \\
\hline \multirow{2}{*}{$\begin{array}{l}\text { LSHT-C } \\
\text { (Neut) }\end{array}$} & Sharpeners & 15.242 & 1.069 & 6 \\
\hline & Levelers & 12.583 & 1.205 & 6 \\
\hline 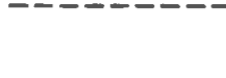 & All & 10.845 & 1.888 & 9 \\
\hline \multirow{2}{*}{$\begin{array}{l}\text { LSIAT-C } \\
\text { (Agg) }\end{array}$} & Sharpeners & 11.556 & 1.721 & 8 \\
\hline & Levelers & 10.150 & 1.787 & 9 \\
\hline \multirow{3}{*}{$\begin{array}{l}\text { LSHT-FS } \\
\text { (Neut) }\end{array}$} & All & 9.243 & 4.415 & 23 \\
\hline & Sharpeners & 6.815 & 2.855 & 13 \\
\hline & Levelers & 11.614 & 4.388 & 23 \\
\hline \multirow{3}{*}{$\begin{array}{l}\text { LSIAT-FS } \\
\text { (Agg) }\end{array}$} & All & 11.179 & 6.661 & 27 \\
\hline & Sharpeners & 9.677 & 5.980 & 24 \\
\hline & Levelers & 12.646 & 6.980 & 27 \\
\hline \multirow{3}{*}{$\begin{array}{l}\text { LSHT-R } \\
\text { (Neut) }\end{array}$} & All & 11.178 & 3.437 & 15 \\
\hline & Sharpeners & 8.270 & 3.399 & 14 \\
\hline & Levelers & 14.308 & 3.465 & 15 \\
\hline \multirow{3}{*}{$\begin{array}{l}\text { LSIAT-R } \\
\text { (Agg) }\end{array}$} & All & 16.827 & 3.163 & 15 \\
\hline & Sharpeners & 15.684 & 2.854 & 14 \\
\hline & Levelers & 17.944 & 3.057 & 15 \\
\hline
\end{tabular}


Table II.

ANOVA Summary Source table for 2 (male/female) 83 (High/Moderate/Rejection Interpersonal violence) $\& 2$ (Leveling/Sharpening) \& 2 repeated measures Tasks (HT-C vs IAT-C, of correct changes score) as dependent variable.

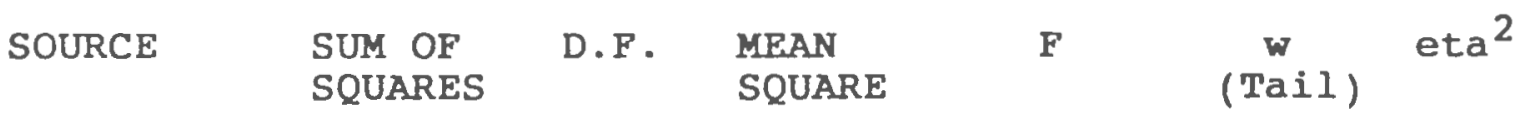

\begin{tabular}{|c|c|c|c|c|c|}
\hline Mean & 65510.297 & 1 & 65510.297 & 25885.65 & \\
\hline Sex & 10.73 & 1 & 10.73 & 4.24 * & 0.0405 \\
\hline AIV & 0.65 & 2 & 0.32 & 0.13 & \\
\hline
\end{tabular}

Leveling/

Sharpening

$\begin{array}{rrrrr}429.070 & 1 & 429.070 & 169.54 \star \star \star & 0.0000 .167 \\ 2.70 & 2 & 1.35 & 0.53 & \\ 11.42 & 1 & 11.42 & 4.51 * & 0.0347 .004 \\ 1.06 & 2 & 0.53 & 0.21 & \\ 1.45 & 2 & 0.72 & 0.29 & \end{array}$

$S \mathrm{x}$ AIV

$604.850 \quad 239$

2.53

1 ERROR

$\begin{array}{cc}984.819 & 1 \\ 3.46 & 1 \\ 0.36 & 2 \\ 50.99 & 1\end{array}$

984.819

$551.78 * \star \star 0.0000 \quad .385$
1.94
0.10
$28.57 \star \star * 0.0000 \quad .019$

$\mathrm{T} \times \mathrm{L} / \mathrm{S}$

$T \times$ Sex

0.32

2

3.46

0.18

50.99

0.16

0.09

$\mathrm{T} x$ Sex

$\mathrm{x} \mathrm{L} / \mathrm{S}$

7.35

7.35

4. 12

$0.0436 \quad .002$

$T \times$ AIV

$x$ L/S

18.15

9.08

$5.09 * 0.0069 \quad .007$

$T \times$ Sex

$\mathrm{x}$ AIV $\mathrm{x} \mathrm{L} / \mathrm{S}$

0.90

0.45

0.25

2 ERROR

$427.566 \quad 239$

1.78

$\star \quad \mathrm{P}<.05$

* $* \mathrm{P}<.01$

$\star \star \star \mathrm{p}<.001$ 
First, simple effects follow up tests were done on the interaction effect of Acceptance of Interpersonal Violence 8 Leveling-Sharpening $\mathrm{X}$ Tasks (neutral versus aggressive). Looking at levels of acceptance of interpersonal violence (High Acceptors, Moderate Acceptors, and Rejectors) across tasks (neutral and aggressive) revealed that for Levelers and Sharpeners who were Rejectors of interpersonal violence there were no differences in their drop off rates of detecting fewer changes as they moved from the neutral to the aggressive task (i.e., no interaction). For Moderate Acceptors of interpersonal violence, Sharpeners made significantly more of a drop off in their rates of detecting changes from the neutral to the aggressive task as compared to their Leveler counterparts. Further, subjects who were High Acceptors of interpersonal violence and were Sharpeners also had a significant drop off in their rates of detecting changes from the neutral to the aggressive task as compared to their counterparts who were Levelers. Moreover, High Acceptors of interpersonal violence who were Sharpeners made a greater shift in detecting less changes (leveled) as they moved from the neutral to the aggressive task than did their Sharpener counterparts who were Moderate Acceptors or Rejectors. Results also revealed that all subjects, irrespective of whether they were Levelers or Sharpeners or their attitudes toward interpersonal violence, detected fewer changes on the aggressive task (LSIAT-C) as compared 
with the neutral task (LSHT-C). Figure 5 gives a graphic representation of this relationship.

Secondly, simple effects follow up tests were done on the simple interaction effect for Sex $x$ Leveling-Sharpening $x$ Tasks (neutral versus aggressive). Looking at subjects by individual task revealed that for Levelers and Sharpeners, both males and females scored about the same on the neutral task (LSHT-C). However on the inter-sex aggressive task (LSIAT-C) sex differences between males and females depended on whether subjects were Levelers or Sharpeners. There was no difference between male and female Levelers. The differences lay with Sharpeners. Female Sharpeners scored significantly lower than their male counterparts on the aggressive task (LSIAT-C). Figure 6 gives a graphic representation of this relationship.

In addition, a follow up t-test comparing the two Sexes on Acceptance of Interpersonal Violence was conducted and found to be significant $\underline{t}(249)=4.56, p<.001$. This result indicates that overall males were significantly more accepting of interpersonal violence than were females accounting for about 88 variance $\left(\right.$ eta $\left.{ }^{2}=.08\right)$. 
Figure 5

Acceptance of Interpersonal Violence (AIV) X Leveling Sharpening $X$ Tasks (Content Score, LSHT-C vs LSIAT-C).
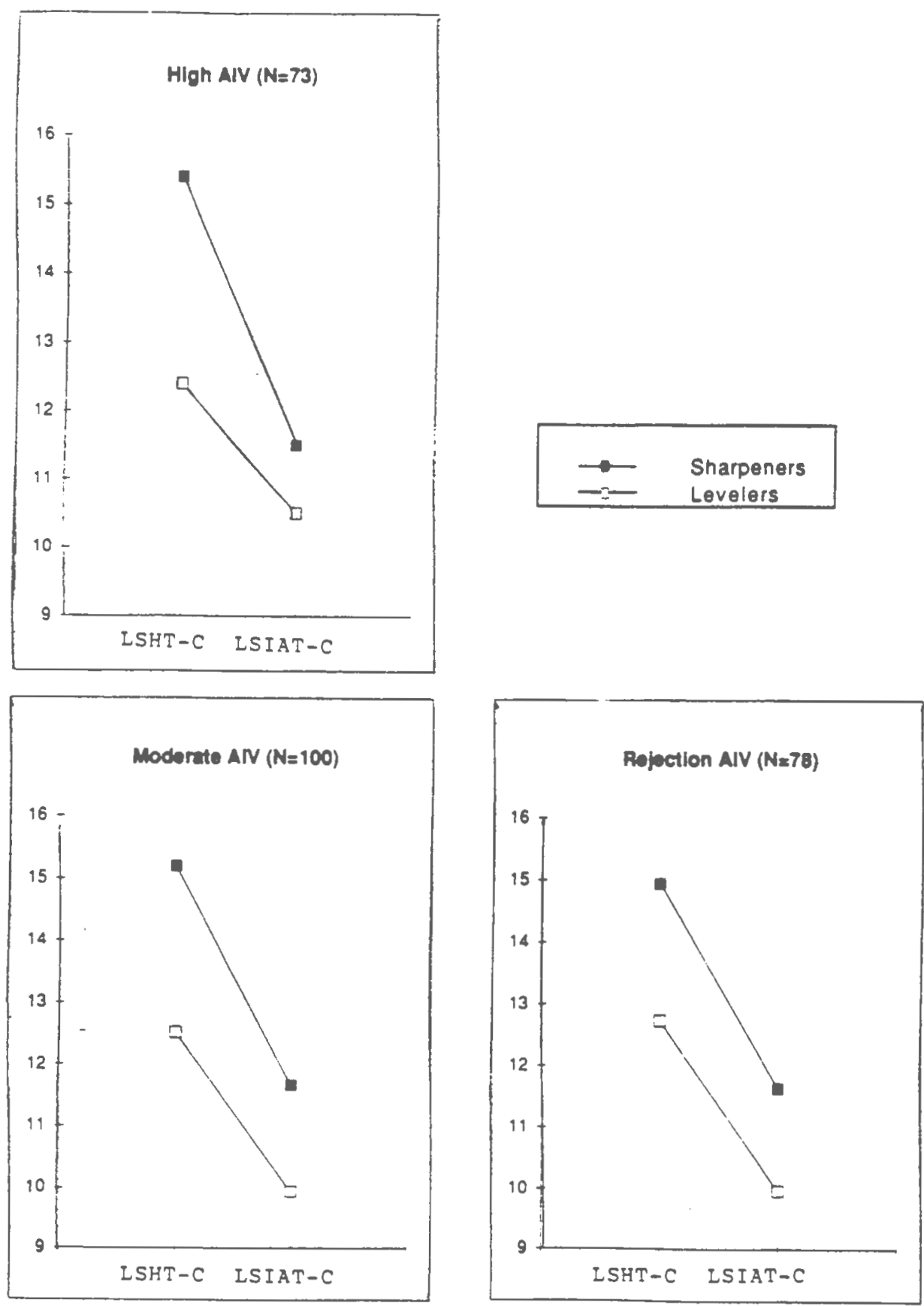
Figure 6

Leveling - Sharpening X Sex X Tasks

(Content Score, LSHT-C vs LSIAT-C).
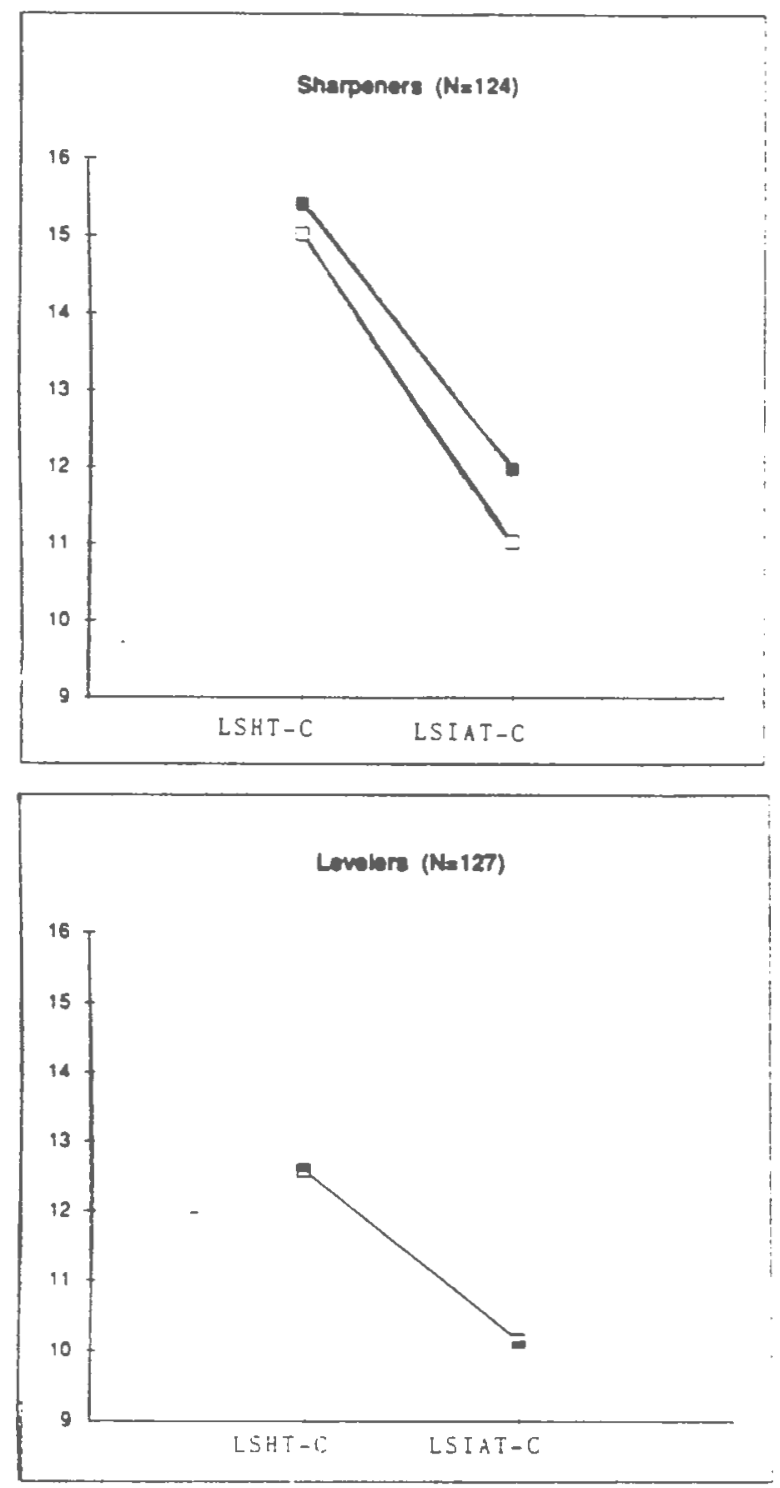

- Mele

- Female 
The second ANOVA was conducted with the dependent variable, tasks (repeated measures) being the First Stop scores from the LSHT (LSHT-FS) and LSIAT (LSIAT-FS). The ANOVA consisted of a 2 (male versus female) $\times 3$ (High Acceptors x Moderate Acceptors x Rejectors) x 2 (Levelers versus Sharpeners) $\times 2$ (Tasks: LSHT-FS versus LSIAT-FS). This ANOVA summary source table is presented in Table III. While results showed a main effect for LevelingSharpening, $F(1,239)=48.16^{\star \star}, p<.001$, and a main effect for Tasks $F(1,239)=15.79 \star \star, p<.001$, due to the interaction effect for Tasks $x$ Leveling Sharpening $F(1,239)=5.70$ * significant at $p<.05$, interpretation of the main effects were delayed until the interaction was further examined. Follow up simple effects tests looking at differences between Levelers and Sharpeners across tasks (neutral versus aggressive) revealed that Sharpeners were more likely to detect first changes significantly later on the aggressive task than their counterparts who were Levelers (i.e., interaction). Figure 7 gives a graphic representation of this relationship. Results also revealed that overall, all subjects made a significant shift in detecting their first change later on the aggressive task than on the neutral task.

Further, for each of the demographic IVs (maxital status, age, ethnicity and socioeconomic status) a set of analyses using both the Content score and the First Stop score in separate analyses were completed. This was 
performed with the use of separate ANOVAs with repeated measures. To guard against Type I error, a more conservative alpha level $\mathrm{p}<.01$ was used. Results revealed no significant effects for any of the demographic IVs. 
Table III.

ANOVA Summary Source table for 2 (male/female) \& 3 (High/Moderate/Rejection Interpersonal violence) $\mathbf{x} 2$ (Leveling/Sharpening) 82 Tasks (HT-FS vs IAT-FS) with repeated measures on the last factor.

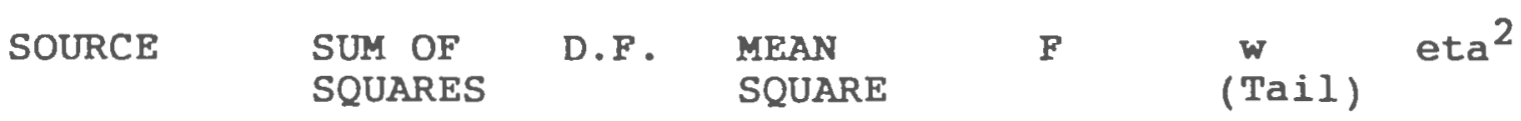

\begin{tabular}{|c|c|c|c|c|c|c|}
\hline Mean & 45283.097 & 1 & 45283.097 & 1406.94 & & \\
\hline Sex & 12.05 & 1 & 12.05 & 0.37 & & \\
\hline AIV & 53.15 & 2 & 26.57 & 0.83 & & \\
\hline Leveling/ & & & & & & \\
\hline Sharpening & 1549.92 & 1 & 1549.92 & $48.16 * *$ & 0.0000 & .096 \\
\hline$S \times A I V$ & 51.44 & 2 & 25.72 & 0.80 & & \\
\hline$S \times L / S$ & 50.06 & 1 & 50.06 & 1.56 & & \\
\hline AIV $\times \mathrm{L} / \mathrm{S}$ & 0.01 & 2 & 1.00 & 0.00 & & \\
\hline $\mathrm{L} / \mathrm{S}$ & 71.62 & 2 & 35.81 & 1.11 & & \\
\hline 1 ERROR & 7692.34 & 239 & 32.91 & & & \\
\hline Tasks & 389.934 & 1 & 389.934 & $15.79 * \star$ & 0.0001 & .024 \\
\hline$T \times$ Sex & 5.38 & 1 & 5.38 & 0.22 & & \\
\hline$T \times$ AIV & 56.94 & 2 & 28.47 & 1.15 & & \\
\hline$T \times L / S$ & 140.78 & 1 & 140.78 & $5.70 \star$ & 0.0177 & .009 \\
\hline$T \times$ Sex & & & & & & \\
\hline x AIV & 32.97 & 2 & 16.49 & 0.67 & & \\
\hline$T \times$ Sex & & & & & & \\
\hline $\begin{array}{l}x \mathrm{~L} / \mathrm{S} \\
\mathrm{T} \times \mathrm{AIV}\end{array}$ & 0.96 & 1 & 0.96 & 0.04 & & \\
\hline$x \mathrm{~L} / \mathrm{S}$ & 16.93 & 2 & 8.46 & 0.34 & & \\
\hline$T \times$ Sex & & & & & & \\
\hline$\times$ AIV $\times L / S$ & 53.19 & 2 & 26.69 & 1.08 & & \\
\hline 2 ERROR & 5900.86 & 239 & 24.69 & & & \\
\hline
\end{tabular}

$$
\begin{aligned}
& \star \quad \mathrm{P}<.05 \\
& \star \star \quad \mathrm{P}<.001
\end{aligned}
$$


Figure 7

Leveling - Sharpening X Tasks

(First Stop Score, LSHT-FS vs LSIAT-FS).

\section{All Subjects $(\mathrm{N}=251)$}

14

13

13

$12 \div$

$11 \div$

$10-$

9

8

7

6

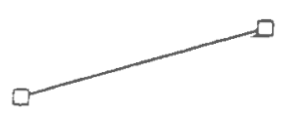

5

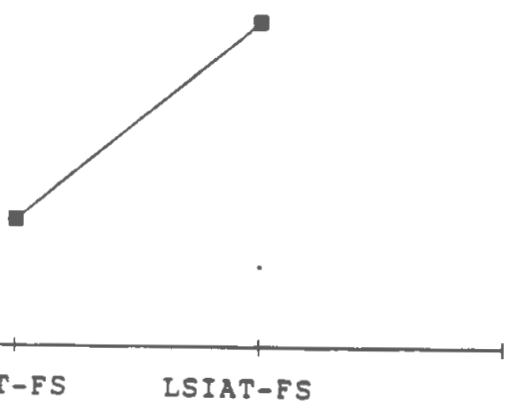

$\rightarrow$ 


\section{DISCUSSION}

The major hypothesis of this research was that people's attitudes toward the acceptance of interpersonal violence affects their leveling-sharpening cognitive control processing. This hypothesis was generated from Santostefano's $(1978,1984)$ thesis that an individual's predisposition to incorporate or reject affectively charged stimuli alters the leveling-sharpening process. According to this notion, regressive and progressive shifts in leveling-sharpening functioning are predictable given the context and one's psychological predisposition toward the situation in which leveling-sharpening occurs.

An individual's predisposition to incorporate or reject aggressively charged stimuli is based upon whether the person scores high on aggression or low on aggression. If the individual measures high on aggression it is presumed that they tend toward incorporation of the aggressive stimuli and therefore would process aggressive material more efficiently. That is, as was predicted by the major hypothesis of this experiment, subjects who showed acceptance of interpersonal violence (High Acceptors and Moderate Acceptors) would notice a greater amount of changes in content (sharpen more) on the task portraying interpersonal aggression (LSIAT) than on the neutral house 
task. Whereas if the person scores low on the acceptance of interpersonal violence scale (Rejectors) it is presumed that he or she will tend toward rejecting aggressive stimuli and thus, in the process, detect less changes (level more) on the task of interpersonal aggression when compared with their performance on the neutral task.

Given a subject's attitude toward accepting or rejecting interpersonal violence, an exploration of this hypothesis was accomplished in this experiment by comparing a subject's leveling-sharpening cognitive control functioning as he or she processed a neutral versus an interpersonal (inter-sex) aggressive stimulus. Thus, it was predicted that as subjects go from the LSHT (neutral) to LSIAT (inter-sex aggressive), those who showed acceptance of interpersonal violence (High Acceptors and Moderate Acceptors, high scores on the AIV scale) would exhibit the most pronounced differences reflecting increased sharpening (detecting more changes). Whereas those who showed a rejection of interpersonal violence (Rejectors, low score on the AIV scale) would show the converse trend of increased leveling (detecting less changes).

While the empirical results from the repeated measures analysis revealed that subjects, depending on their attitudes toward the acceptance of interpersonal violence, did show a differential shift in their leveling-sharpening cognitive control functioning, the direction of the shift was contrary to what was predicted by the major hypothesis. 
Firstly, contrary to Santostefano (1978) and Santostefano and Reider's (1984) findings with children who scored high on aggression, in terms of the adults in this study, for subjects who accepted interpersonal violence (High Acceptors and Moderate Acceptors) there was a significant difference in the way Levelers and Sharpeners performed on the neutral versus the aggressive task. High Acceptors and Moderate Acceptors who were Sharpeners were significantly less efficient at maintaining images of the interpersonally aggressive stimuli in memory (detected less changes) when compared with High Acceptors and Moderate Acceptors who were Levelers. Moreover, High Acceptors who were Sharpeners made the greatest shift in their drop off rate of detecting significantly fewer changes on the aggressive task than on the neutral task compared with either Moderate Acceptors or Rejectors.

Secondly, for subjects who were rejectors of interpersonal violence, regardless of whether they were Levelers or Sharpeners, there was no difference in their drop off rate across tasks (neutral to aggressive).

The change in the leveling-sharpening process is said to depend upon whether the particular meaningful affectively charged stimulus generates anxiety. If the person is measured high on aggression it is presumed that aggressive material does not generate anxiety for them. Therefore they would be more efficient at processing the material. Whereas if an individual scores low on aggression, aggressive 
stimuli is expected to elicit higher levels of anxiety making them less efficient at processing the aggressive material.

There are perhaps many reasons why the levelingsharpening cognitive control did not shift in the direction expected for acceptors of interpersonal violence versus rejectors of interpersonal violence. One major reason may be due to the actual nature of the type of aggression measured, acceptance of interpersonal violence. Attitudes toward interpersonal violence are very unlike other measures of aggression that were used in prior experiments.

One such example is the Multiple Situations Test (MST) employed by Santostefano (1978) and Santostefano and Reider (1984). Instead of having subjects rate their attitudes toward interpersonal aggression on a scale like the AIV, in the MST the subject is presented with five sets of items. At each instance, the subject is asked to perform, in whichever order they choose, three actions (e.g., hit doll, smash glass, shoot at target) which are rated as representing different levels of aggression from direct intensive to delayed attenuated. A score is assigned according to the order the actions are performed and averaged across the five sets of items. A low score is indicative of direct intensive aggression and a high score delayed attenuated aggression.

Another study (Moncata, 1990) divided subjects in terms of an "in vivo" rating of aggression. Moncata simply 
divided subjects in terms of the facility in which they were housed (e.g., training school, psychiatric hospital, behavior disordered classroom and public school) and assigned a level of aggression that ranged from the most restricted (High Aggressive) to the least restricted (low aggressive) environment. Still another example is the study by Libon (1985) which employed a personality inventory a small portion of which contained a generalized measure of aggression, the Edwards Personality Preference Scale (EPPS). In addition to being a different dimension of what we call aggression when compared to those used by these other researchers, attitudes that are accepting of interpersonal violence may also be quite guilt provoking particularly for people in an intellectual nonviolent climate of a university setting. This guilt, in turn, may generate much anxiety for those who are accepting of attitudes which support interpersonal violence.

Another reason for the subjects (acceptors versus rejectors of intexpersonal violence) in the present study not shifting their cognitive control behavior in the direction predicted (acceptors detecting more changes and rejectors detecting less changes) may lie in the nature of the subjects themselves. In almost all the previous research where differences in leveling-shaxpening behavior and aggression were studied (Santostefano, 1978., Santostefano \& Reider, 1984., Moncata, 1990), except for Libon (1985) whose administration of the measures were not 
standard, clinical (or other special) populations were used. Whereas in this study normal adult college students were the subjects. The attitudes of clinical populations toward interpersonal violence and other aggression may be quite different from those of college students. College students may be more aware of their attitudes and therefore may be more anxious about them, whereas clinical and other special populations may be less aware or concerned.

Results of this experiment certainly replicated the first hypothesis of this research since there was a main effect for task which revealed that all subjects, irrespective of whether they were Levelers or Sharpeners or their attitudes toward the acceptance of interpersonal violence, made a significant shift in their cognitive control behavior by detecting fewer changes on the aggressive task (LSIAT) than on the neutral task (LSHT).

Contrary to Santostefano (1978) and Santostefano and Reider's (1984) findings with psychiatrically hospitalized girls, females in the present study who scored high on acceptance of interpersonal violence did not shift any differently than males who were High Acceptors. This trend was the same for Moderate Acceptors and also Rejectors.

However, this study did find that female Sharpeners as a group, irrespective of whether they were acceptors or rejectors of interpersonal violence, detected significantly fewer changes on the inter-sex aggressive task as compared with their counterpart male Sharpeners. There was no 
difference between male and female Levelers on the aggressive task. There was also no difference between males and females on the neutral task regardless of whether they were Levelers or Sharpeners.

There are perhaps a variety of reasons that could account for the differences in the performances of male Sharpeners and female sharpeners on the interpersonal aggressive task. It could be successfully argued that females would be expected to be much more anxious around inter-sex aggressive material than males. For one, females are typically socialized to be nonaggressive as opposed to their male counterparts. For another, females are overwhelmingly more likely to be the victims of inter-sex aggression such as rape and other violence than are males. Furthermore, as evidenced by this study from the t-test comparing the two sexes with AIV $(t(249)=4.56$, significant at $p<.001$ ) and many others (e.g., Burt, 1980., Hyde, 1984., Maccoby \& Jacklin, 1974), females are significantly less accepting of interpersonal aggression and other violence than are males. Much research has shown, including the work of Santostefano on cognitive controls, that anxiety disrupts performance on cognitive tasks. Given all of the above, it follows that we should expect females to be more anxious around inter-sex aggression. Thus this anxiety could certainly account for the cognitive control inefficiencies of the females on the interpersonal, inter-sex aggressive task (LSIAT) . 
Results of the analysis with the First Stop scores (LSHT-FS and LSIAT-FS) as the dependent variable (repeated measures) confirmed the hypothesis that cognitive controls change under different stimuli. These results revealed that while both Levelers and Sharpeners detected their first changes later as they moved from the neutral to the interpersonal aggressive task, the sharpeners detected their first changes significantly much later on the aggressive task than did the Levelers. This result is consonant with the results obtained using the Content score as the dependent variable (repeated measures) as reported above.

Given the complexity of influence on human behavior, how might these modest, higher order differences that are reflected by the results of the present study manifest in every day experiences given the compromises that may occur in leveling-sharpening functioning. Since a regressive shift (leveling) decreases one's efficiency at registering and holding vivid memory images over time, one can speculate as to what adaptive outcome, whether adequate or inadequate, will result from such a shift.

Anxiety and subsequent cognitive control imbalance may very well contribute to female sharpeners not paying sufficient attention to material in the media around rape and other acts depicting interpersonal aggression. Furthermore, this compromised cognitive control efficiency may not be serving sucessful adaptations and thus may very well be contributing to females not paying sufficient 
attention to the visual cues that may possibly be inclinations of potential aggressive tendencies of acquaintances. These female Sharpeners may therefore be at further risk of being the objects of aggression.

Purthermore, if as Burt (1980) postulates, acceptance of interpersonal violence is the attitudinal releaser of assaultive action, then acceptors of interpersonal violence on the whole, given their cognitive slippage around violent stimuli may be at increased risk of acting out in an impulsive aggressive manner around aggressive stimuli. The finding of this experiment that both Levelers and Sharpeners who were rejectors of interpersonal violence scored similarly in their detection rates on both the neutral and aggressive task, as opposed to acceptors of interpersonal violence, lends further support to this notion.

Another area of vulnerability may be in long term versus short term memory functioning. One must be able to retain information for a sufficient period in short term memory in order for proper retention in long term memory. The process of shifts toward leveling information certainly does not seem to provide well for adequate long term memory storage..

On the other hand, could the reason why Levelers did not manifest any changes from the neutral to the aggressive task be precisely related to the fact of their leveling style itself. The argument follows that since this style is to hold global memory images of information, this may be 
done irrespective of context, making it so that Levelers have a restrictive range in which they can vary. In this sense, Levelers may be thought of as avoiders of information and Sharpeners processors of information. Therefore for Sharpeners, since they are extremly vigilant processors and hold vivid images, when there is a shift toward leveling there may be a propensity for this change to be more manifest than for Levelers. This certainly has some support in this experiment given the fact that all Levelers showed similar detection rates on both the neutral and aggressive task.

One possible explanation that may account in part for the results of the present study is that the two levelingsharpening tasks may not be sufficiently related to truly measure differences equitably in the leveling-sharpening process. Comparing performances on the motionless picture of a house with an action picture of two people engaged in a fight, may in part contribute to the aggressive task being more complex. This possibly may be partly reflected by the fact that all subjects were much less efficient at detecting changes on the aggressive task (LSIAT) than they were on the neutral task (LSHT).

Limitations of This Study:

Given that college students as a group (even with the varied academic interest of the subjects in this study) are 
different from the general population, one must be cautious as to how much the results of the present study could be generalized to other situations and other adult populations. In fact, Burt's (1980) sample from the general adult population of a large city was much more accepting of interpersonal violence than were the college students in this research. Whereas Burt's (1980) sample from the adult population ( $\mathrm{N}=598$ ) obtained an AIV mean score of 18.2 $(\mathrm{SD}=5.9)$, in the present study, college students $(\mathrm{N}=251)$ had a mean score of $13.3(\mathrm{SD}=4.7)$. It is therefore abundantly clear that the college students in the present study were significantly much less accepting of interpersonal violence than was the general adult city population of 12 years ago (i.e., Burt,1980). In fact college students as a group may still very well be less accepting of interpersonal violence than the general public. It would therefore be expected that future research with adults from the general population may show more pronounced shifts (regressive or progressive) in cognitive control functioning due to their higher levels of accepting interpersonal violence when compared to other groups such as college students. If future studies of this type were to be conducted a more representative sample of adults from the general population should be examined to see whether the same phenomena holds true as with the college students alone. 
IMPLICATIONS FOR FURTHER RESEARCH

If further research is to be conducted in this area, some modifications in the paradigm that was used may remediate some of the problems discussed above. For example, rather than using the house test (LSHT) as a comparable stimulus task alongside the LSIAT, a more appropriate task to replace the LSHT might be one developed from a scene depicting a friendly male-female interaction. This may be a more appropriate stimulus with which to compare the other action scene of a man and woman engaged in a fight (LSIAT). Scales that measure different dimensions of anxiety should also be employed to explore the implications of this study around whether anxiety does cause cognitive control imbalance.

The question also arises as to whether dividing subjects on the basis of a median split was sufficiently powerful to have created different enough groups to elucidate better the cognitive differences that were hypothesized between Levelers and Sharpeners. For this experiment constructing groups of Levelers and Sharpeners who fell beyond one standard deviation (+ or - ) from the mean did-not increase the difference between the groups. This failure could have conceivably been due to the reduction in the overall $\mathbf{N}$ at the extremes of the distribution ( $1 \mathrm{SD}, \mathbf{N}=11 .,-1 \mathrm{SD}, \mathbf{N}=13)$.

An alternative procedure may be to gather data from a much larger sample so as to generate the possibility of a 
larger $\mathbf{N}$ toward both ends of the distribution. Next, conduct the procedure of dividing Levelers and Sharpeners by the fact that they fell at the tail of the distribution of Leveling-Shaxpening Ratio, that is, beyond (+ or -) one standard deviation from the mean. This would maximize the differences between groups regarding their propensity toward leveling-sharpening. Nonetheless, this experiment did reach significance with the division by the median split process for groups of Levelers and Sharpeners. In fact in this research the differences between Levelers versus Sharpeners resulted in by far the largest difference among the independent variables, accounting for some 17.5 \& of the variance in correlation with the dependent variable. Dividing subjects into groups of Levelers and Sharpeners by the median split process in this experiment was done for two main reasons (1.) to assure equal group sizes and (2.) to afford for a better comparison with other findings in cognitive control research since all prior research also used the median split method for dividing groups.

When we look at the distribution of leveling-sharpening ratios obtained with the LSHT in this study and compare them with distributions reported elsewhere, they do not appear to be significantly different. For example Lemieux (1966) using the LSHT with college students ( $N=45,22$ male, 23 female) reported a mean of 12.5 for the LS-Ratio. Libon (1985) also used the LSHT with college students (N=48, 24 male, 24 female) and reports a mean of $13.6(S D=2.5)$ and a 
range of 6.6 to 19.4. Guthrie (1967) also reported a mean of 12.5 with a range of 7.7 to 20.6 . with young adult male parachutists $(\mathrm{N}=44)$. The present research $(\mathrm{N}=251)$ found a mean of $11.2(S D=3.4)$ and a range of 3.7 to 19.3 for the LSHT-Ratio scores.

No previous research was done with the LSIAT before the present study therefore it could not be compared. However, Libon (1985) has used the LSAT (which, as stated prior, was used as a model for the development of the LSIAT) with a college population $(\mathrm{N}=48)$ and reported a mean of 19.2 $(\mathrm{SD}=4.2)$ and a range of 9.8 to 25.5. However, Libon's experiment (Libon,1985) did not afford the test to be administered in the standardized manner which may account for his scores being somewhat inflated. Libon projected the scenes of the LSAT onto a television screen and had longer intervals between each of the trials (scene changes) to accommodate the recording of the subject's pulse rate. The present research with the LSIAT yielded a LS-Ratio with a mean of $16.8(S D=3.2)$ and a range of 9.0 to 24.3 .

While the main effect for sex indicated that males scored slightly higher than females on both the neutral and aggressive task, the percentage of variance accounted for by this main effect for sex was less than 18 reflecting this difference to be quite marginal.

It seems possible that attitudes toward accepting interpersonal violence may lead one to level (avoid) information in a violent scene in order for it to be 
adaptive in terms of lowered anxiety about guilt feeling over one's attitude. This may of course come at the expense of decreased efficiency in cognitive processing of external information.

Differences in the results of the present study compared with others may also be due to the fact that Santostefano along with almost all the other researchers who used the leveling-sharpening control in research mostly found differences with First Stop scores rather than the Content score. Functionally, the leveling-sharpening cognitive control involves the ability to hold information in memory over time. Since Sharpeners by definition notice more changes and Levelers notice less changes over time, it would seem that the Content score (LSHT-C and LSIAT-C), which is number of correct changes identified by a subject, exemplifies the operational definition of Levelers versus Sharpeners better than the First Stop score (first correct change identified). In fact the present study did employ both the Content score and the First Stop score. However, while differences were found with both scores, higher order interaction effects were only found with the Content score. Attitudes toward interpersonal violence while a major factor in "rape myth acceptance" (Burt, 1980), is itself only one dimension of aggression. To see if more dimensions of what we mean by aggression play a role in cognitive control functioning in adults, in future studies more measures of aggression should be employed (i.e., aggressive 
history, aggressive actions, aggressive feelings, attitudes toward aggression in war etc...).

Predicting someone's actual behavior in real world situations from such a small piece of evidence as offered by this research should be approached cautiously. While Santostefano (1990) does present some evidence that children's functioning on leveling-sharpening aggressive tasks reflects their aggressive behavior in the classroom, predicting adult behavior may be more complex, particularly given that adults may gain autonomy from childhood needs and desires (Allport, G., 1961). 
APPENDIX I

\section{CONSENT FORM}

I have been asked to take part in a research project described below. The researcher will explain the project to me in detail. I should feel free to ask any questions. If I have more questions later, $\mathrm{Mr}$. Bertram Gibbes, the person mainly responsible for this study, Phone \# (401) 783-1246, will discuss them with me.

I have been asked to take part in a study having to do with cognition and interpersonal attitudes. If I decide to take part in this study here is what will happen. I will be expected to spend a total of one hour completing a set of procedures. These include a questionnaire which I fill out privately and two (2) individually administered perceptualcognitive measures given by Mr. Bertram Gibbes the researcher in this study. Following this, I will be given the opportunity to talk further with the examiner about my reactions and any of my concerns.

There are no known physical or psychological risks to this research although it may be reasonable to expect to feel some discomfort with some of the material. Benefits for me include knowledge and experience of participating in a social science study, having the opportunity to examine my attitudes toward some intriguing interpersonal questions and an opportunity to directly contribute to scientific advancement.

My part in this study is strictly confidential. None of the information that is gathered in this study will be able to identify me by name. All records will be maintained in the personal care of $\mathrm{Mr}$. Bertram Gibbes.

Medical and psychological services are available through the University of Rhode Island should I feel them necessary. If this study causes me any injury, I should write or call the University of Rhode Island's Director of Research, 70 Lower College Road, University of Rhode Island, Ringston 02881, telephone: (401) 792-2635.

The decision whether or not to take part in this study is up to me. I do not have to participate. If I decide to take part in this study, I may quit at any time. Whatever I decide will in no way affect my grade, status as a student or penalize me in any way. If I decide to quit I simply 
inform Mr. Bertram Gibbes, telephone: (401) 783-1246 of my decision.

If I am not satisfied with the way this study is performed, I may discuss my complaints with Mr. Bertram Gibbes or with Dr. Allan Berman telephone (401) 792 2193, anonymously if I choose.

I have read the Consent Form. My questions have been answered. My signature on this form means that I understand the information and I agree to participate in this study.

Signature of Participant

Printed Name

Date
Signature of Researcher

Bertram Gibbes Printed Name

Date 


\section{APPENDIX II}

Demographic Questionnaire

On my last birthday I was years old.

I am Male ., Female

I am single ., Married

I consider myself:

Anglo/European American Hispanic American Native American __.. Other___. , Asian American Native American __.. Other___. African American - '

My Income (joint if married) for 1990 was approximately: Under $\$ 35,000$

Under $\$ 65,000$

Over $\$ 65,000$

Ignore next section if married.

My Parents Income for 1990 was approximately:

Under $\$ 35,000$

Under $\$ 65,000$

Over $\$ 65,000$

My major at the University is 
APPENDIX III
QUESTIONNAIRE
(Accceptance of Interpersonal violence Scale)

Please indicate your opinion by circling the appropriate number that best conveys how strongly you agree or disagree with the following statements.

Strongly

Agree
Strongly

Disagree

1. A man should fight when the woman

he's with is insulted by another man.l $2 \begin{array}{llllll}3 & 4 & 5 & 6 & 7\end{array}$

2. It is acceptable for the woman

to pay for the date.

$\begin{array}{lllllll}1 & 2 & 3 & 4 & 5 & 6 & 7\end{array}$

3. A woman should be a virgin when she marries.

$\begin{array}{lllllll}1 & 2 & 3 & 4 & 5 & 6 & 7\end{array}$

4. There is something wrong with a woman who doesn't want to marry and raise
a family.
12
3
$\begin{array}{llll}4 & 5 & 6 & 7\end{array}$

5. A wife should never contradict her husband in public.

6. It is better for a woman to use her feminine charm to get what she wants rather than ask for it outright.

$\begin{array}{lllllll}1 & 2 & 3 & 4 & 5 & 6 & 7\end{array}$

7. It is acceptable for a woman to have a career, but marriage and family should come first.

$\begin{array}{lllllll}1 & 2 & 3 & 4 & 5 & 6 & 7\end{array}$

8. It looks worse for a woman to be drunk than for a man to be drunk. $\quad \begin{array}{lllllll} & 2 & 3 & 4 & 5 & 6 & 7\end{array}$ 
Strongly

Strongly

Agree

Disagree

9. There is nothing wrong with a woman

going to a bar alone.

$\begin{array}{lllllll}1 & 2 & 3 & 4 & 5 & 6 & 7\end{array}$

10. People today should not use "an eye for

an eye and a tooth for a tooth" as a rule

$\begin{array}{lrrrrrrr}\text { for living. } & 1 & 2 & 3 & 4 & 5 & 6 & 7\end{array}$

11. Being roughed up is sexually

stimulating to many women.

$\begin{array}{lllllll}1 & 2 & 3 & 4 & 5 & 6 & 7\end{array}$

12. Many times a woman will pretend she doesn't want to have intercourse because she doesn't want to seem loose, but she's

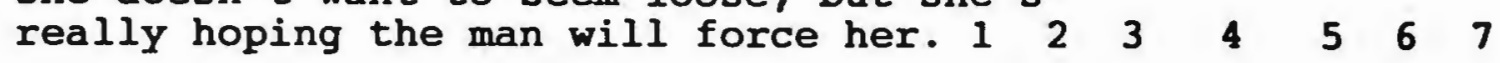

13. A wife should move out of the

house if her husband hits her. $\quad \begin{array}{llllllll} & 1 & 2 & 3 & 4 & 5 & 6 & 7\end{array}$

14. Sometimes the only way a man can get

a cold woman turned on is to use force. $\begin{array}{lllllll}2 & 3 & 4 & 5 & 6 & 7\end{array}$

15. A man is never justified in hitting

$\begin{array}{llllllll}\text { his wife. } & 1 & 2 & 3 & 4 & 5 & 6 & 7\end{array}$

16. A woman will only respect a man who

$\begin{array}{llllllll}\text { will lay down the law to her. } & 1 & 2 & 3 & 4 & 5 & 6 & 7\end{array}$

17. Many women are so demanding sexually

that a man just can't satisfy them. $\begin{array}{llllllll}1 & 2 & 3 & 4 & 5 & 6 & 7\end{array}$

18. A man's got to show the woman who's

boss right from the start or he'll end

up henpecked.

$\begin{array}{lllllll}1 & 2 & 3 & 4 & 5 & 6 & 7\end{array}$

19. Women are usually sweet until they've caught a man, but then they let their true self show. 
20. A lot of men talk big, but when it comes down to it, they can't perform well sexually.

21. In a dating relationship a woman is

largely out to take advantage of a man. $\begin{array}{lllllll}2 & 3 & 4 & 5 & 6 & 7\end{array}$

22. Men are out for only one thing. $\begin{array}{llllllll}1 & 2 & 3 & 4 & 5 & 6 & 7\end{array}$

23. Most women are sly and manipulating

when they are out to attract a man. $\begin{array}{llllllll}1 & 2 & 3 & 4 & 5 & 6 & 7\end{array}$

24. A lot of women seem to get pleasure

in putting men down.

$\begin{array}{lllllll}1 & 2 & 3 & 4 & 5 & 6 & 7\end{array}$

25. A woman who goes to the home of a man on their first date implies that she is willing to have sex.

$\begin{array}{lllllll}1 & 2 & 3 & 4 & 5 & 6 & 7\end{array}$

26. Any female can get raped.

$\begin{array}{lllllll}1 & 2 & 3 & 4 & 5 & 6 & 7\end{array}$

27. One reason that women falsely report

rape is that they frequently have a

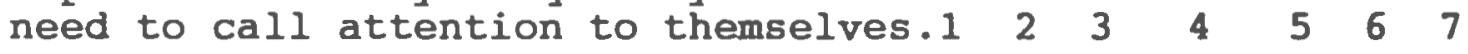

28. Any healthy woman can successfully

resist a rapist if she really wants to. $\begin{array}{lllllll}2 & 3 & 4 & 5 & 6 & 7\end{array}$

29. When women go around braless or wearing short skirts and tight tops, $\begin{array}{lllllllll}\text { they are just asking for trouble. } & 1 & 2 & 3 & 4 & 5 & 6 & 7\end{array}$

30. In the majority of rapes, the victim

is promiscuous or has a bad reputation. $\begin{array}{lllllll}2 & 3 & 4 & 5 & 6 & 7\end{array}$

31. If a girl engages in necking or petting and she lets things get out of hand, it is her own fault if her partner forces sex on her. 
Strongly

Agree
Strongly

Disagree

32. Women who get raped while hitchhiking get what they deserve.

$\begin{array}{llll}3 & 4 & 5 & 6\end{array}$

33. A woman who is stuck-up and thinks she is too good to talk to guys on the street deserves to be taught a lesson. 1

$\begin{array}{lllll}3 & 4 & 5 & 6 & 7\end{array}$

34. Many women have an unconscious wish to be raped, and may then unconsciously set up a situation in which they are likely to be attacked.

$\begin{array}{lllllll}1 & 2 & 3 & 4 & 5 & 6 & 7\end{array}$

35. If a woman gets drunk at a party and has sex with a man she's just met there, she should be considered "fair game" to other males at the party who want to have sex with her too, whether she wants to or not.

$\begin{array}{lllllll}1 & 2 & 3 & 4 & 5 & 6 & 7\end{array}$




\section{APPENDIX IV}

\section{Main Scene of Leveling-Sharpening Training Test}

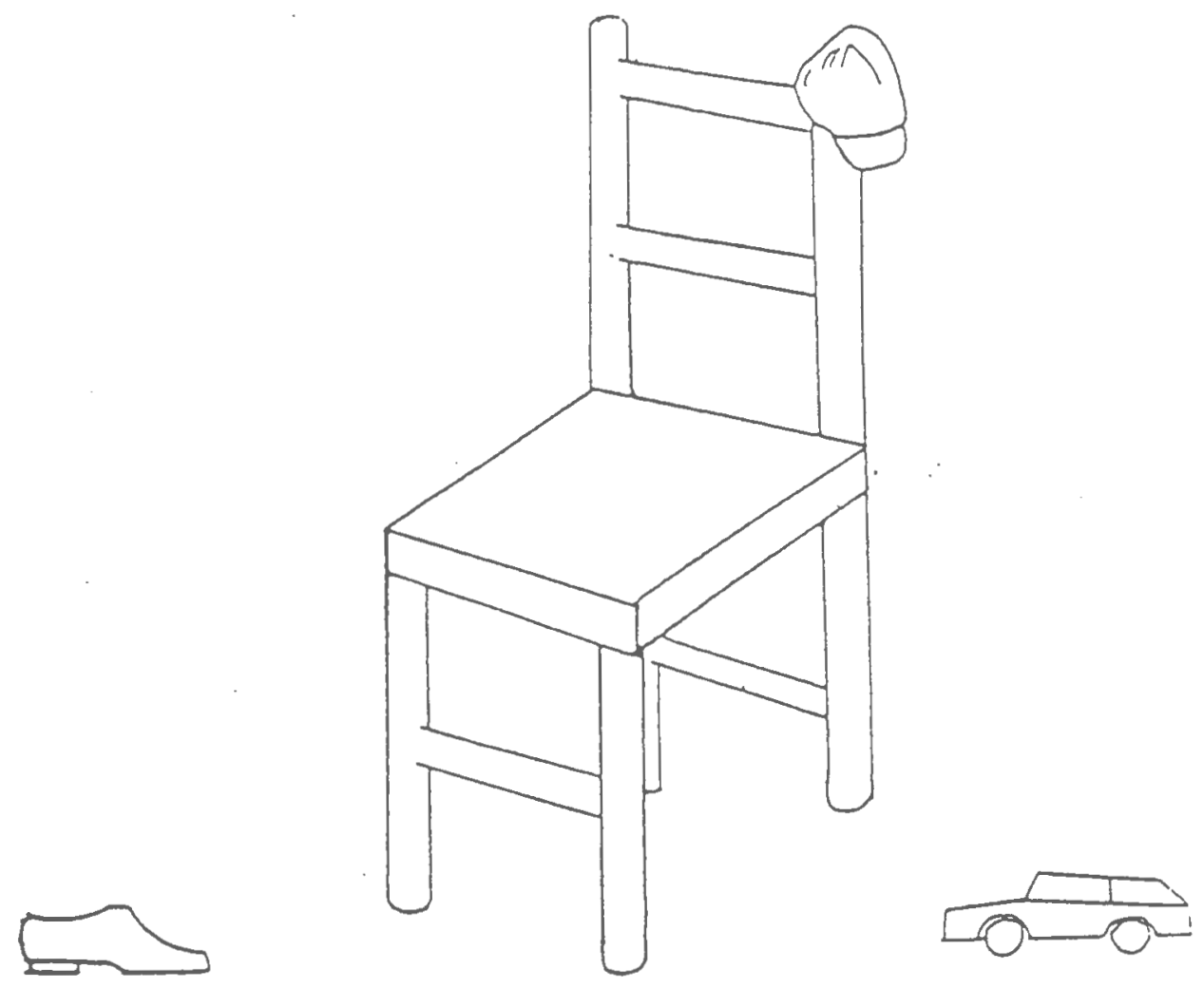

(Santostefano, 1990). 
APPENDIX V

\section{Main Scene of the LSHT}

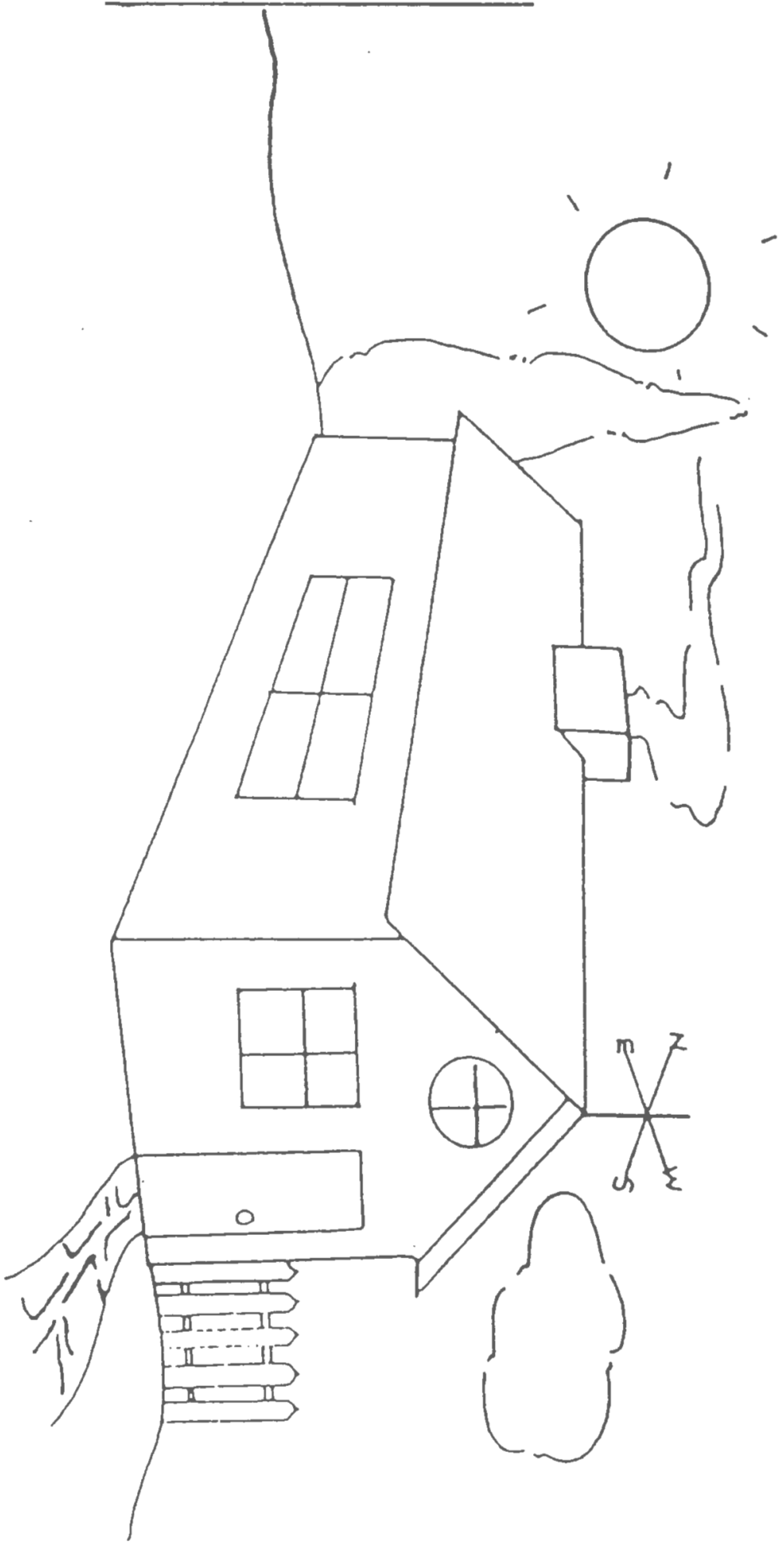

(Santostefano, 1978). 


\section{APPENDIX VA}

\section{List of details that drop out of the LSHT}

4. Doorknob.

7. Fence board.

10. Rays of the sun.

13. Ground line to right of fence.

16 Top of weather vane pole.

19. Ground Iine to the left of evergreen.

22. Directions (NSEW).

25. Horizontal pane of side windows.

28. Horizontal pane of front window.

31. Three pickets of fence.

34. Panes of oval window.

37. Smoke from chimney.

40. Oval window.

43. Roof line.

46. Remainder of weather vane.

49. Vertical window panes of front and side windows.

52. Flagstones in walk.

55. Evergreen tree.

58. Remainder of walk. 
APPENDIX VI

Main Scene of the

Leveling - Sharpening Interpersonal Aggression Test

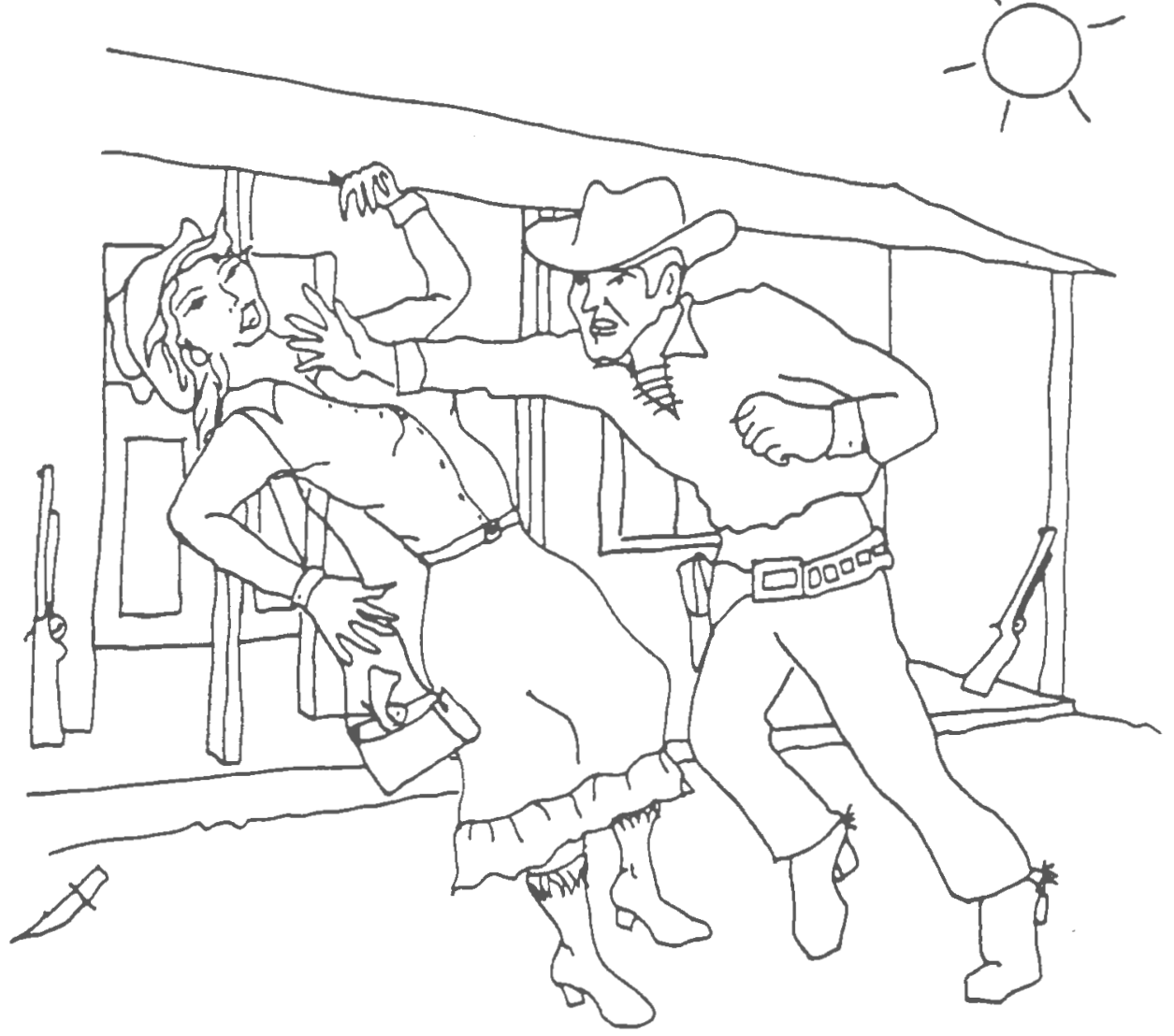




\section{APPENDIX VIA}

\section{List of details that drop out of the LSIAT}

4. Two spurs of right figure.

7 Door line on left (under head of left figure.

10. Pistol of right figure.

13. Line in window.

16. Ground line on right. (bottom of post).

19. Top of left rifle.

22. Pistol of left figure.

25. Cuffs on left figure.

28. Rays of the sun.

31. Knife on the ground.

34. Bullets in the belt of right figure.

37. Buttons on the shirt of left figure.

40. Rifle on right.

43. Post on left (doorway entrance).

46. Laces on shirt neck of right figure.

49. Purse of left figure.

52. Post on right.

55. Rifle on left.

58. Two hands of right figure.

61. Hat left figure. 


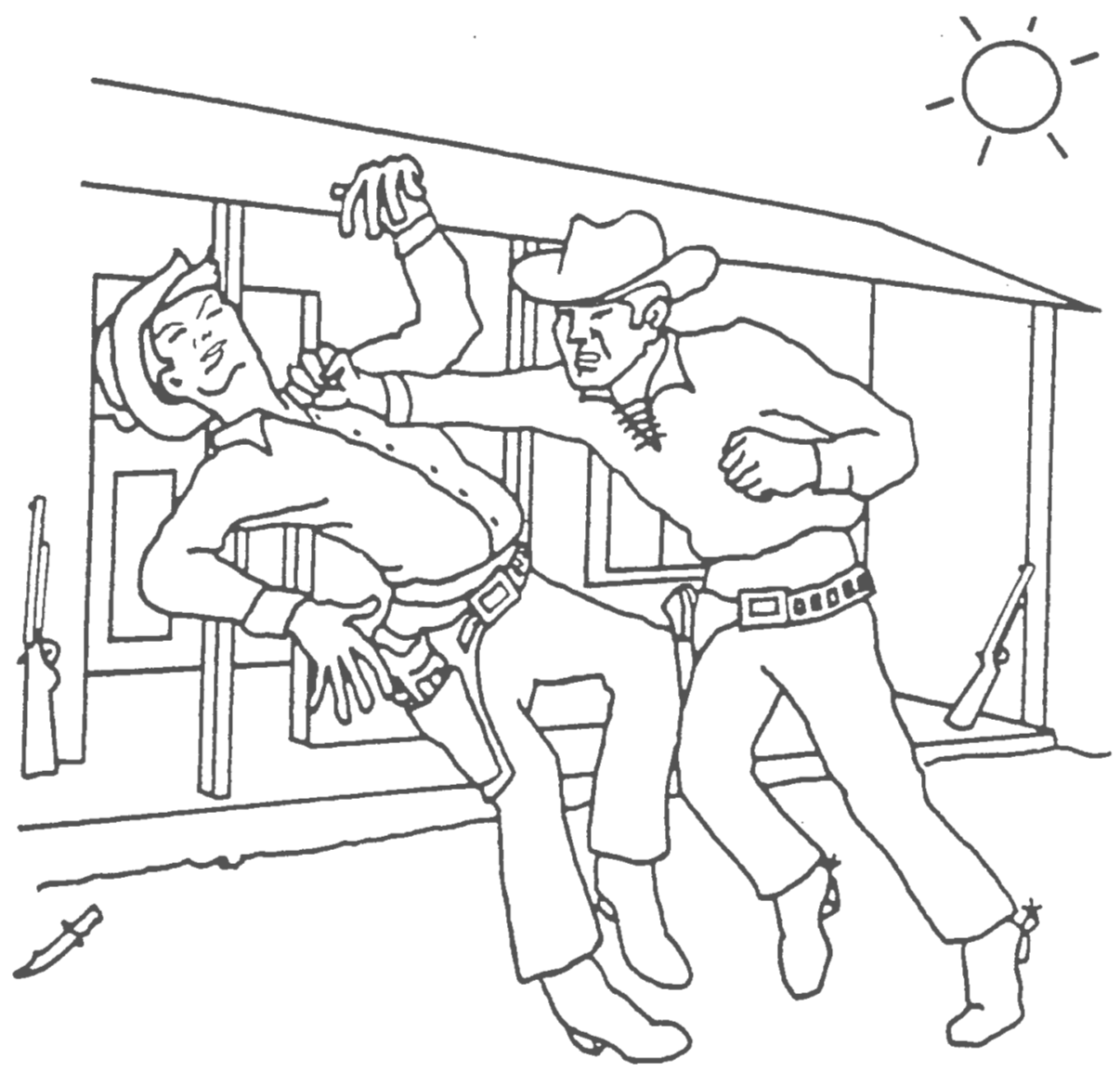

Leveling - Sharpening Aggression Test

(Santostefano, 1984 ). 


\section{APPENDIX VIII}

Instructions for the Administration of Leveling-Sharpening Tests

The instructions herewith are taken from Santostefano (1990) and as suggested "the wording is altered to suit the person's (subject's) age, vocabulary level, and general psychological status" (Santostefano, 1990. p.17., my italics). These instructions are intended to present information necessary to help a subject understand what the test requires, or establish the set.

The cards of each test are stacked face down with Card 1 at the top and card 6 at the bottom (in the case of the LSHT and LSIAT Card 60 (63) at the bottom).

A watch is also used to time presentations. Each card is presented for 5 seconds. It is suggested by this researcher that a watch with a second hand be used since it was found that visually the count was maintained much more readily than when it is presented in numbered digital format.

1.) Training Phase - The examiner says, "The best way to explain the next two tests we are going to do is to give you an example". Card 1 of the Leveling-Sharpening Training Test (a picture of a chair with a hat on it and a shoe and toy car next to it) is presented. "Do you see this picture of the chair? I want you to look it over carefully so that you can remember as much as you can about it. I 
will then take it away and show you another picture of the same scene. Now look at this next picture of the chair and tell me if the picture looks the same or whether anything has changed".

Card 2 is presented for five seconds. If a subject says nothing's changed, the examiner then says, "Only tell me when you see a change, say 'stop' and tell me what it is."

If a change is reported, the subject is asked to describe what has changed. Since the picture does not change, the subject is describing a change that has not occurred. If this occurs, card 1 is shown again, then it is placed face down and Card 2 is displayed again. The examiner says, "Now look at this picture again. Is this picture the same as the first or has it changed?" If the subject indicates that the pictures are the same, the examiner says, "That's right." If a change is still reported, Cards 1 and 2 are held alongside each other and the subject is asked to look at the pictures simultaneously. The examiner says, "Look at this first picture again and then look at the second one again. Do they look the same?" The subject is coached until it is established that the picture does not change.

Card 3 is presented. The examiner says, "Now look at this picture. Is the picture the same as the others or is it different?" The card is displayed for five seconds. If the subject correctly notes the change, Card 4 is presented. 
If the change is not noticed, the procedures described above are followed.

This procedure is followed in displaying Cards 4, 5, and 6. After Card 6 the examiner says, "Do you understand? We will do two other tests like this practice one, they are somewhat longer (the examiner points to the two stacks of LSHT and LSIAT cards) and I will be showing you one picture at a time for a brief time. I want you to look at each picture as carefully as you can so you can remember what is in the picture and tell me if you see something change. Remember if the picture looks the same, you do not have to say anything. If the picture changes, just say 'stop' and tell me what is different." Remember, sometimes the pictures will look the same and sometimes they will look different. Do you understand? Okay, here we go." The LSHT and/or the LSIAT are then administered.

After this the examiner is instructed to make only two further comments: if a change has not been reported by Card 15, the examiner will say, "Look at the picture carefully and say 'stop' if the picture looks different." If a change is reported twice, the examiner says, "That's right. You already told me about that. You only need to tell me about the change once. Tell me when you notice something else changes or looks different."

When the person describes a change it is recorded on scoring forms (abbreviations are used for greater efficiency). A copy of these scoring forms are presented in 
Appendix IX for the LSHT, and Appendix $X$ for the LSIAT (Santostefano, 1978, 1990). The examiner then continues to turn the cards over one at a time, every five seconds, until every card has been shown. Of course the subject is not allowed to look back at cards that have already been seen. 
APPENDIX IX

Scoring Form for the

\section{Leveling-Sharpening House Test (LSHT)}

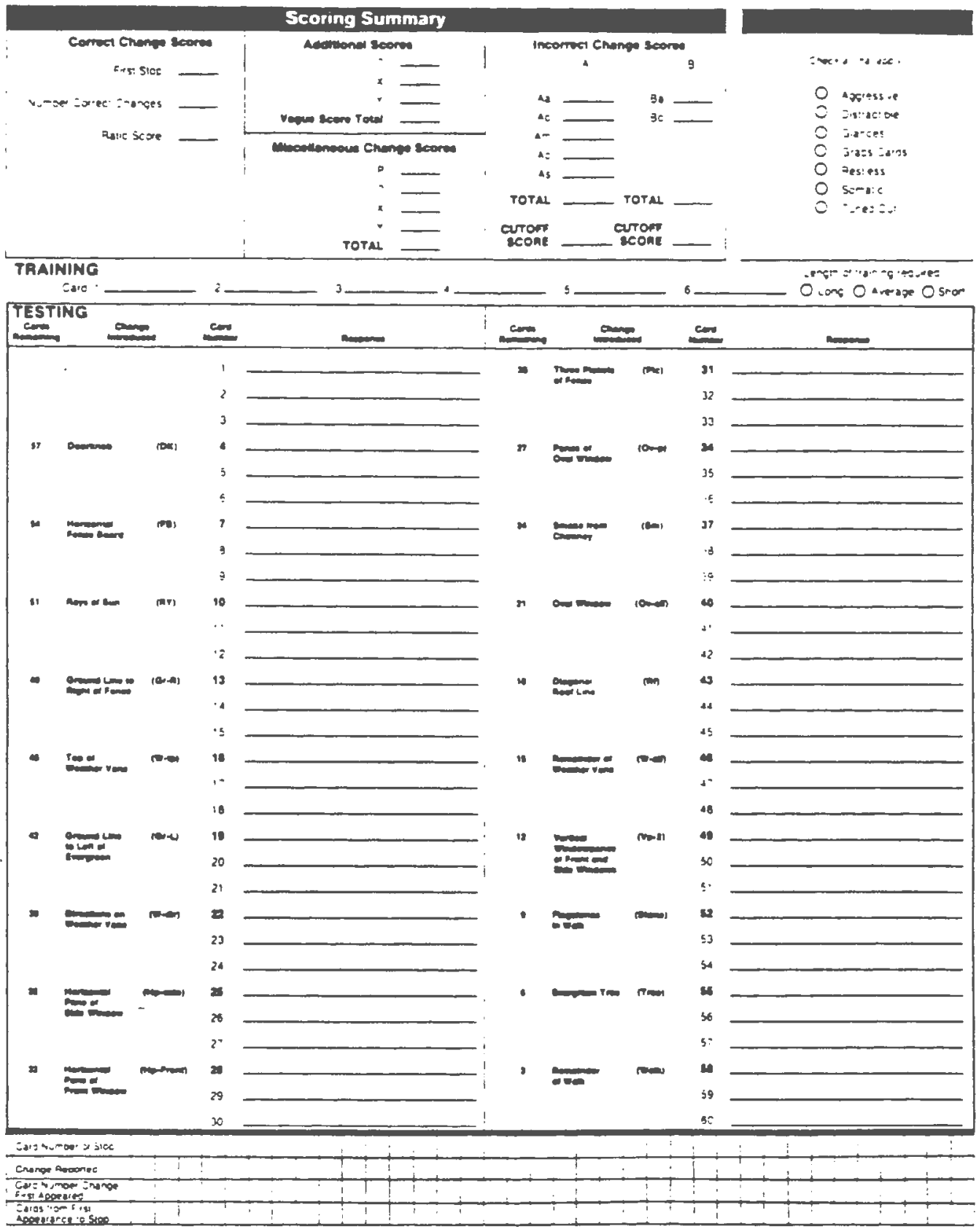

(Santostefano, 1978). 


\section{APPENDIX $X$}

Scoring Form for the Leveling - Sharpening

Interpersonal Aggression Test (LSIAT).

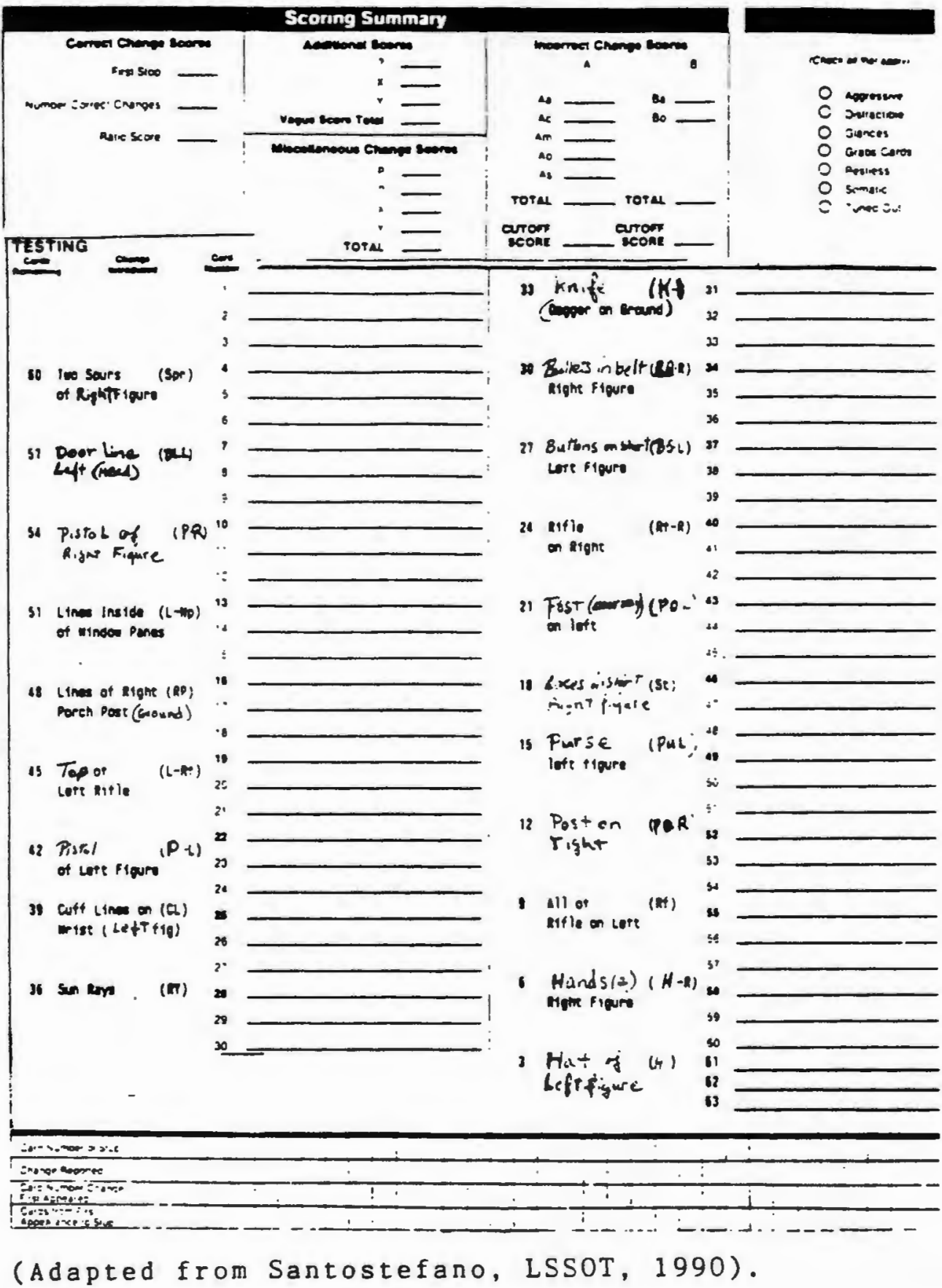


APPENDIZ XI

Raw Data For All Subjects on All Variables ( $N=251$ )

* AIV hT hT hT IAT IAT IAT Age Sex M-S Eth SES -FS $\quad-C \quad-R \quad$-FS $\quad-C$ - R $\quad$ nic $\$ 1 \$ 2$

$\begin{array}{llllllllllllll}001 & 16 & 05 & 17 & 05.4 & 11 & 15 & 11.3 & 21 & 1 & 1 & 1 & 1 & 3\end{array}$ $\begin{array}{llllllllllllll}002 & 23 & 12 & 12 & 14.8 & 11 & 10 & 17.3 & 19 & 1 & 1 & 1 & 1 & 2\end{array}$ $\begin{array}{llllllllllllll}003 & 20 & 07 & 13 & 11.7 & 22 & 08 & 22.1 & 19 & 1 & 1 & 1 & 1 & 1\end{array}$ $\begin{array}{llllllllllllll}004 & 17 & 12 & 13 & 12.7 & 22 & 11 & 18.9 & 19 & 2 & 1 & 1 & 1 & 3\end{array}$ $\begin{array}{llllllllllllll}005 & 16 & 07 & 12 & 15.2 & 22 & 09 & 20.6 & 19 & 1 & 1 & 1 & 1 & 2\end{array}$ $\begin{array}{llllllllllllll}006 & 09 & 10 & 13 & 12.7 & 10 & 12 & 15.3 & 19 & 1 & 1 & 1 & 1 & 2\end{array}$

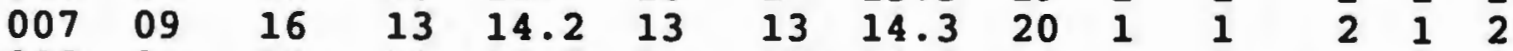
$\begin{array}{llllllllllllll}008 & 21 & 11 & 14 & 10.7 & 04 & 10 & 17.3 & 22 & 2 & 1 & 1 & 1 & 2\end{array}$ $\begin{array}{llllllllllllll}009 & 16 & 04 & 14 & 13.9 & 10 & 13 & 15.8 & 21 & 2 & 1 & 3 & 1 & 2\end{array}$ $\begin{array}{llllllllllllll}010 & 07 & 04 & 16 & 05.6 & 04 & 11 & 17.5 & 21 & 2 & 1 & 2 & 1 & 2\end{array}$ $\begin{array}{llllllllllllll}011 & 07 & 13 & 15 & 10.0 & 15 & 14 & 12.2 & 19 & 1 & 1 & 1 & 1 & 3\end{array}$

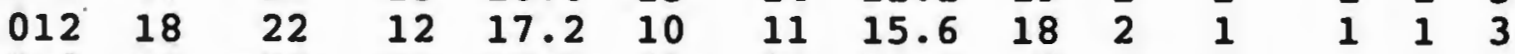
$\begin{array}{llllllllllllll}013 & 12 & 22 & 11 & 17.7 & 22 & 09 & 21.2 & 18 & 2 & 1 & 1 & 1 & 2\end{array}$ $\begin{array}{llllllllllllll}014 & 12 & 15 & 12 & 15.4 & 22 & 08 & 20.7 & 22 & 1 & 1 & 1 & 1 & 2\end{array}$

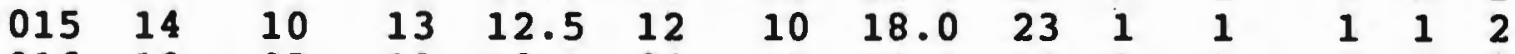
$\begin{array}{llllllllllllll}016 & 10 & 07 & 13 & 12.1 & 04 & 15 & 10.4 & 19 & 2 & 1 & 1 & 1 & 2\end{array}$ $\begin{array}{llllllllllllll}017 & 24 & 11 & 11 & 16.0 & 14 & 10 & 18.3 & 19 & 1 & 1 & 1 & 1 & 3\end{array}$ $\begin{array}{llllllllllllll}018 & 10 & 07 & 14 & 11.3 & 11 & 10 & 18.2 & 19 & 2 & 1 & 1 & 1 & 2\end{array}$ $\begin{array}{llllllllllllll}019 & 11 & 10 & 13 & 12.7 & 22 & 10 & 20.7 & 18 & 2 & 1 & 1 & 1 & 2\end{array}$ $\begin{array}{llllllllllllll}020 & 10 & 10 & 13 & 13.0 & 04 & 11 & 16.1 & 20 & 1 & 1 & 1 & 1 & 2\end{array}$ $\begin{array}{llllllllllllll}021 & 16 & 05 & 14 & 09.8 & 04 & 13 & 12.3 & 19 & 1 & 1 & 3 & 1 & 1\end{array}$ $\begin{array}{llllllllllllll}022 & 20 & 16 & 14 & 13.6 & 22 & 09 & 20.5 & 19 & 1 & 1 & 1 & 1 & 3\end{array}$

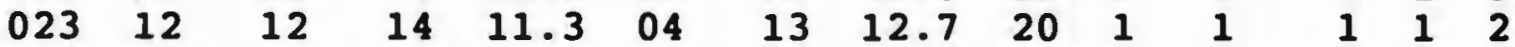

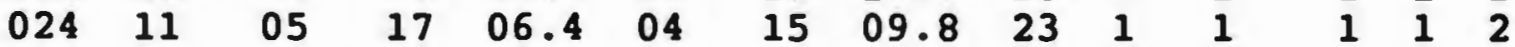

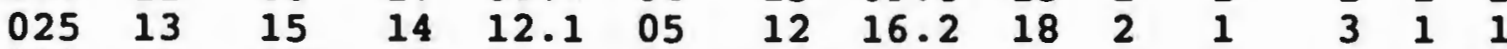
$\begin{array}{llllllllllllll}026 & 16 & 06 & 16 & 08.4 & 04 & 14 & 13.1 & 18 & 1 & 1 & 1 & 1 & 2\end{array}$

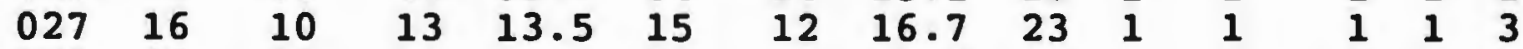

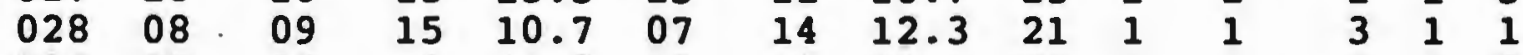
$\begin{array}{llllllllllllll}029 & 20 & 10 & 12 & 11.8 & 10 & 13 & 14.1 & 23 & 1 & 1 & 1 & 1 & 2\end{array}$ $\begin{array}{llllllllllllll}030 & 19 & 04 & 15 & 09.3 & 04 & 12 & 13.3 & 22 & 2 & 1 & 1 & 1 & 2\end{array}$ $\begin{array}{llllllllllllll}031 & 06 & 23 & 10 & 17.5 & 05 & 07 & 21.3 & 19 & 2 & 1 & 1 & 1 & 3\end{array}$ $\begin{array}{llllllllllllll}032 & 20 & -10 & 12 & 16.4 & 04 & 12 & 15.5 & 20 & 2 & 1 & 3 & 1 & 1\end{array}$ $\begin{array}{llllllllllllll}033 & 11 & 10 & 14 & 11.9 & 10 & 12 & 16.8 & 21 & 1 & 1 & 1 & 1 & 2\end{array}$ $\begin{array}{llllllllllllll}034 & 20 & 09 & 16 & 06.8 & 10 & 12 & 15.8 & 20 & 1 & 1 & 2 & 1 & 1\end{array}$ $\begin{array}{llllllllllllll}035 & 11 & 16 & 13 & 14.2 & 08 & 13 & 13.9 & 18 & 2 & 1 & 1 & 1 & 3\end{array}$

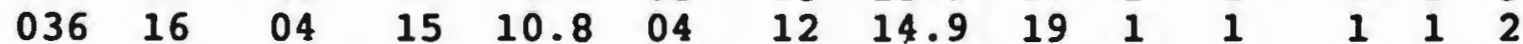

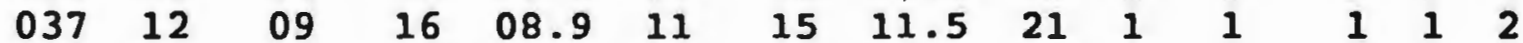
$\begin{array}{llllllllllllll}038 & 14 & 14 & 14 & 11.0 & 12 & 11 & 17.6 & 20 & 2 & 1 & 1 & 1 & 3\end{array}$ $\begin{array}{llllllllllllll}039 & 16 & 23 & 11 & 18.6 & 19 & 10 & 16.7 & 18 & 2 & 1 & 1 & 1 & 3\end{array}$

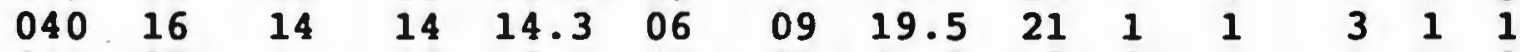
$\begin{array}{llllllllllllll}041 & 09 & 11 & 14 & 12.4 & 22 & 08 & 21.2 & 18 & 2 & 1 & 1 & 1 & 3\end{array}$ 
\# AIV HT HT HT IAT IAT IAT Age Sex M-S Eth SES -FS $-\mathrm{C} \quad-\mathrm{R} \quad$-FS $\quad-\mathrm{C} \quad-\mathrm{R} \quad$ nic $\$ 1 \geqslant 2$

$\begin{array}{llllllllllllll}042 & 06 & 20 & 13 & 14.5 & 22 & 09 & 20.9 & 18 & 2 & 1 & 4 & 1 & 2\end{array}$

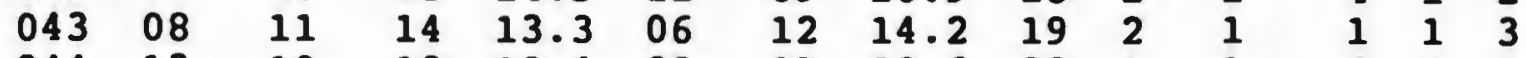
$\begin{array}{llllllllllllll}044 & 13 & 10 & 13 & 12.4 & 22 & 07 & 22.6 & 22 & 1 & 1 & 2 & 1 & 1\end{array}$

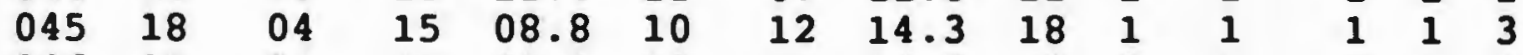
$\begin{array}{llllllllllllll}046 & 11 & 04 & 17 & 03.7 & 10 & 13 & 14.9 & 19 & 2 & 1 & 3 & 1 & 1\end{array}$ $\begin{array}{llllllllllllll}047 & 15 & 07 & 13 & 12.1 & 11 & 11 & 17.6 & 20 & 1 & 1 & 3 & 1 & 1\end{array}$

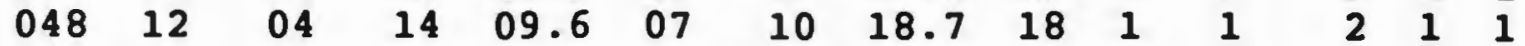
$\begin{array}{llllllllllllll}049 & 06 & 11 & 13 & 11.7 & 23 & 08 & 22.4 & 24 & 2 & 2 & 1 & 2 & 2\end{array}$ $\begin{array}{llllllllllllll}050 & 11 & 04 & 16 & 06.5 & 22 & 10 & 19.2 & 19 & 2 & 1 & 2 & 1 & 2\end{array}$

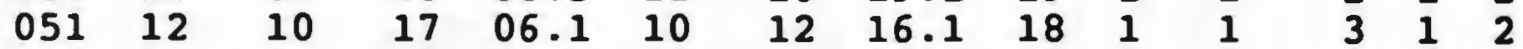
$\begin{array}{llllllllllllll}052 & 16 & 04 & 16 & 06.5 & 10 & 12 & 14.7 & 19 & 1 & 1 & 1 & 1 & 2\end{array}$ $\begin{array}{llllllllllllll}053 & 09 & 04 & 15 & 08.6 & 11 & 14 & 11.5 & 20 & 1 & 1 & 4 & 1 & 3\end{array}$

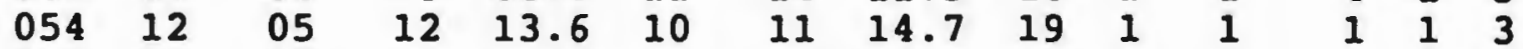
$\begin{array}{llllllllllllll}055 & 12 & 10 & 14 & 12.3 & 22 & 07 & 22.6 & 18 & 2 & 1 & 1 & 1 & 3\end{array}$

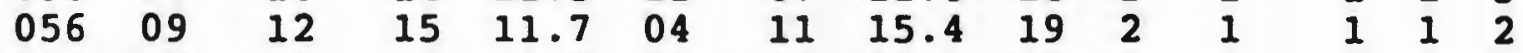
$\begin{array}{llllllllllllll}057 & 10 & 10 & 12 & 15.0 & 17 & 10 & 19.1 & 22 & 1 & 1 & 1 & 1 & 2\end{array}$ $\begin{array}{llllllllllllll}058 & 10 & 08 & 12 & 10.6 & 22 & 07 & 23.2 & 26 & 2 & 2 & 1 & 1 & 2\end{array}$

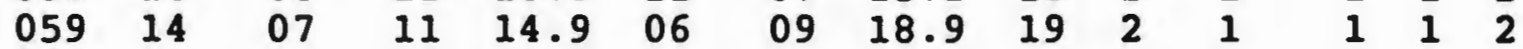
$\begin{array}{llllllllllllll}060 & 10 & 04 & 15 & 08.7 & 04 & 12 & 14.7 & 20 & 2 & 1 & 1 & 1 & 2\end{array}$ $\begin{array}{llllllllllllll}061 & 11 & 07 & 14 & 07.8 & 11 & 08 & 20.0 & 18 & 2 & 1 & 1 & 1 & 3\end{array}$

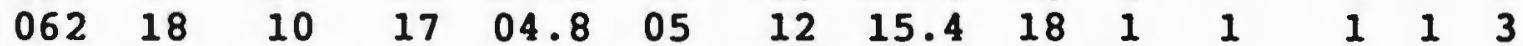

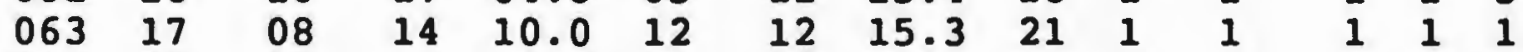

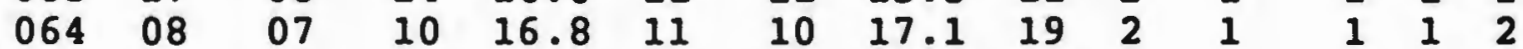

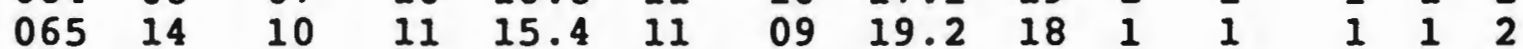

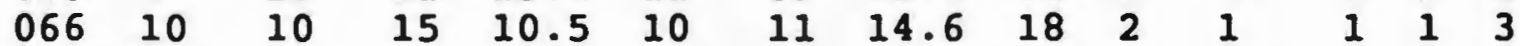

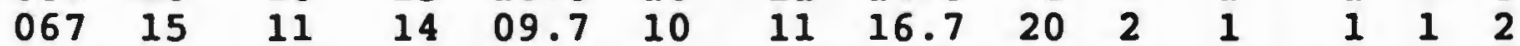

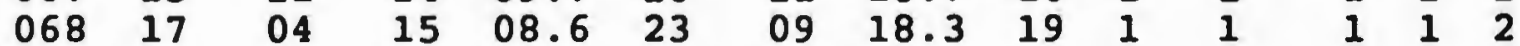

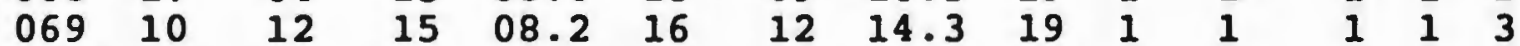

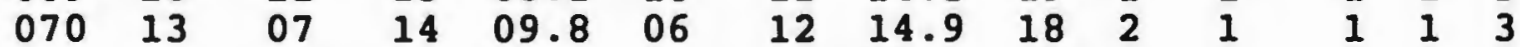

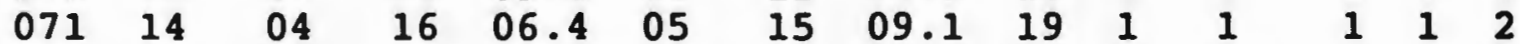

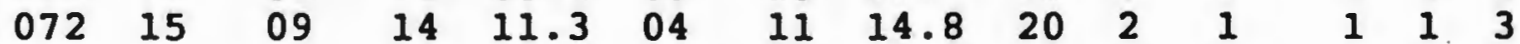

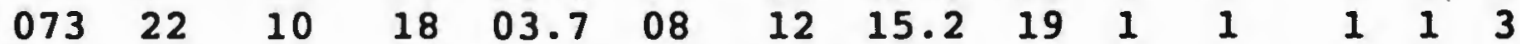

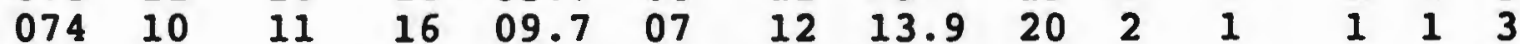

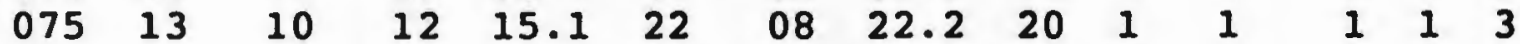
$\begin{array}{llllllllllllll}076 & 08 & 10 & 12 & 14.7 & 22 & 08 & 21.2 & 19 & 2 & 1 & 1 & 1 & 3\end{array}$

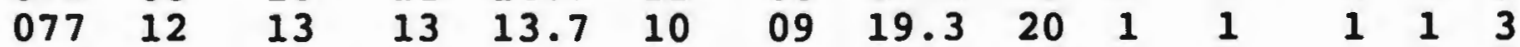

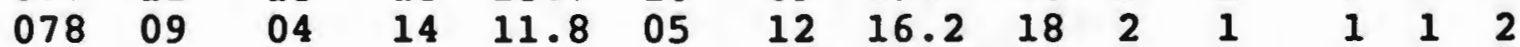

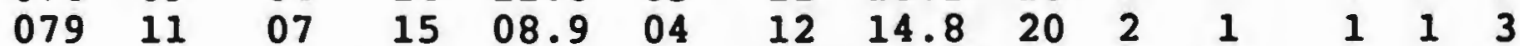

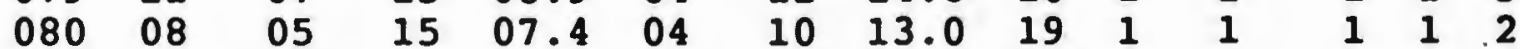

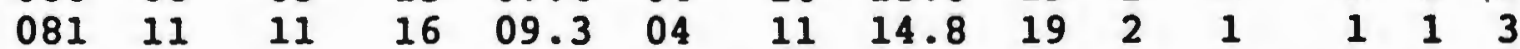

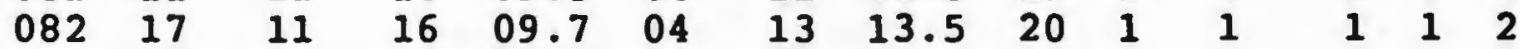

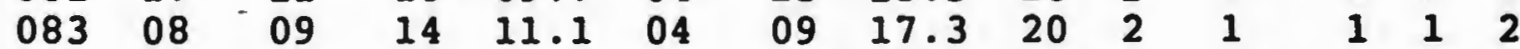

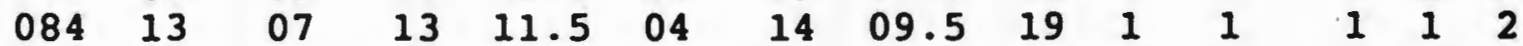

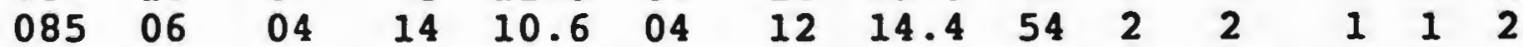

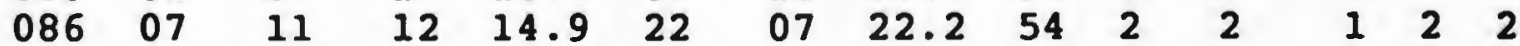
$\begin{array}{llllllllllllll}087 & 08 & 07 & 12 & 16.0 & 12 & 10 & 18.7 & 53 & 2 & 2 & 1 & 2 & 2\end{array}$

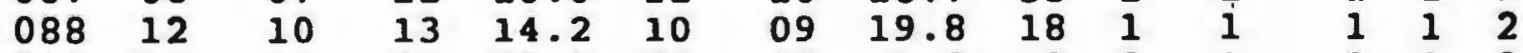

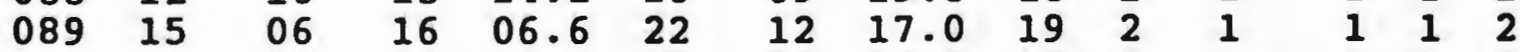

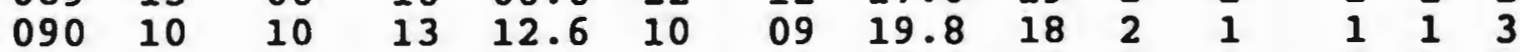
$\begin{array}{llllllllllllll}091 & 24 & 04 & 16 & 07.4 & 17 & 10 & 18.4 & 18 & 2 & 1 & 5 & 1 & 1\end{array}$

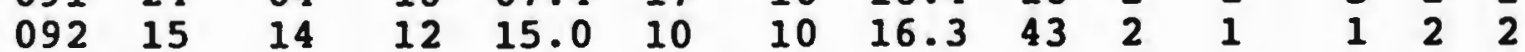


* AIV HT HT HT IAT IAT IAT Age Sex M-S Eth SES -FS $-C \quad-R \quad-F S \quad-C \quad-R \quad$ nic 112

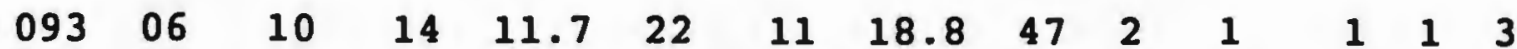

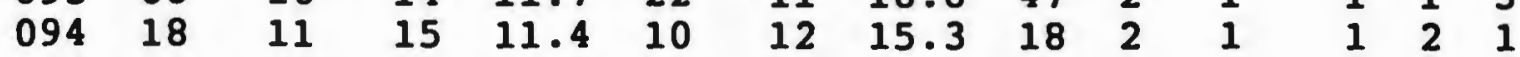

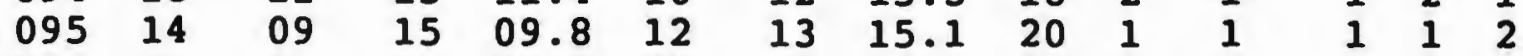

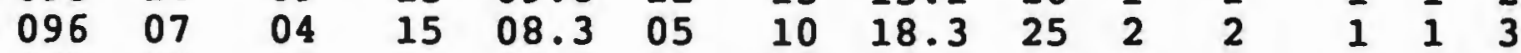

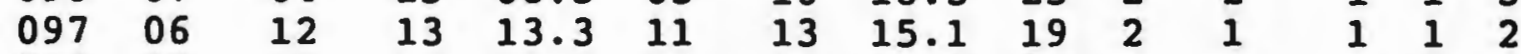

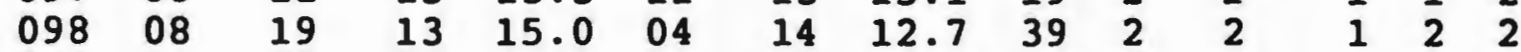

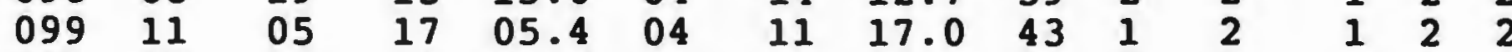

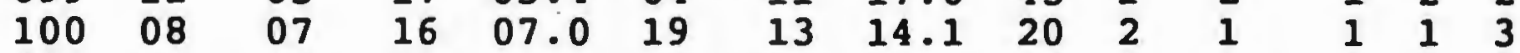

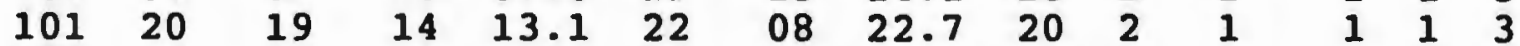

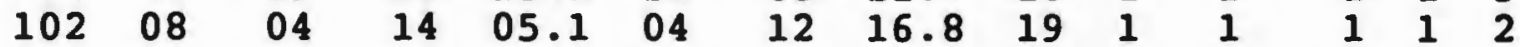

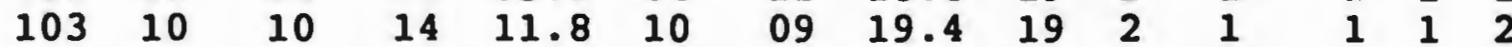

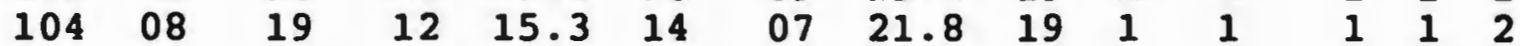

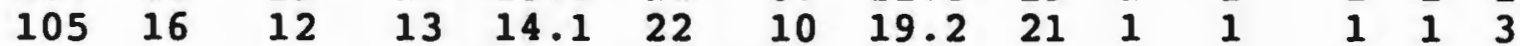

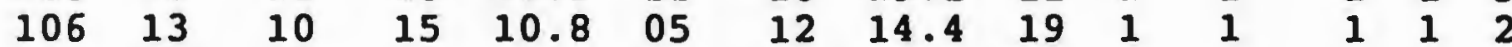

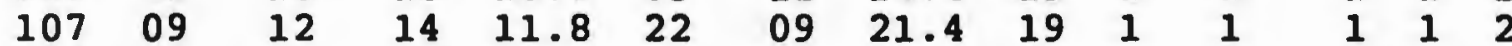

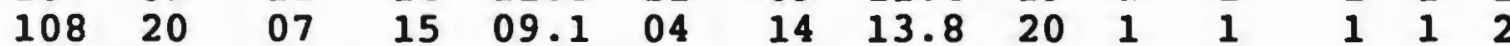

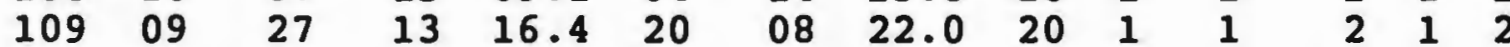

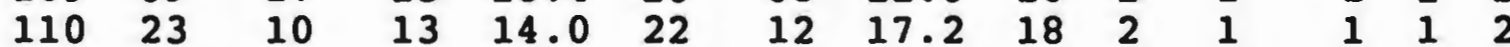

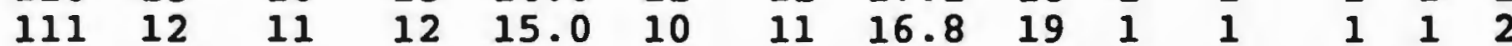

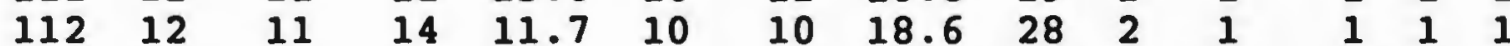

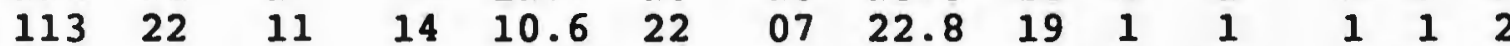

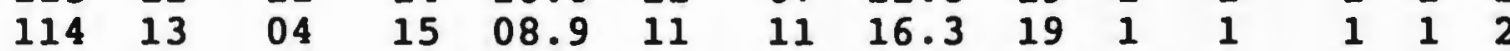

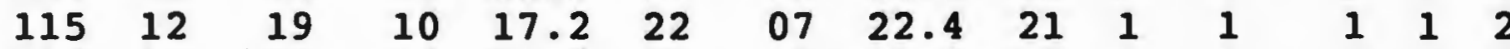

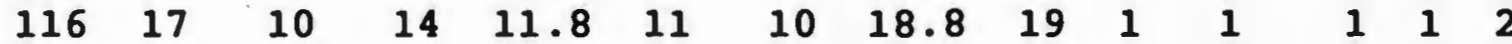

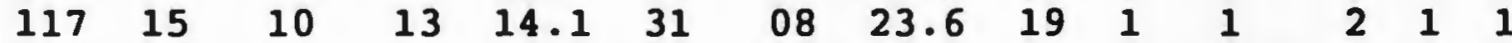

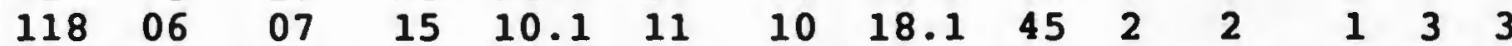

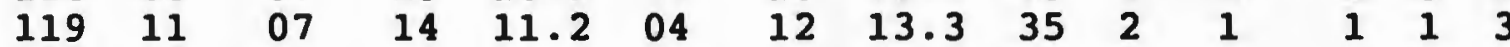

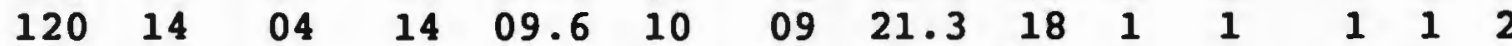

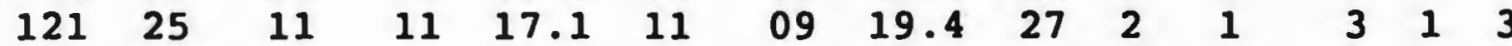
$\begin{array}{lllllllllllll}122 & 16 & 10 & 11 & 14.8 \cdot 04 & 12 & 13.8 & 20 & 2 & 1 & 3.1 & 1\end{array}$

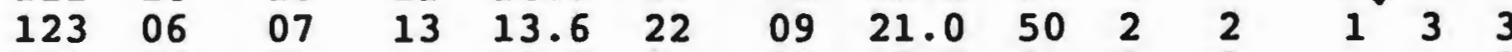

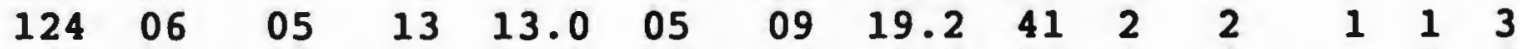
$\begin{array}{lllllllllllll}125 & 15 & 20 & 11 & 16.9 & 10 & 10 & 16.2 & 23 & 2 & 2 & 1 & 2\end{array}$

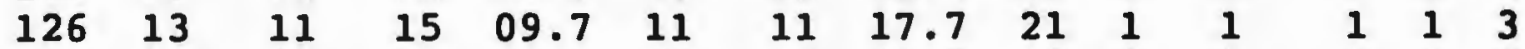

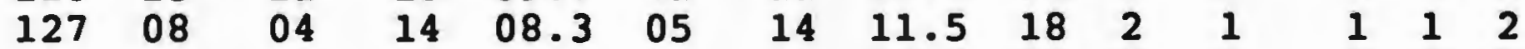

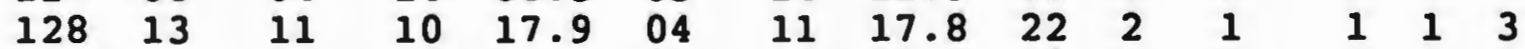

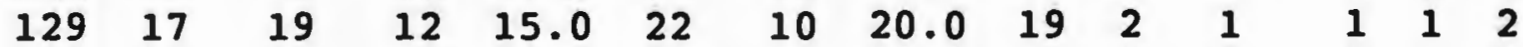

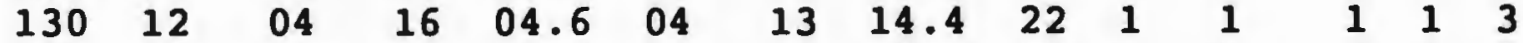
$\begin{array}{llllllllllllll}131 & 12 & 11 & 15 & 10.3 & 14 & 10 & 18.1 & 19 & 1 & 1 & 1 & 1 & 3\end{array}$

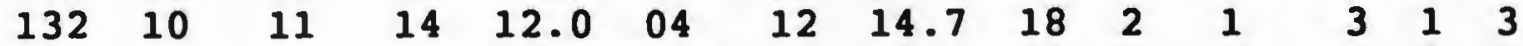

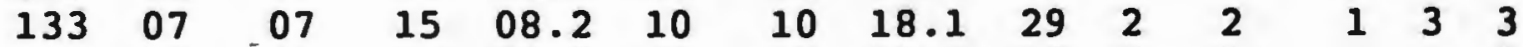

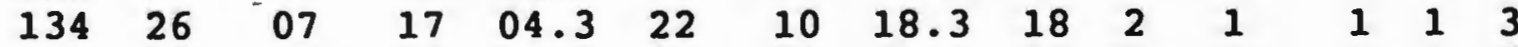

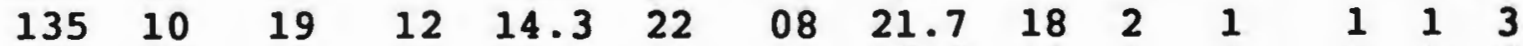

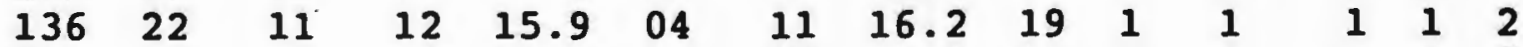

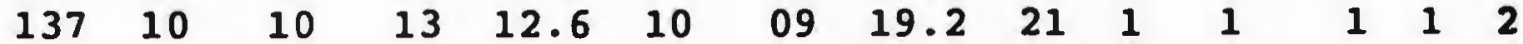

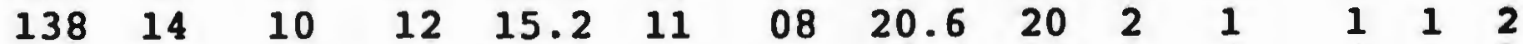

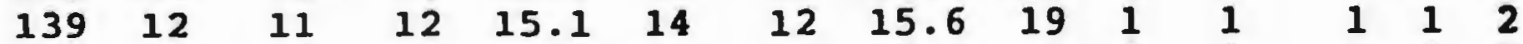

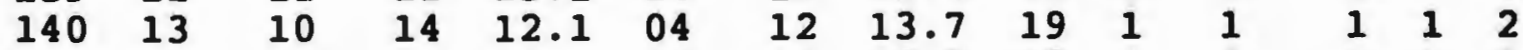

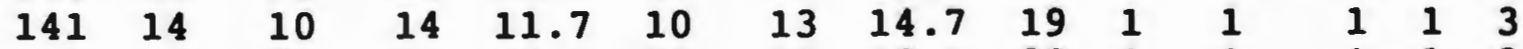

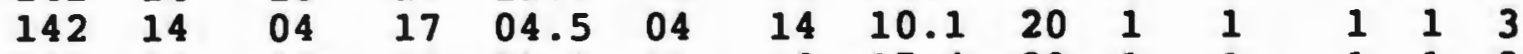

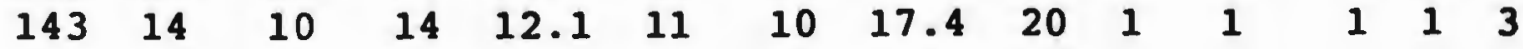


* AIV HT HT HT IAT IAT IAT Age Sex M-S Eth SES $-F S \quad-C \quad-R \quad-F S \quad-C \quad-R \quad$ nic $\neq 1 * 2$

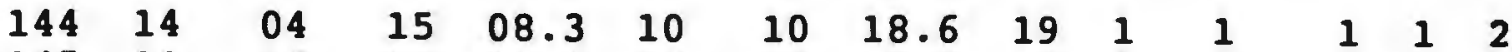

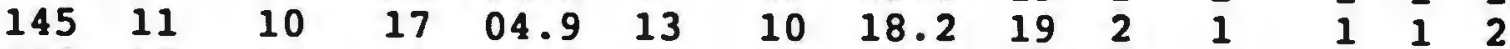

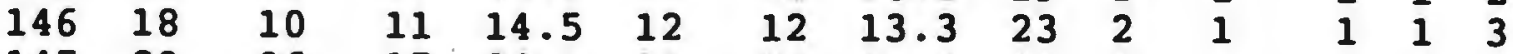

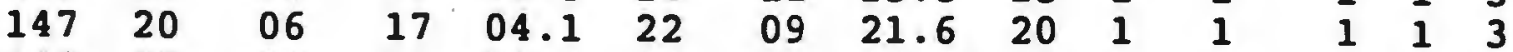

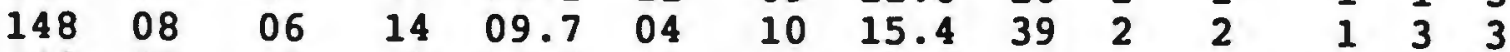

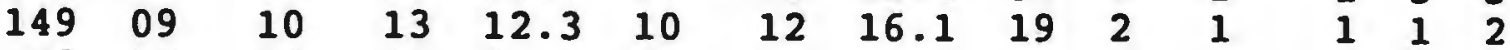

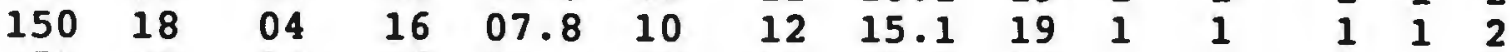

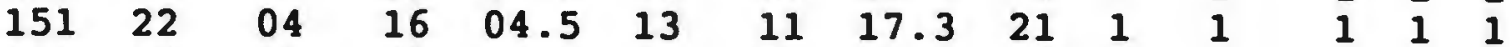

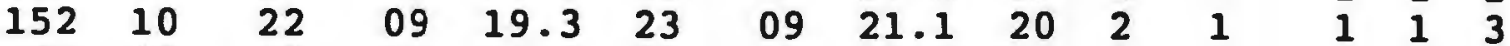

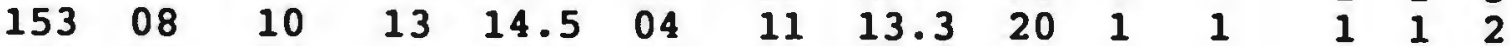

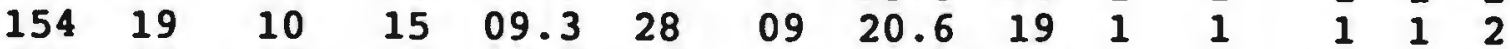

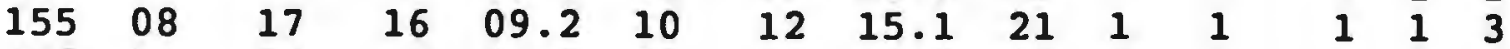

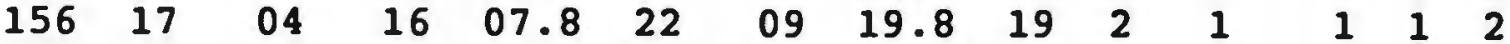

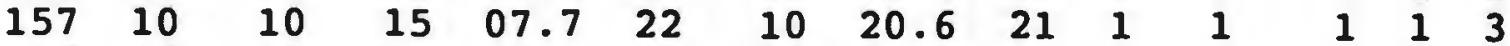

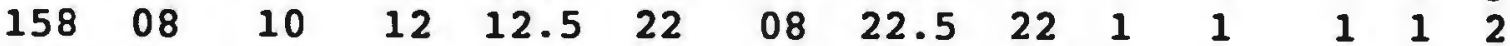

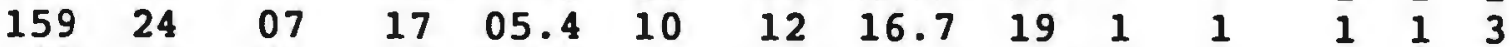

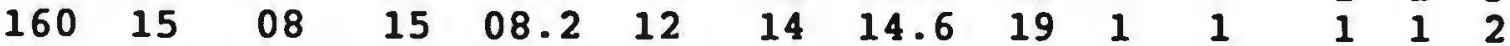

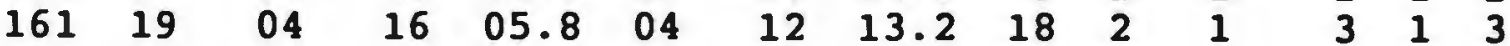

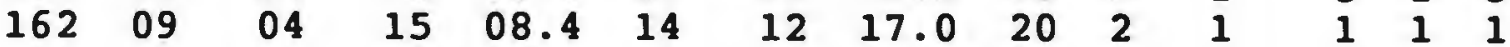

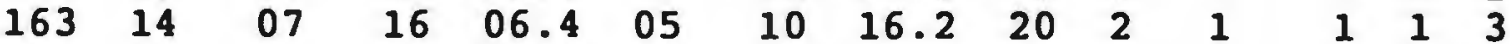

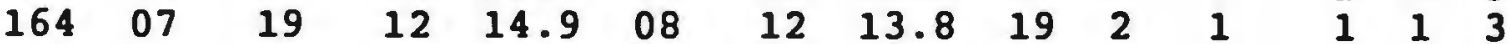

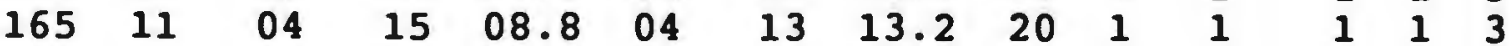

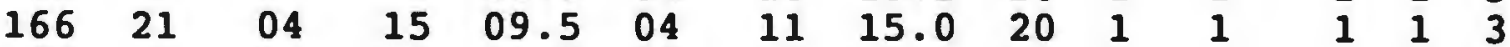

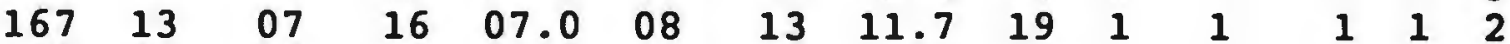

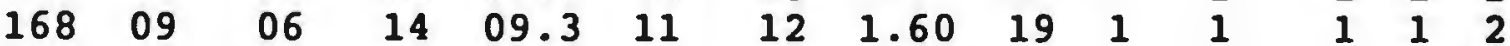

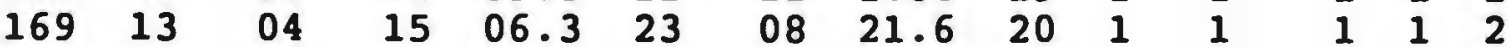

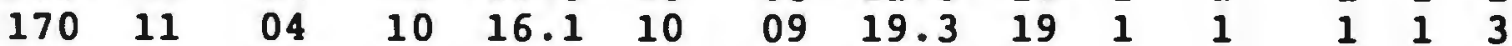

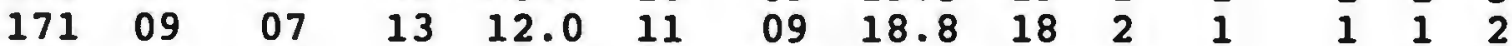

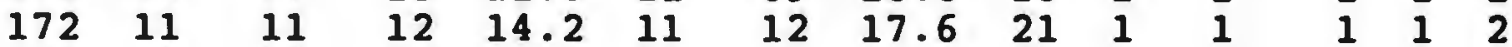

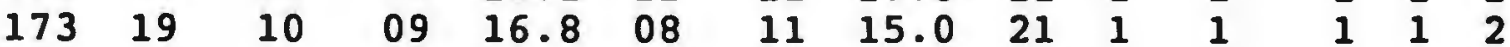

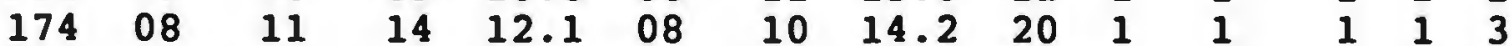

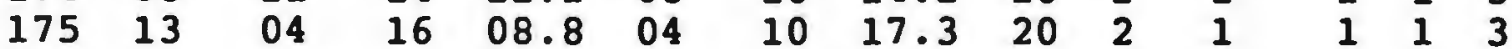

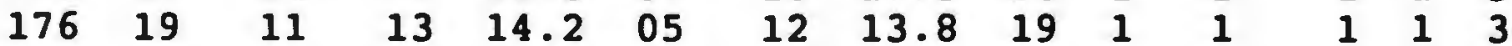

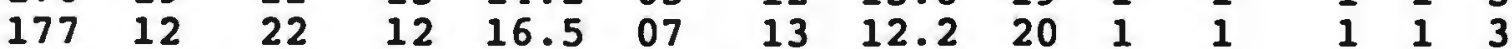

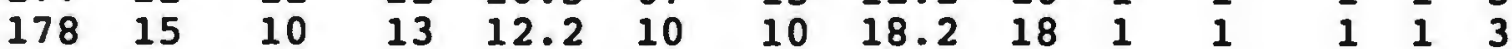

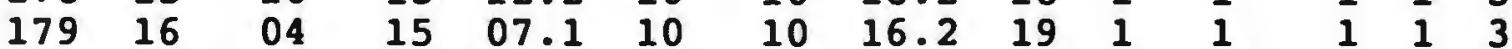

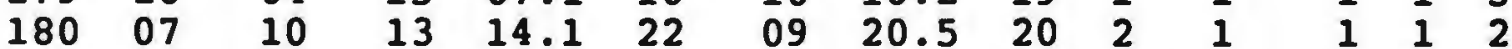

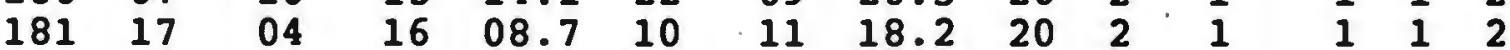

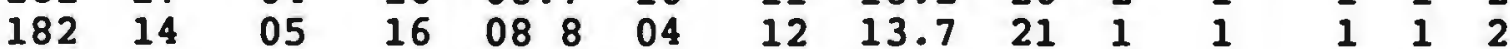

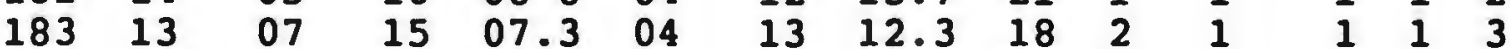

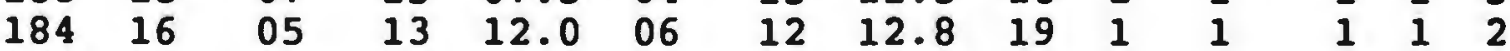

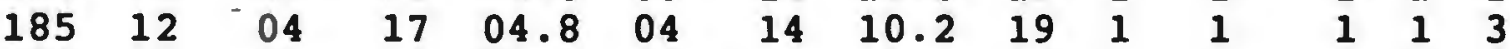

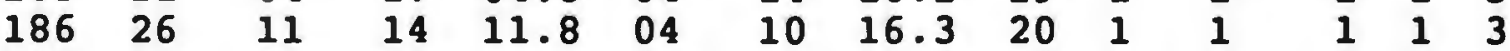

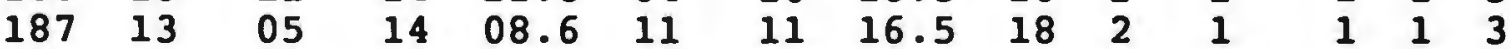

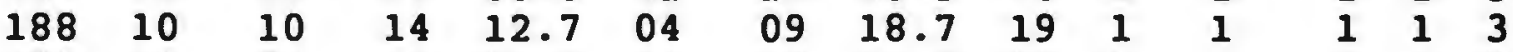

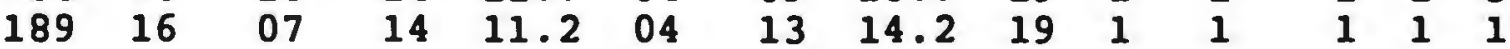

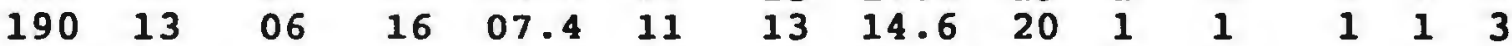

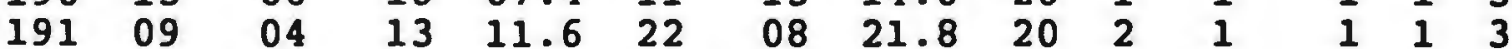

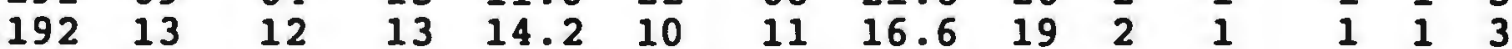

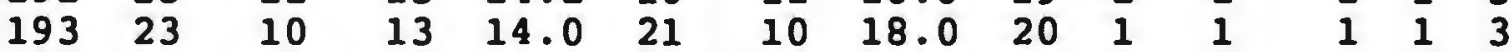

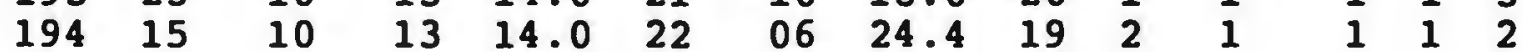



$\begin{array}{lllllllll}\text { * AIV } & \text { HT } & \text { HT } & \text { HT } & \text { IAT } & \text { IAT } & \text { IAT Age Sex M-S Eth SES } \\ & - \text { FS } & -C & -R & \text {-PS } & -C & -R & & \text { nic } \neq 1 \neq 2\end{array}$

$\begin{array}{llllllllllllll}195 & 13 & 17 & 12 & 15.4 & .23 & 09 & 21.5 & 20 & 1 & 1 & 1 & 1 & 1\end{array}$

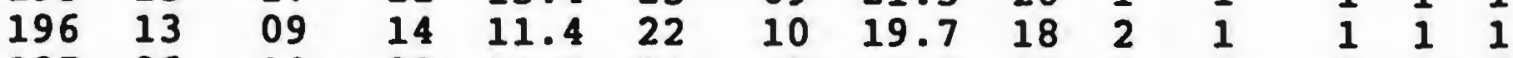

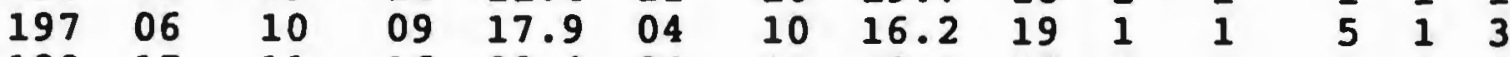

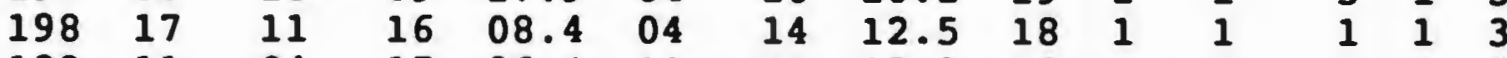

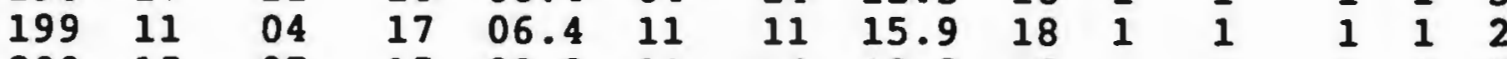

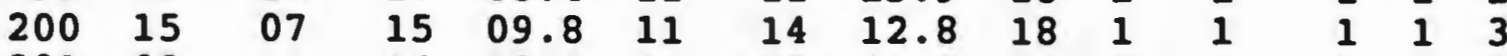

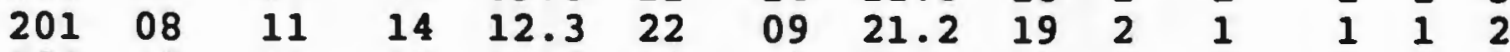

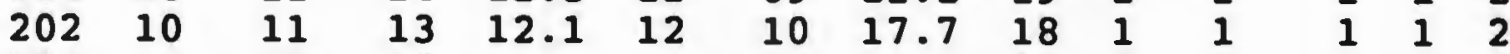

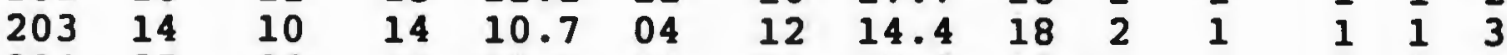

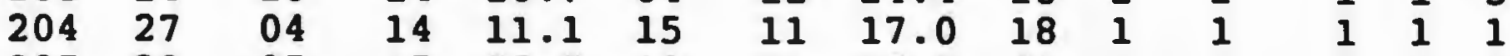

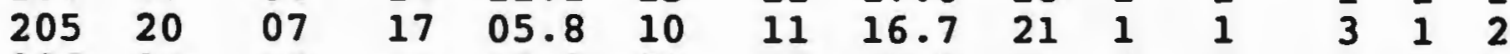

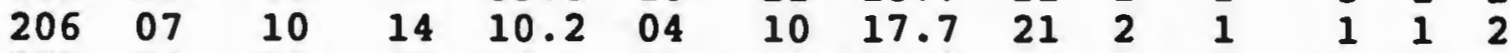

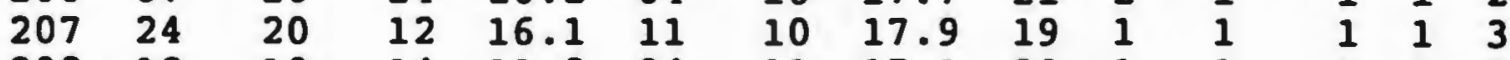

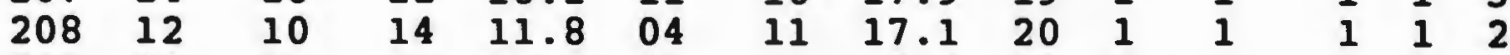

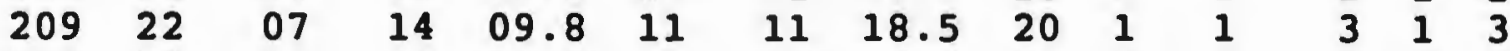

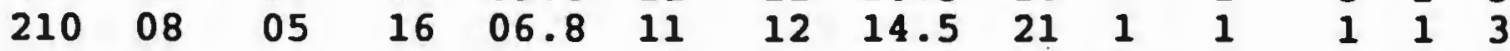

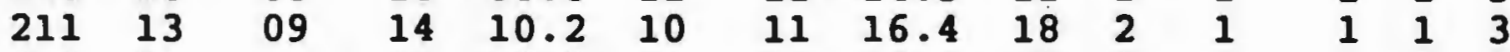
$\begin{array}{llllllllllllll}212 & 06 & 11 & 14 & 10.0 & 04 & 14 & 10.8 & 18 & 2 & 1 & 1 & 1 & 2\end{array}$

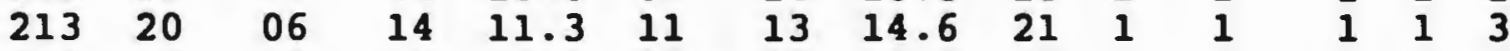

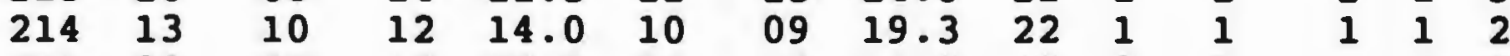

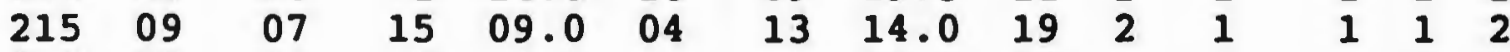

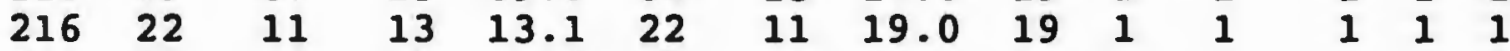

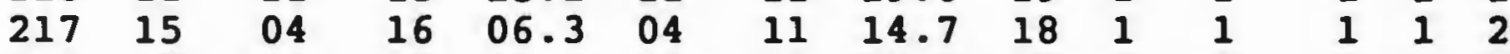

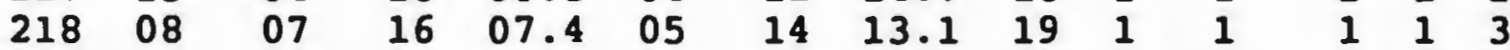
$\begin{array}{llllllllllllll}219 & 17 & 08 & 14 & 10.0 & 10 & 10 & 14.5 & 18 & 1 & 1 & 1 & 1 & 2\end{array}$

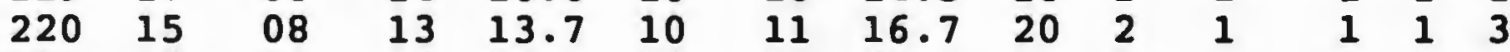

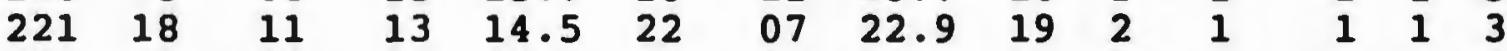

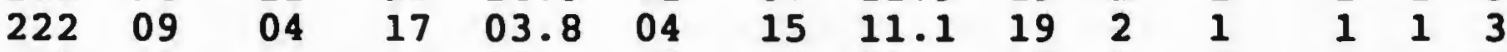

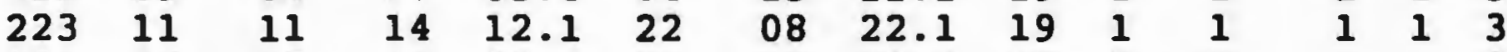

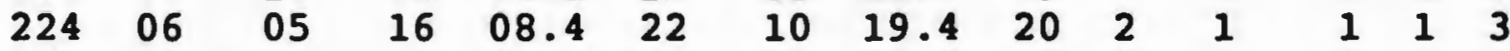

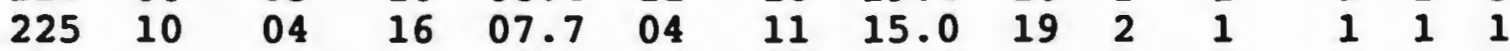

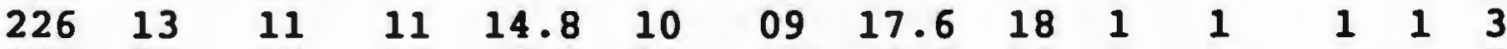

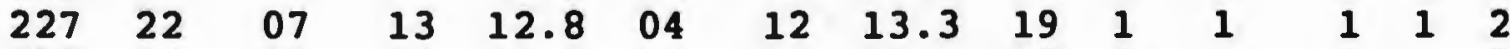
$\begin{array}{llllllllllllll}228 & 14 & 04 & 14 & 11.1 & 11 & 10 & 18.7 & 19 & 2 & 1 & 1 & 1 & 3\end{array}$ $\begin{array}{llllllllllllll}229 & 12 & 08 & 14 & 09.8 & 10 & 10 & 17.7 & 19 & 2 & 1 & 1 & 1 & 3\end{array}$

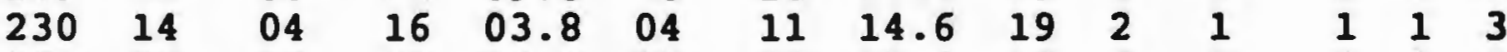

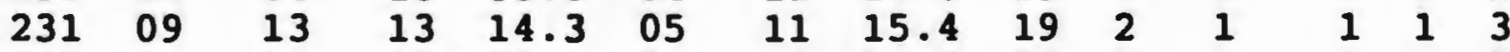

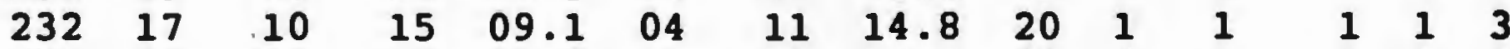

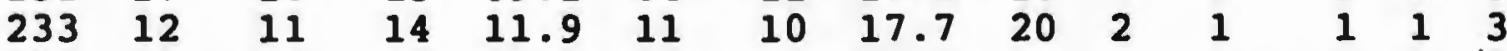

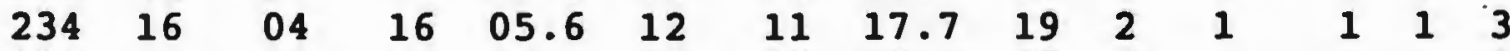

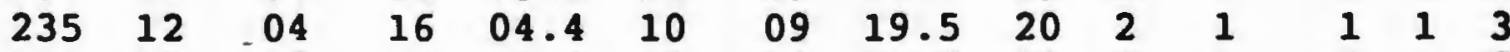

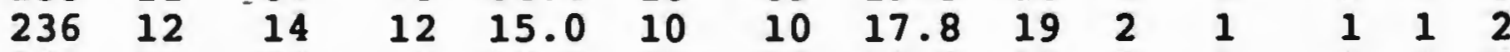

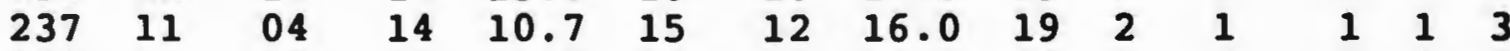
$\begin{array}{llllllllllllll}238 & 15 & 10 & 14 & 11.5 & 06 & 11 & 16.2 & 20 & 1 & 1 & 1 & 1 & 3\end{array}$ $\begin{array}{llllllllllllll}239 & 18 & 10 & 13 & 11.5 & 04 & 13 & 12.0 & 18 & 2 & 1 & 1 & 1 & 2\end{array}$

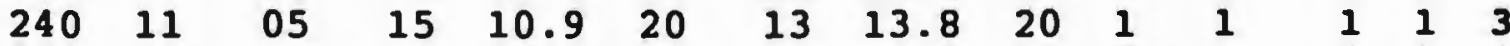
$\begin{array}{llllllllllllll}241 & 11 & 07 & 12 & 13.6 & 06 & 12 & 15.8 & 19 & 2 & 1 & 1 & 1 & 1\end{array}$ $\begin{array}{llllllllllllll}242 & 14 & 10 & 13 & 13.8 & 04 & 09 & 19.7 & 19 & 1 & 1 & 1 & 1 & 3\end{array}$ $\begin{array}{llllllllllllll}243 & 14 & 09 & 13 & 12.3 & 11 & 12 & 16.6 & 18 & 2 & 1 & 1 & 1 & 1\end{array}$

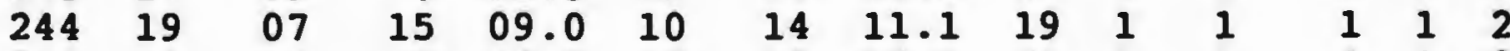

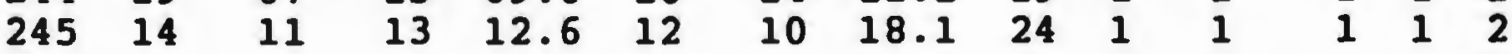


* AIV HT HT HT IAT IAT IAT Age Sex M-S Eth SES $\begin{array}{lllllll}-F S & -C & -R & -F S & -C & -R & \text { nic }\end{array}$

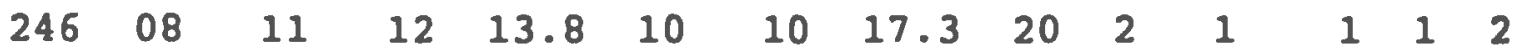

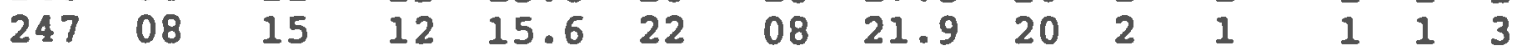

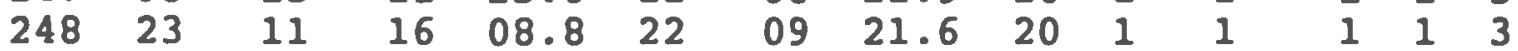

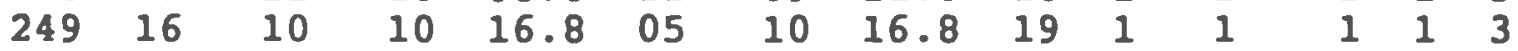

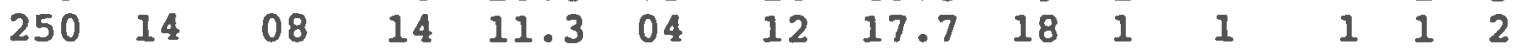

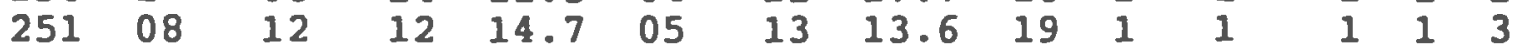

Abbreviations are as follows:

AIV = Acceptance of Interpersonal Violence Scale score. HT-FS = First Stop score on L-S House Test. HT-C = Content score on L-S House Test. HT-R = L-S Ratio score House Test. IAT-FS = First Stop score on L-S Inter-Sex Aggression Test. IAT-C = Content score on LSIAT.

IAT-R = L-S Ratio score on LSIAT.

M-S = Marital Status.

Ethnic = Ethnic Ancestry. SES = Socioeconomic Status. 


\section{BIBLIOGRAPHY}

Allport,G. W. (1961). Pattern and Growth in Personality. Holt, Rinehart and Winston, NY.

Allport, G. W. and Vernon, P. E. (1933). Studies in Expressive Movement. Macmillan, NY.

Bandura, A. (1978). The Self System in Reciprocal Determinism. American Psychologist, 344-358.

Bandura, A. (1986). Social Foundations of Thought and Action: A Social Coonitive Theory. Prentice-Hall, NJ .

Broverman, D., Broverman, I., Vogel, w., Palmer, R., \& Klaiber, E. (1964). The Automization Cognitive Style and Physical Development. Child Development, 1342-1359.

Brownmiller, S. (1975). Against Our Will: Men, Women and Rape. Simon Schuster, NY.

Briere, J. (1987). Predicting Self-Reported Likelihood of Battering: Attitudes and Childhood Experiences. Journal of Research in Personality, 61-69.

Bruner, J. (1956). A Cognitive Theory of Personality. Contemporary Psychology, 355-357.

Bruner, J. S. (1951). Personality Dynamics and the Process of Perceiving. In R. R. Blake and G. V. Ramsey (Eds.), Perception: An Approach to Personality, 121-147. Ronald Press, NY.

Bruner, J. S., and Klein, G. S. (1960). The Functions of Perception: New Look Retrospect. In B. Raplan \& S. Wapner (Eds.), Perspectives in Psychological Theory, 61-67. International Universities Press, NY. 
Bruner, J. S., and Postman, L. (1948). An Approach to Social Perception. In $\mathrm{w}$. Dennis (Ed.), Current Trends in Social Psychology, 71-118. University of Pittsburg Press, PA.

Burt, M. (1980). Cultural Myths and Supports for Rape. Journal of Personality and Social Psychology, 217230 .

Burt, M. R. (1978). Attitudes supportive of rape in American culture. House Committee on Science and Technology, Subcommittee Domestic and International Scientific Planning, Analysis, and Cooperation, Research into Violent Behavior: Sexual Assaults (Hearing, 95th Congress, 2nd Session, January 1012, 1978). Washington, D. C.: U.S. Printing Office, $1978,277-322$.

Clark, L., and Lewis, D. (1977). Rape: The price of coercive sexuality. The Women's Press, Toronto, Canada.

Erdelyi, M. H. (1974). A New Look at the New Look: Perceptual Defense and Vigilance. Psychological Review, 1-25.

Gardner, R., Holzman, P., Klein, G., Linton, H., \& Spence, D. (1959). Cognitive Control: A Study of Individual Consistencies in Cognitive Behavior. International University Press, NY.+

Gardner, R. W. Jackson, D. N., and Messick, S. J. (1960). Personality Organization in Cognitive Controls and Intellctual Abilities. Psychological Issues, International University Press, NY.

Gardner, R. W. (1964). In C. Scheere (ed.), Coonition: Theory, Research, Promise. Harper and Row, NY.

Gardner, R. W. (1969). Organismic Equilibration and the Energy-Structure Duality in Psychoanalytic Theory An Attempt at Theoretical Refinement. Journal of The American Psychoanalytic Association, p. 3-67. 
Gardner, R. W. (1969). Individuality in Developement. Presented at a regional meeting of the American Association of Psychiatric Clinics for Children, Topeka, Ransas.

Gardner, R. W. (1962). Cognitive Controls and Adaptation: Research and Measurement. In S. J. Messick \& Ross (Ed.). Measurement in Personality and Coanition. Wiley, NY, 183-198.

Gardner, R. W., Jackson, D. N., and Messick, S. J. (1960). Personality organization in cognitive controls and intellectual ability. Psychological Issues, 2 (4), Monograph 8.

Gardner, R. W. and Moriarty, A. (1968). Personality Development at Preadolescence: Explorations of Structure Formations. University of Washington Press, Seattle, WA.

Guthrie, G. D. (1967). Changes in Cognitive Control Function Under Stress: A Study of Plasticity in Cognitive Controls. Doctoral Dissertation, Clark University. Dissertation Abstracts International, 28, 2125B.

Hartmann, H. (1958). Ego psychology and the problem of adaptation. International University press, NY.

Hartmann, H. (1964). Essays in eqo psychology: selected problems in psychoanalytic theory. International University Press, NY.

Hartmann, H. (1952). The Mutual Influences in the Development of the Ego and Id. Psychoanalytic Study of The Child, 9-30.

Hartmann, H. (1950). Comments on the Psychoanalytic Theory of the Ego. Psychoanalytic Study of the Child, 7496 .

Helson, H. (1964). Adaption Level Theory. Harper and Row, NY. 
Holzman, P. Klein, G. (1951). Perceptual Attitudes of "Leveling" and "Sharpening". Journal of Personality, 105-122.

Holzman, P. Klein, G. (1954). Cognitive Systems: Principles of Leveling and Sharpening. Journal of Personality, 105-122.

Hyde, J. S. (1984). How Large are Gender Differences in Aggression? A Developmental Meta-Analysis. Developmental Psychology, 722-736.

Hyde, J. S. (1981). How Large are Cognitive Gender Differences? American Psychologist, 892-901.

Israel, N. (1969). Leveling and Sharpening and Anticipatory Cardiac Response. Psychosomatic Medicine, 499-509.

Israel, N. (1966). Individual Differences in GSR orienting response and cognitive control. Journal of Experimental Research in Personality, 244-248.

Kiesler, C. A. (1982). Comments. In M. S. Clark and S. T. Fiske (Eds.), Affect and Cognition, 111-118. Lawrence Erlbaum, NJ.

Klein, G. S. (1949). Adaptive properties of Sensory Punctioning. Bulletin Yenninger Clinic, 16-23.

Klein, G., \& Schlesinger, H., (1949). Where is the Perceiver in Perceptual Theory. Journal of Personality, 32-47.

Klein, G. S. (1951). The Personal World Through Perception. In R. R. Blake \& G. V. Ramsey (Eds.), Perception: An Approach to Personality, 328-355. Ronald Press, NY.

Klein, G. S. (1954). Need and Regulation. In M. R. Johes (Ed.). Nebraska Symposium on Yotivation. Vol. 2. University of Nebraska Press, Lincoln.

Klein, G. S. (1970). Perception, Yotives and Personality. Knopf, NY. 
Koss, M., Gidyczi, C., \& Wisniewski, N. (1987). The Scope of Rape: Incidence and Prevalence of sexual aggression and victimization in a National Sample of Higher Education Students. Journal of Consulting and Clinical Psychology, 162-170.

Lemieux,G. J. (1966). Leveling-Sharpening Cognitive Control and Masculinity-Femininity in College Students. National Science Foundation Research, Clark University, Worcester, MA.

Libon, D. J., (1985). The Role of The Orientation Response In The Cognitive Control of Leveling and Sharpening. Unpublished Doctoral Dissertation, University of Rhode Island, RI.

Loevinger, J. (1987). Paradiams of Personality. Freeman, NY. Maccoby, E. M., and Jacklin, C. N. (1974). The Psychology of Sex Differences. Stanford University Press, Stanford, CA.

Malamuth, N. (1983). Factors Associated With Rape as Predictors of Laboratory Aggression Against Women. Journal of Personality and Social Psychology, 432442 .

Moncata, S. (1990). Cognitive-Affective Coordination and the Leveling-Sharpening Cognitive Control: Balancing Concordant and Discordant "Calls for Action". Unpublished doctoral dissertation. University of Hartford.

Norman, D. A. (1980). Twelve Issues for Cognitive Science. In Norman, D. A. (Ed.), Perspectives on Cognitive Science: Talks from the La Jolla Conference. Erlbaum, NJ.

Ottenson, J. P., and Holzman, P. S. (1976). Cognitive controls and psychopathology. Journal of Abnormal Psychology, 85, 125-139.

Rieder, C. (1986). Coonitive Controls and CognitiveAffective Balance in Haltreated Children. Unpublished Doctoral Dissertation. Harvard University, Cambridge.

Sander, L. W. (1969). Regulation and Organization in the Early Infant-Caretaker System. In $R$. Robinson (Ed.), Brain and Early Behavior, 78-92. Academic Press, London. 
Santostefano, S. (1990). Manual: The Leveling-Sharpening Shoot-out Test, The Leveling-Sharpening Friends Test. McLean Hospital, Belmont, MA.

Santostefano, S. (1988). Cognitive Control Battery (CCB) Manual. Western Psychological Services, CA.

Santostefano, S. (1988). Cognitive Control Tests for Children and Adolescents. Western Psychological Services, CA.

Santostefano, S. (1986). Cognitive Controls, Metaphors and Contexts: An Approach to Cognition and Bmotion. In D. Bearison \& Himiles (Eds.). Thought and Emotion, 175-210. Hilsdale, NJ.

Santostefano, S. (1985). Cognitive Control Therapy with Children and Adolescents. Pergamon Press, NY.

Santostefano, S., \& Reider, C. (1984). Cognitive Controls and Aggression in Children: The Concept of Cognitive-Affective Balance. Journal of Consulting and Clinical Psychology, 46-56.

Santostefano, S. (1983, June). Cognitive Controls, Metaphors, and Contexts: An Approach to Cognition and motions. Paper presented at the Thirteenth Annual Symposium of the Jean Piaget Society, Philadelphia, PA.

Santostefano, S. (1978). A Biodevelopmental Approach to Clinical Child Psychology: Cocnitive Controls and Cognitive Control Therapy. John wiley and Sons, NY.

Santostefano, S. (1964). A Developmental Study of the Cognitive Control Leveling-Sharpening. MerrillPalmer Quarterly, 343-360.

Santostefano, S. and Baker, H. (1972). Research in Child Psychopathology: The Contributions of

Developmental Psychology. In B. B. Wolman (Ed.), Manual of Child Psychopatholocy, 1113-1152. McGraw-Hill, NY.

Santostefano, S. Paley, E. (1964). Development of Cognitive Controls in Children. Child Development, 939- 949 .

Santostfano, S. Moncata, S. (1989). A Psychoanalytic View of Cognition Within Personality: Cognitive Dysfunctions and Bducating Troubled Youth. Residential Treatment for Children and Youth, 4162 . 
Santostfano, S. Reider, C. (1984). Cognitive Controls and Aggression in Children: The Concept of Cognitive-Affective Balance. Journal of Consulting and Clinical Psychology, 46-56.

Santostfano, S. (1963). A Developmental Study of the Deboeuf Illusion. Perceptual Motor Skills, 23-29.

Seligman, J., Huck, J., Joseph, N., Namuth, T., Prout, L., Robinson, T., \& Maniel, A. (1984). The Date who Rapes. Newsweek, April 9, p. 91-92.

Shapiro, D. (1965). Neurotic Styles. Basic Books Inc. NY.

Shapiro, I. F. (1972). Cognitive Controls and Adaptation in Children. Doctoral Dissertation, Boston College. Dissertation Abstracts International, 33, $1780 \mathrm{~B}$.

Silverman, J. (1964a). Perceptual Control of Stimulus Intensity in Paranoid and Nonparanoid Schizophrenia. Journal of Consulting Psychology, 385-393.

Silverman, J. (1964b). Scanning-Control Mechanism and "Cognitive Filtering" in Paranoid and Non-Paranoid Schizophrenia. Journal of Consulting Psychology, 385-393.

Silverman, J. (1964C). Perceptual Control of Stimulus Intensity in Paranoid and Non-Paranoid Schizophrenia. Journal of Nervous and Kental Disease, 139 , p. 545-49.

Silverman, J., Gaarder, K. (1967). Rates of saccadic eye movement and Size Judjments of Normals and - Schizophrenics. Perceptual and Yotor Skills, 661667 .

Sweet, E. (1985). Date Rape: The Story of an Epidemic and Those Who Deny it. MS/Campus Times, p. 54-85.

Thurstone, L. L. (1944). A Factorial Study of Perception. Chicago, Ill.: University of Chicago Press, 1944, 5-148. 
Wachtel, P. (1972). Cognitive Style and Style of Adaptation. Perceptual Motor Skills, 779-785.

Weis, R., and Borges, S. (1973). Victimology and rape: The case of the legitimate victim. Issues in.

Criminology, 71-114.

Werner. H. (1957). The concept of development from a comparative organismic point of view. In D. B. Harris (Ed.), The concept of development: An issue. in the study of human behavior. University of Minnesota Press, MN.

Witkin, H. A., et al (1954). Personality Through Perception:An Experimental and Clinical Study. Harper, NY.

Witkin, H. A., and Oltman, P. K. (1967). Cognitive Style. International Journal of Neurology, 1967, 6, 119137 .

Witkin, H. A., Goodenough, D. R., and Karp, S. A. (1967). Stability of cognitive style from childhood to young adulthood. Journal of Personality and Social. Psychology, 1967, 7, 291-300.

Wolitzky, D., \& Wachtel, P. (1973). Personality and Perception. In B. B. Wolman (Ed.), Handbook of. General Psychology, 826-857. Prentice-Hall, NJ.

Zimbardo, P. B. (1969). The cognitive control of motivation: The consequences of choice and dissonance. Glenview, Ill.: Scott, Poresman.

Zimilies, H. (1981). Cognitive-Affective Interaction: A Concept that Exceeds the Researcher's Grasp. In E. R. Shapiro and E. Weber (Eds.), Coonitive and. Affective Growth. (47-63). Lawrence Erlbaum, N.J. 